University of Nebraska - Lincoln DigitalCommons@University of Nebraska - Lincoln

USGS Staff -- Published Research

US Geological Survey

2004

\title{
The H4IIE Cell Bioassay as an Indicator of Dioxin- like Chemicals in Wildlife and the Environment
}

\author{
J.J. Whyte \\ Columbia Environmental Research Center, U.S. Geological Survey-Biological Resources Division, Columbia, Missouri \\ Christopher J. Schmitt \\ U.S. Geological Survey, cjschmitt@usgs.gov \\ D.E. Tillitt \\ Columbia Environmental Research Center, U.S. Geological Survey-Biological Resources Division, Columbia, Missouri
}

Follow this and additional works at: http:// digitalcommons.unl.edu/usgsstaffpub

Whyte, J. J.; Schmitt, Christopher J.; and Tillitt, D. E., "The H4IIE Cell Bioassay as an Indicator of Dioxin-like Chemicals in Wildlife and the Environment" (2004). USGS Staff -- Published Research. 885.

http:// digitalcommons.unl.edu/usgsstaffpub/885

This Article is brought to you for free and open access by the US Geological Survey at DigitalCommons@University of Nebraska - Lincoln. It has been accepted for inclusion in USGS Staff -- Published Research by an authorized administrator of DigitalCommons@University of Nebraska - Lincoln. 


\title{
The H4IIE Cell Bioassay as an Indicator of Dioxin-like Chemicals in Wildlife and the Environment
}

\author{
J. J. Whyte, ${ }^{1,2}$ C. J. Schmitt, ${ }^{1}$ and D. E. Tillitt ${ }^{1 *}$ \\ ${ }^{1}$ Columbia Environmental Research Center, U.S. Geological Survey-Biological \\ Resources Division, Columbia, Missouri, USA; and ${ }^{2}$ U.S. Geological Survey \\ Cooperative Fish and Wildlife Research Unit, University of Missouri-Columbia, \\ Columbia, Missouri, USA
}

* Corresponding author: Columbia Environmental Research Center, U.S. Geological Survey-Biological Resources Division, 4200 New Haven Road, Columbia, MO 65201, USA. E-mail: Donald_Tillitt@usgs.gov

\begin{abstract}
The H4IIE cell bioassay has proven utility as a screening tool for planar halogenated hydrocarbons (PHHs) and structurally similar chemicals accumulated in organisms from the wild. This bioassay has additional applications in hazard assessment of PHH exposed populations. In this review, the toxicological principles, current protocols, performance criteria, and field applications for the assay are described. The H4IIE cell bioassay has several advantages over the analytical measurement of PHHs in environmental samples, but conclusions from studies can be strengthened when both bioassay and analytical chemistry data are presented together. Often, the bioassay results concur with biological effects in organisms and support direct measures of PHHs. For biomonitoring purposes and prioritization of PHH-contaminated environments, the H4IIE bioassay may be faster and less expensive than analytical measurements. The H4IIE cell bioassay can be used in combination with other biomarkers such as in vivo measurements of CYP1A1 induction to help pinpoint the sources and identities of dioxin-like chemicals. The number of studies that measure H4IIE-derived TCDD-EQs continues to increase, resulting in subtle improvements over time. Further experiments are required to determine if TCDD-EQs derived from mammalian cells are adequate predictors of toxicity to non-mammalian species. The H4IIE cell bioassay has been used in over 300 published studies, and its combination of speed, simplicity, and ability to integrate the effects of complex contaminant mixtures makes it a valuable addition to hazard assessment and biomonitoring studies.
\end{abstract}

KEYWORDS: TCDD, TEQs, Screening assay

\section{TABLE OF CONTENTS}

I. Introduction 2

A. Background 2

B. PHH Structure and Toxicity 2

C. Induction Potency Versus Toxic Potency 3

D. Cultured Cells as Model Systems 3

E. The H4IIE Cell Line 4

II. H4IIE Cell Bioassay Protocol 6

A. Chemical Extract Preparation 6 
$\begin{array}{lr}\text { B. H4IIE Cell Culture } & 11\end{array}$

$\begin{array}{lr}\text { C. Plating } & 12\end{array}$

D. Dosing and Incubation $\quad 13$

E. Measurement of CYP1A1 Catalytic Activity (AHH or EROD) 15

F. Data Analysis $\quad 18$

III. H4IIE Cell Bioassay Characterization and Method Validation 22

$\begin{array}{lr}\text { A. Accuracy } & 22\end{array}$

B. Precision $r$

C. Limit of Detection and Limit of Quantitation $\quad 25$

D. CYP1A1 Activity Range $r$

E. Quality Assurance in the H4IIE Cell Bioassay 26

$\begin{array}{ll}\text { F. Summary } & 28\end{array}$

IV. H4IIE Cell Bioassay as a Screening Tool for Environmental Contaminants 28

A. TEQs Calculated from H4IIE Relative Potency Factors (RPFs) 28

B. H4IIE Toxic Equivalents (TCDD-EQs) in Field Studies and Biomonitoring 34

C. H4IIE-Derived TCDD-EQs as a Tool for Hazard Assessment 68

V. Summary: Advances and Future Directions for the H4IIE Cell Bioassay 70

A. Reporter Gene Systems for TCDD-EQ Determination in H4IIE 70

B. Wise Use of the H4IIE Cell Bioassay $\quad 71$

$\begin{array}{lr}\text { Acknowledgments } & 71\end{array}$

$\begin{array}{lr}\text { References } & 72\end{array}$

\section{INTRODUCTION}

\section{A. Background}

Planar halogenated hydrocarbons (PHHs) are structurally similar chemicals that typically refer to polychlorinated biphenyls (PCBs), polychlorinated dibenzo- $p$-dioxins (PCDDs), and polychlorinated dibenzofurans (PCDFs). PHHs originate from industrial activities or as unwanted by-products of chemical synthesis or combustion; (Hutzinger et al., 1974; Metcalfe and Haffner, 1995; Rappe et al., 1987; Safe, 1994). Accordingly, PHHs have been released into the environment both intentionally and inadvertently. These contaminants can enter the environment through both point sources and atmospheric deposition, and have been detected at various trophic levels in aquatic and terrestrial ecosystems. Concerns surround PHH contamination of the environment due to their inherent toxicity and strong tendency to bioaccumulate in fish (Muir et al., 1985) as well as through the aquatic food chain to wildlife and humans (Borgmann and Whittle, 1991; Hellou et al., 1993; van den Heuvel and Lucier, 1993). Despite declining environmental concentrations of some PHHs during the 1980s (Schmitt et al., 1999), PHHs are continually released from waste incineration facilities, contaminated sediments, and derelict PCB-containing equipment. Although structurally and chemically similar, PHHs vary greatly in toxicity (Grimwood and Dobbs, 1995). The current degree of PHH contamination at certain locations in the environment is still above concentrations that are considered a threat to human and wildlife health.

\section{B. PHH Structure and Toxicity}

The toxicity of PHHs is dependent on their structure, with the most toxic compound being 2,3,7,8-tetrachlorodibenzo- $p$-dioxin or TCDD (Poland et al., 1979; Poland and Bradfield, 1992; Nebert et al., 1993; Okey et al., 1994). A number of common toxic responses are observed in laboratory animals exposed to PHHs. These include loss of body weight, thymic atrophy, immunotoxicity, hepatotoxicity, chloracne, and other dermal lesions (reviewed in Safe, 1990). Many biochemical changes are also observed in animals and cells in culture exposed to PHHs. A common biochemical indicator of PHH exposure is the induction of a number of specific "drug-metabolizing" enzymes including cytochrome P-450 1A1 and 1A2, and four non-P450 proteins (Nebert et al., 2000). The correlation between the degree of this enzyme induction by individual $\mathrm{PHH}$ congeners and their relative toxic potencies in animals led to the development of a receptor-mediated model to describe the mechanism of action for PHHs (Poland et al., 1976, 1979). Current understanding of $\mathrm{PHH}$ toxicity indicates that 
TCDD or structurally similar compounds enter a living cell and bind to a cytosolic protein, the aryl hydrocarbon receptor (AhR). The AhR-ligand complex translocates into the nucleus and acts as a transcription factor for specific dioxin-responsive elements (DREs). Genes associated with these DREs increase in expression and include the previously mentioned drug-metabolizing enzymes (Whitlock, 1999; Nebert et al., 2000). The exact mechanistic relationships between gene expression and toxicity is still unknown. Toxicity of PHHs through AhRindependent mechanisms likely also exists (Hoffer et al., 1996; Peters et al., 1999), but strong correlations between AhR-mediated events and toxicity suggest that this pathway plays the most significant role in the effects of PHH exposure. The mechanism of AhR signal transduction and that of gene expression are believed to operate similarly in all vertebrates (Hahn et al., 1998).

The relationship between $\mathrm{PHH}$ structure and toxicity is the basis of toxic equivalency factors (TEFs) and the toxic equivalents (TEQ)* approach (Safe et al., 1986; Safe, 1990, 1999; van den Berg et al., 1998; Sanderson and van den Berg, 1999; Birnbaum, 1999; Tillitt, 1999). The TEQ approach is used to determine the toxic potency of complex PHH mixtures in the environment. Assuming a similar mechanism of action for all PHHs, the potency of each chemical in a mixture to cause a particular toxic or biological effect can be expressed as a fraction of the potency of TCDD (the most potent PHH) to cause the same effect. Based on a variety of biological endpoints, "relative potency factors" or RPFs are assigned to different PHHs (van den Berg et al., 1998). All RPFs for an individual PHH are evaluated to derive a consensus value that describes an order-of-magnitude toxic potency for that $\mathrm{PHH}$, its toxic equivalency factor (TEF; van den Berg et al., 1998). The toxic potency of PHHs in a sample from the environment is estimated by the multiplication of the concentrations of individual PHHs by their respective TEFs and summed to yield a final TEQ. RPFs based on long-term in vivo studies of toxic effects are given more weight in the derivation of a TEF than short-term in vitro studies of biochemical responses.

*The standard notation of TEQs will be used when we discuss toxic potency derived from chemical concentrations and TEF/RPF values. Throughout the text we will use TCDD-EQs to designate toxic potency estimates derived from the H4IIE bioassay.

\section{Induction Potency Versus Toxic Potency}

It should be stressed that TEQs derived from CYP1A1 induction assays estimate the toxic potency of a chemical mixture based on the relationship between induction of this enzyme and in vivo toxic effects. Induction of CYP1A1 alone does not constitute a toxic effect per se, but likely occurs in parallel with disruption of other biological processes. Studies by Safe and coworkers (Safe et al., 1986; Safe, 1990) demonstrated rank-order correlations between biochemical measurements in H4IIE cells (e.g., enzyme induction, receptor binding) and whole-animal effects. This suggested that cell culture systems could be used as a rapid, inexpensive tool to estimate the toxic potency of PHHs and their mixtures. One of the fundamental assumptions underlying the H4IIE cell bioassay is that PHHs exert their effects through a similar characterized mechanism of action. Although literally thousands of research papers have been published on the responses of vertebrates to PHHs, we still lack true knowledge of the exact biochemical pathways that are altered by exposure to these chemicals (Tillitt, 1999; Nebert et al., 2000). It is unclear if gene products induced by AhR ligands are responsible for toxic outcomes or simply correlated to them. The vast number of organ systems and physiological processes that PHHs affect suggests that AhR-mediated responses are not the only pathway to toxicity (Enan and Matsumura, 1995). These limitations, while they do create uncertainty, are of a theoretical nature and do not necessarily limit the predictive benefits that the H4IIE cell bioassay can provide. The relationship between activation of the AhR gene battery (including CYP1A1) and adverse toxicological outcomes is well documented, supporting the use of the H4IIE cell bioassay in the development of TEQs and TCDD-EQs.

\section{Cultured Cells as Model Systems}

The use of cultured cells as model systems to investigate mechanisms of PHH toxicity and predict adverse effects offers many advantages in terms of cost and speed over in vivo studies. Cultured cells have been used for decades in toxicology to study important biochemical events and pathways related to environmental contaminant exposure (Rees, 1980; Bols et al., 1985). Cell lines responsive to PHH exposure allow rapid development of RPFs used for ranking the toxic potency environmental samples and in the development of TEFs. The 
most widely used biochemical indicator of the presence of PHHs is cytochrome $\mathrm{P}-4501 \mathrm{~A} 1$, or CYP1A1 induction. Induction of CYP1A1 (measured as aryl hydrocarbon hydroxylase, or $\mathrm{AHH}$, activity) in mammalian cell culture (hamster fetus cells) was first reported by Nebert and Gelboin (1968a). Since that time, a number of cell culture bioassays have been used to determine RPFs of individual chemicals and extracts from environmental samples relative to TCDD. These include mammalian (Hammond and Strobel, 1992), fish (Hightower and Renfro, 1988; Lee et al., 1993; Jung et al., 2001), and avian (Kennedy et al., 1993) cultured cells. RPFs are derived by comparing the activity of $\mathrm{AHH}$ or ethoxyresorufin $O$-deethylase (EROD, another catalytic measure of CYP1A1) in cells exposed to PHHs or chemical mixtures to the activity in TCDD exposed cells. These RPFs are then used to support TEF development or estimate the toxic potency of environmental extracts.

\section{E. The H4lIE Cell Line}

Benedict et al. (1973) reported that an ideal cell line for examining PHH potency was the H4IIE rat hepatoma cell line due to its excellent growth properties and low basal AHH activity. The H4IIE cell line was derived from Reuber Hepatoma H-35 (Reuber, 1961) by Pitot et al. (1964). The H4IIE cells have low basal CYP1A1 activity along with a high degree of responsiveness towards PHHs. The net result is an observed 20- to over 100-fold induction above basal CYP1A1 enzyme activity in the H4IIE cells after PHH exposure. The extreme potency of TCDD as a CYP1A1 inducer in H4IIE was demonstrated by Niwa et al. (1975). Based on their findings, the authors suggested that H4IIE cells could be used in a bioassay for the detection of minute $\left(10^{-14} \mathrm{~mol}\right)$ amounts of TCDD. Bradlaw and Casterline (1979) first described the use of H4IIE cells to screen for the presence of planar polychlorinated organic compounds in foods prior to analytical identification. The authors reported the relative AHH-inducing potency in H4IIE of 24 PCDDs, 11 PCDFs, 7 PCBs, and extracts from several food sources. This was the first use of H4IIE as a tool to rank the potency of PHHs, an idea first proposed by Poland and Glover (1973).

The relationship between the induction of CYP1A1 in H4IIE and in vivo toxicity was examined extensively by Safe and coworkers in the 1980s (Bandiera et al., 1984; Safe et al., 1986; Mason et al., 1986). These studies demonstrated that for PCDD and PCDF congeners, comparable structureactivity relationships (SARs) were observed using the H4IIE cell bioassay (AHH and EROD induction), in vitro $\mathrm{AhR}$ receptor binding assays, and in vivo responses in immature male Wistar rats (hepatic EROD and AHH activity, thymic atrophy, and body weight loss). Significant linear relationships were observed between the - $\log$ EC50 (H4IIE AHH induction) of 8 PCB, 5 PCDD, and 15 PCDF congeners versus $-\log$ ED50 for body weight loss $(r=.93)$ and thymic atrophy $(r=.92$; Safe, 1987). Similarity in CYP1A1 induction patterns in vivo and in vitro was demonstrated by Yu et al. (1996), supporting the use of the H4IIE cell bioassay as a tool to predict CYP1A1 induction potential. Radiolabeled PCB 77 was used to compare the induction of CYP1A1 in dosed H4IIE cells and rat livers. The enzyme induction pattern was similar in both in vivo and in vitro systems. Radioactivity of $\mathrm{PCB}$ 77 and EROD activity were significantly correlated $\left(r^{2}=.985\right)$ when compared on an equivalent weight basis for both systems. This study was an important contribution to the validation of the in vitro assay with in vivo data. These results support the use and development of the H4IIE cell bioassay as a practical, short-term test to quantitatively predict the potential toxicity of a sample containing PHHs and structurally similar compounds.

The H4IIE cell bioassay is not very effective for assessment of potential toxicity of PAHs in organisms. This is true for the same reasons that routine analytical measurement of PAHs are not very effective for estimation of chronic exposure or effects of PAHs. Large hydrophobic PAHs can be AhR active, but they are easily metabolized in part due to their lack of halogenation (Nebert et al., 1993). As a result, PAHs do not bioaccumulate substantially in vertebrates, or at least not to the predicted amounts based on physical properties such as $K_{\text {ow }}$ (Schnitz and O'Connor, 1992). Thus, measures of PAH exposure in vertebrates, including the H4IIE cell bioassay, underestimate the potential toxicity of PAHs and other AhR ligands that are readily metabolized and excreted. Examples of this phenomenon have been published: Rainbow trout (Oncorhynchus mykiss) exposed to PAH (creosote)-contaminated water displayed a dose-dependent increase in hepatic EROD (in vivo), but both H4IIE TCDD-EQs and measured PAHs in tissue extracts did not differ from reference tissue extracts (Whyte et al., 2000). Certain naturally occurring PAHs such as 7-isopropyl1-methylphenanthrene (retene) can be enriched in 
sediments, like those downstream of some pulp and paper mills, and have demonstrated CYP1Ainducing activity (Fragoso et al., 1999). Retene is believed to be a contributor to in vivo CYP1A induction and toxicity (Basu et al., 2001), yet it would not contribute to TCDD-EQs due to its metabolic elimination.

The absence of the PAHs in biological extracts does not mean that these chemicals have not caused an adverse effect in the organism, only that they are too short-lived to be accurately measured. Detection of rapidly metabolized contaminants is not a challenge unique to the H4IIE cell bioassay. Chemical analysis of PAHs in vertebrates is similarly not an effective measure of chronic exposure to organisms. However, the H4IIE bioassay will respond to any AhR ligand if it is present in the matrix of interest. This makes the bioassay a useful tool for detection of PAHs in abiotic matrices (e.g., sediments; Jones et al., 1993a; Hoke et al., 1994; Hilscherova et al., 2000) or biotic matrices where metabolism is not expected to be significant (e.g., molluscs; McDonald et al., 1994; Kennicutt et al., 1995). However, interpretation of H4IIE bioassay results from abiotic matrices (soil, sediment, fly ash, etc.) may not be possible. The individual chemicals (PAHs or other AhR ligands) have unique physicochemical properties of transport and transformation in the environment. Therefore, it is impossible to predict the exposure of an organisms based on the single potency value that results from the H4IIE cell bioassay of an abiotic matrix, such as soil or sediment. The complex processes of chemical fate are chemical specific. The single potency value does not provide distinction of which specific chemicals are present and exert the given potency in the sediment or soil. Chemical-specific rates of sorption, desorption, bioconcentration, metabolism, distribution, and so on are required to determine the overall rates of transfer of specific chemicals from an abiotic portion of the environment to an organism (i.e., sediment to fish). Therefore, although it is tempting to screen sediments or other abiotic matrices with the H4IIE bioassay, it is not a recommended practice without simultaneous chemical characterization. The complementary chemical analysis, in this situation, may drastically reduce the need and/or benefit of the H4IIE cell bioassay. The presence of PHHs and PAHs occurring together as mixtures complicates the hazard or risk assessment process. For instance, high concentrations of PAHs in sediment extracts containing PHHs can result in atypical dose-response behavior in the H4IIE cell bioassay, making data interpretation difficult even with complete characterization (Gale et al., 2000). Fractionation techniques allow the isolation or removal of specific chemicals in extracts, enabling determination of the contribution of different classes of chemicals to CYP1A induction (Gale et al., 2000). Isolation of PHHs in biological samples can be accomplished using sulfuric acid silica gel during extract preparation to destroy (oxidize) nonchlorinated PAHs (Tillitt et al., 1991; Oikari et al., 2002). Using fractionation methods, the identities of the most active CYP1Ainducing classes of compounds in an extract can be determined.

To summarize, the use of the H4IIE bioassay to make predictions about the risk associated with $\mathrm{PAH}$ exposure is not justified at present (Till et al., 1999). This does not, however, decrease the utility of the H4IIE bioassay to screen for the presence of AhR ligands in environmental samples, whether these are PHHs, PAHs, or a complex mixture. It only underscores the need to exercise care when using H4IIE cell bioassay result for hazard assessment purposes when significant amounts of PAHs are present in the samples. Currently, the H4IIE cell bioassay is better suited for toxicity identification procedures for detecting PAH contamination in nonbiological matrices or in organisms where metabolism does not influence PAH concentrations.

An important advantage of the H4IIE cell bioassay over analytical chemistry techniques is that it estimates the sum concentration of biologically active chemicals in an extract based on their respective potencies as CYP1A1 inducers. Analytical techniques such as gas chromatography can indicate the presence of different chemical entities, but by themselves cannot describe the differences in toxicity among chemicals or how these chemicals exert their effects as a mixture. As described previously, researchers use TEFs as an additive index to express the total toxic potential of mixtures of PHHs (Sawyer and Safe, 1985; Eadon et al., 1986; van den Berg et al., 1998). This is reasonable based on the similar mode of action of PHHs; however, there are important uncertainties associated with this approach. Foremost is the possibility of nonadditive interactions among PHHs leading to erroneous predictions of greater or lesser toxic potency of a mixture. Reported PHH interactions include antagonism (Bannister et al., 1987; Aarts et al., 1995) or synergism (Bannister and Safe, 1987). The H4IIE cell bioassay can be used to address this potential problem by estimating the overall potency of a 
chemical extract. The same technique for RPF development is used, but rather than comparing CYP1A1 induction by individual PHHs to that of TCDD, cells are exposed to an entire chemical extract. The ratio of the CYP1A1 induction by the extract to that of TCDD is expressed as a TCDD equivalent concentration (TCDD-EQ, pg/g). The assumption of additivity in the TEF model can be tested by comparing the TCDD-EQ of an extract to the TEQ for the same extract generated using RPFs and analytical chemistry data. Deviations from equality of these two values may indicate nonadditive interactions among chemicals in the mixture tested. The estimation of TCDD-EQs in environmental samples using the H4IIE cell bioassay has been used extensively to quantitatively express the toxic potency of PHHs and related chemicals accumulated in organisms and their habitat.

The objectives of this review are to describe the development and utility of the H4IIE cell bioassay as a tool for estimating the presence and toxic potency of PHHs and related compounds in wildlife and other environmental samples. A discussion of the capabilities of the bioassay is balanced with cautions regarding its limitations. Also included in this discussion are methods to avoid some of these potential pitfalls. An extensive review of the past and current literature allows the reader to evaluate the contributions of the H4IIE cell bioassay to biomonitoring efforts and hazard assessment. In the first section, a detailed analysis of current protocols, characterization, experimental conditions, and performance criteria of the H4IIE cell bioassay is described. This is followed by an appraisal of the H4IIE cell bioassay as a screening tool for environmental contaminants. The third section of this review examines the use of H4IIE-derived TCDD-EQs in hazard assessment. Finally, recent techniques derived from the H4IIE cell bioassay (e.g., H4IIE cell lines transfected with AhR-responsive reporter genes) will be compared to the original bioassay. Other in vitro methods of estimating PHH concentrations in environmental samples exist (Roberts and Durst, 1995; Zajicek et al., 2000), but comparisons of these techniques with the H4IIE cell bioassay are beyond the scope of our review. The goal of this review is to provide the reader with an understanding of how and why the H4IIE cell bioassay has been used. This will, in turn, help scientists more effectively incorporate this tool into studies on environmental contamination by PHHs. Additionally, we hope this review serves as the foundation or platform from which study results from the H4IIE bioassay may be interpreted.

\section{H4IIE CELL BIOASSAY PROTOCOL}

The H4IIE cell bioassay has undergone many changes since its first use as a tool for measuring the dioxin-like activity of chemical extracts from environmental samples. This section reviews the current general procedures for the assay (Figure 1). The general steps include: (1) preparation of the chemical to be tested or chemical extraction; (2) H4IIE cell culture; (3) plating of cultured cells; (4) dosing of H4IIE cells with chemicals and TCDD standards and incubation; and (5) determination of CYP1A1 activity and data analysis. Certain laboratories may use slightly modified versions of the protocol described here due to equipment availability and personal preference (Table 1). For instance, the use of multiwell microtiter plates for cell dosing and conducting the EROD assay has become popular with the increased availability of plate-reading fluorometers, but some researchers perform the assay in petri plates. This review focuses on what are considered to be the most up-to-date techniques, but includes references to previously used techniques as well.

\section{A. Chemical Extract Preparation}

The initial step in using the H4IIE bioassay to estimate chemical concentrations and determine their toxic potency is to isolate specific chemicals of interest and transfer them to a suitable carrier solvent for dosing. Chemicals can be standards purchased from chemical supply companies or analytes extracted from environmental samples (e.g., tissue or sediment). In the case of the H4IIE cell bioassay, chemicals that bind to the AhR (i.e., dioxinlike PHHs) are the targets of interest. The H4IIE cell bioassay is typically used to analyze chemical extracts of tissue or sediment, but extracts of air particulates (Franzén et al., 1988), lipid-containing semipermeable membrane devices (Lebo et al., 1995), and water (Murk et al., 1996) have also been analyzed with H4IIE cells.

Sample extraction and cleanup can follow any one of a number of techniques that are appropriate for PHHs. Environmental samples should be stored frozen at $-20^{\circ} \mathrm{C}$ before the extraction process is initiated to provide protection for the target analytes (Huestis et al., 1995; McFarland et al., 1995). Samples are homogenized and dried with sodium sulfate prior to extraction. Extractions can be made with a number of organic solvents, by column, Soxhlet, or dialysis methods (Hale and Greaves, 1992; 


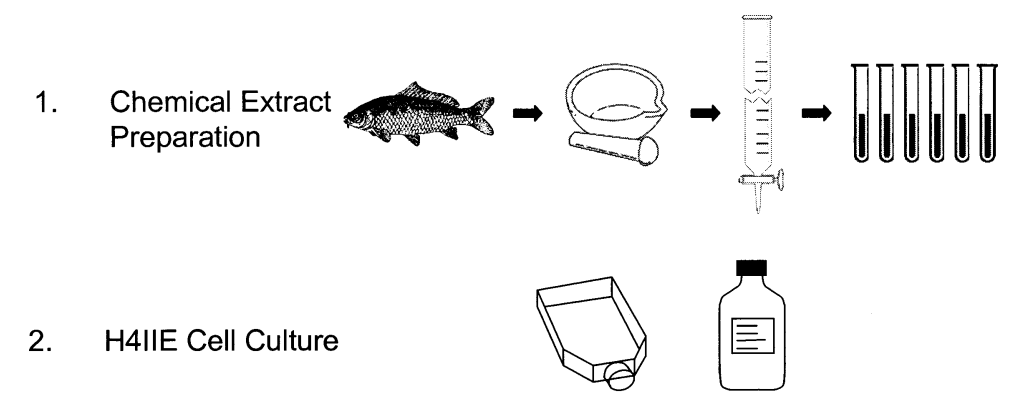

3. Plating

4. Dosing and Incubation

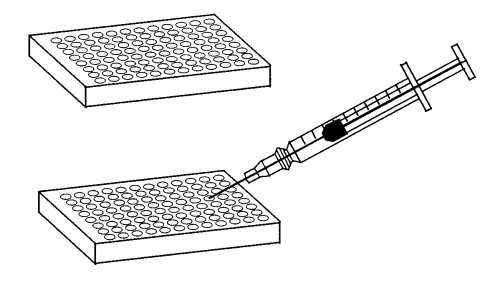
5. CYP1A1 Catalytic Activity (EROD or $\mathrm{AHH})$
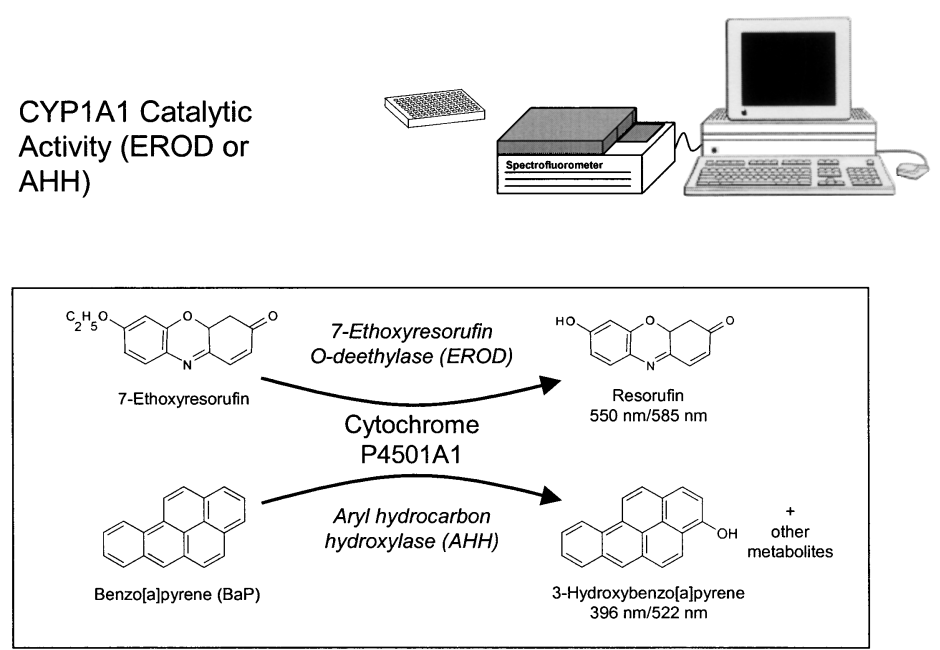

FIGURE 1. Graphic summary of the H4IIE cell line bioassay procedure. Refer to text for detailed description of individual stages of the procedure.

Meadows et al., 1993; Huestis et al., 1995). We routinely use column extraction with methylene chloride. Lipids are removed from the extract by gel permeation chromatography or acid digestion methods (Schwartz and Lehmann, 1982; Hale and Greaves, 1992; Huestis et al., 1995). Lipid removal by gel permeation is a nondestructive method based on size exclusion chromatography (Ribick et al., 1981). This is an additional procedure in sample processing, but it is essential to remove lipids, which can alter the partitioning of chemicals to the cells in the bioassay procedure. Alternatively, a faster and less expensive method of lipid removal is through acidification of the sample. The acid is introduced to the sample by impregnation of an adsorbent, silica gel. Acidic silica gel can be placed at the bottom of the extraction column and lipid removal oc- curs at the same time as extraction (Schwartz and Lehmann, 1982). Internal standards are not generally added to samples that are to be tested with the H4IIE bioassay because the standards may have measurable dioxin-like activity or alter the response of the mixture being tested (Gale et al., 2000). The lack of internal recovery standards is a limitation of the general protocols for testing environmental samples with the H4IIE bioassay. Low recoveries may go undetected, even with external recovery samples in the quality assurance set. Splits of the extracts that are to undergo instrumental analysis can be spiked with internal standards at this point. By using different fractionation techniques, chemical extracts containing specific classes of contaminants can be prepared and tested with the H4IIE bioassay (Figure 2). 


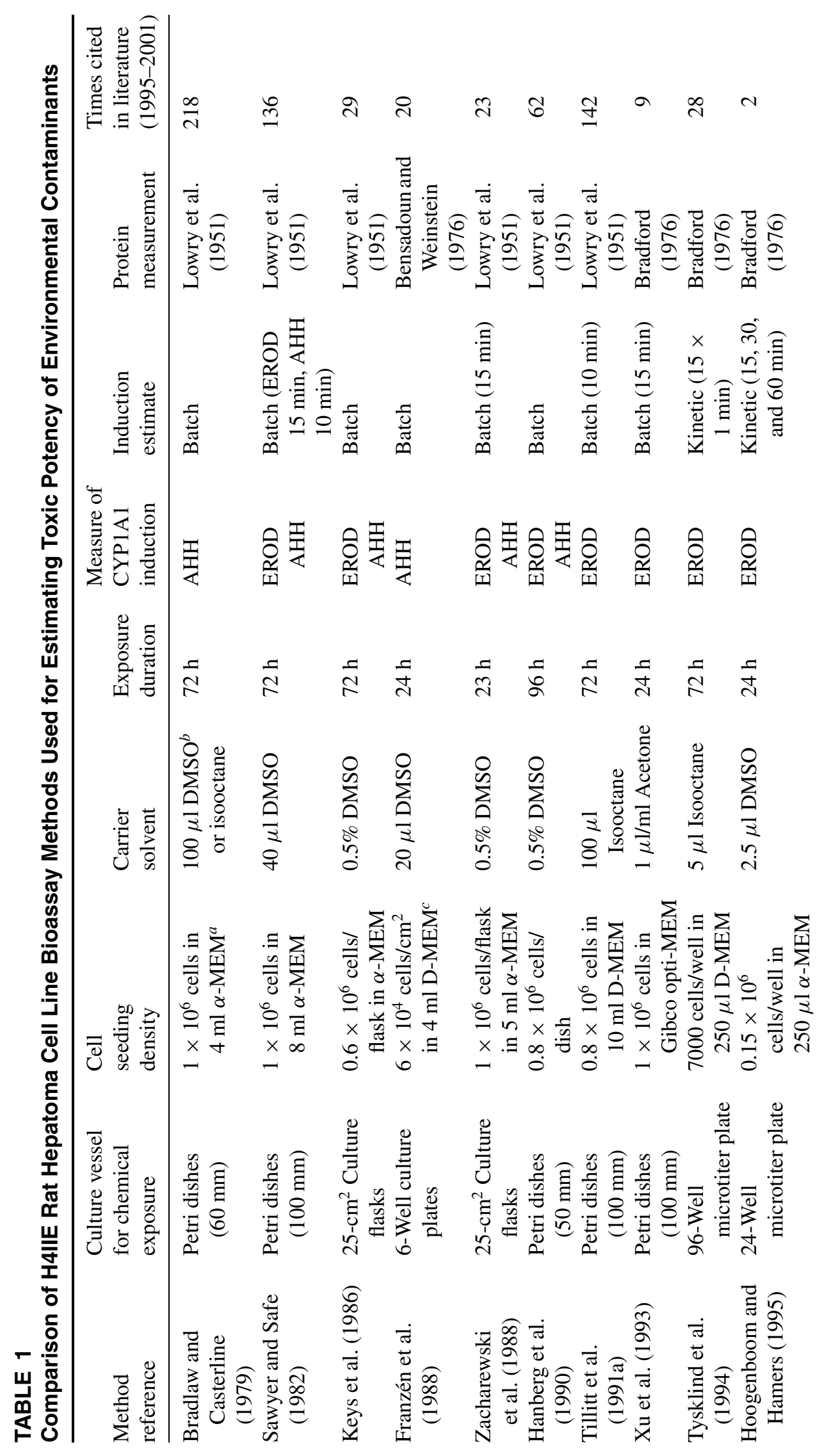




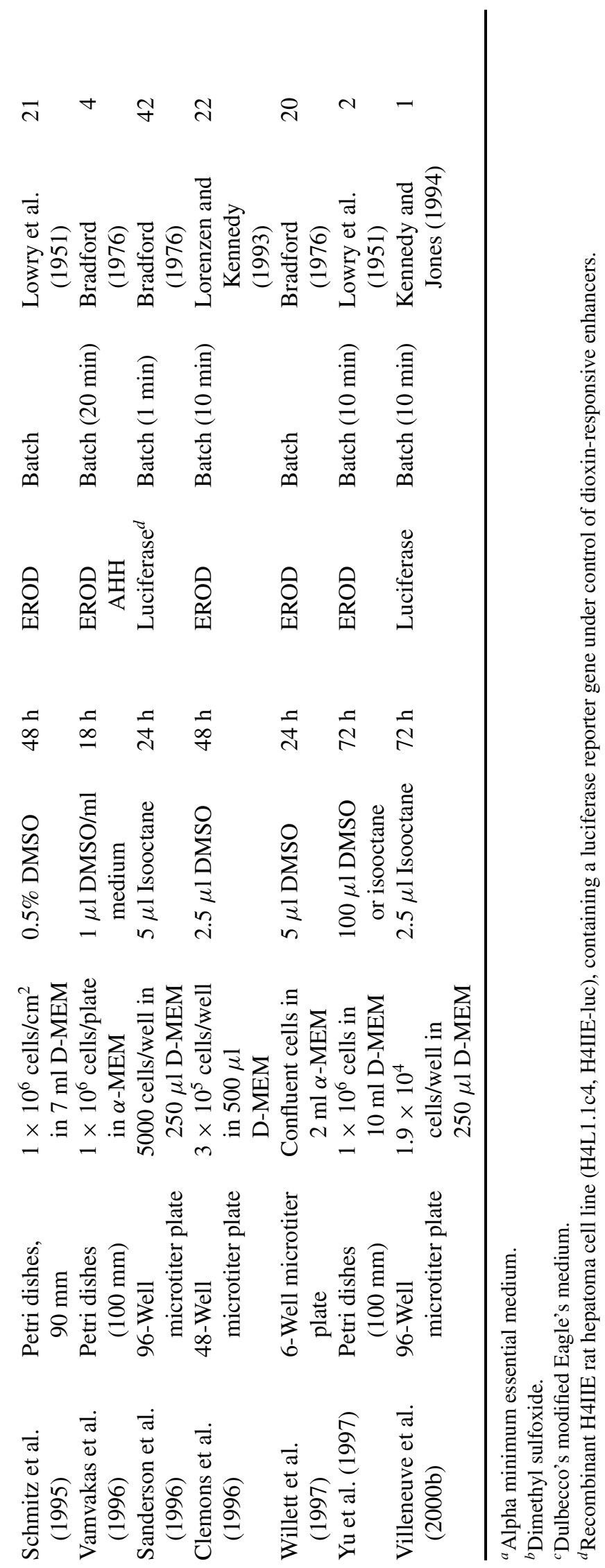




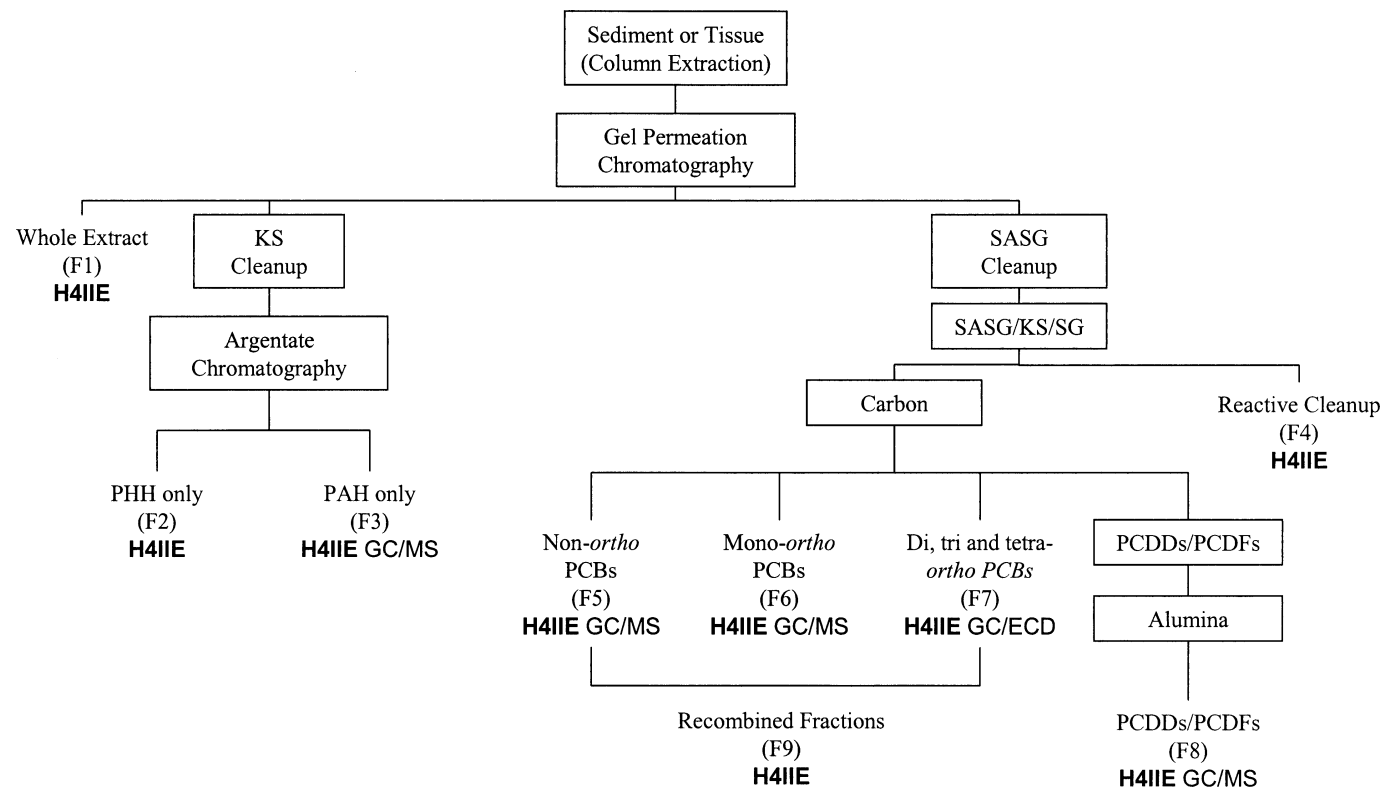

FIGURE 2. Environmental extract fractionation scheme. After gel permeation chromatography, the whole extract (F1) is split. One portion is eluted from potassium silicate (KS), then separated by argentate chromatography into $\mathrm{PHH}$-only (F2) and $\mathrm{PAH}$-only $(\mathrm{F} 3)$ fractions. Another portion is sequentially eluted from sulfuric acid-silica gel (SASG) and SASG/KS/silica gel (F4) and separated by carbon column chromatography into non-ortho (F5), mono-ortho (F6), and bulk PCB (F7), and, after basic alumina, a PCDD/PCDF fraction (F8). PCB fractions (F5, F6, and F7) are recombined as F9 for H4IIE cell bioassay. From Gale et al. (2000).

The hydrophobic solvents used in the extraction process such as hexane and methylene chloride are toxic to H4IIE cells. To eliminate this solventrelated toxicity in the bioassay, extracted contaminants are transferred from the extraction solvents into a suitable carrier solvent that is less toxic to the H4IIE cells. The most commonly used carrier solvents are isooctane and dimethyl sulfoxide (DMSO). In the initial paper describing the H4IIE bioassay as a potential screening tool, Bradlaw and Casterline (1979) initially exposed cells to chemicals dissolved in DMSO and water. The potency of TCDD to induce AHH activity was increased by using isooctane as the carrier solvent, and thus the experimental procedure was changed so that isooctane was used exclusively in subsequent experiments. In contrast to this, Clemons et al. (1994) observed that maximum EROD activity was fourfold greater in cells that received TCDD dissolved in DMSO versus the same concentration of TCDD delivered in isooctane. This observation was supported by Yu et al. (1997); H4IIE cells exposed to 3,3',4,4'-tetrachlorobiphenyl (PCB 77) in DMSO had higher EROD activity than cells that received the same dose of PCB 77 dissolved in isooctane. Tillitt et al. (1991a) reported that isooctane gave optimal response and sensitivity as a solvent carrier.

DMSO mixes readily with cell culture medium and increases cell membrane permeability, and consequently the potential for chemicals to be delivered to the cell (Sanderson et al., 1998). The alteration of membrane permeability by DMSO has been a concern of some researchers (Tillitt et al., 1991a). Cell membrane permeability and the control of osmotic processes are integrally related to a variety of physiological processes of normal cellular homeostasis (Sperelakis, 2001). Thus, alteration in cell permeability by DMSO may have unexpected or unpredictable effects on the responsiveness of the H4IIE cells. DMSO alters the transcriptional and translational activities of CYP1A in cultured cells (Lindsay et al., 1990). Isooctane has minimal solubility in the culture, and forms a thin film at the top of the media. As the isooctane evaporates and diffuses into the media, PHHs will also be allowed to diffuse into the media and cells. An advantage of isooctane is its lower cytotoxicity compared to DMSO. The effect of chemical exposure time on the potency and efficacy of TCDD and PCB 77 in avian primary hepatocytes was much less when isooctane was used as a carrier solvent as compared to DMSO 
(Sanderson et al., 1998). For instance, the potency of PCB 77 decreased 10- to 20-fold when measured at $48 \mathrm{~h}$ as compared to $24 \mathrm{~h}$. With isooctane, the difference over the same time period was less than 2 -fold. More research is needed to determine if potency differences observed in avian systems are as great in mammalian systems and how this should affect carrier solvent selection. Isooctane has advantages over DMSO in that it is compatible with most chemical residue analysis techniques for PHHs and is less expensive than DMSO. Isooctane also has greater consistency among lots of solvent. Finally, DMSO may contain AhR ligands (M. Denison, University of California, Davis, personal communication). Regardless of which solvent is used in the H4IIE cell bioassay, solvent controls should be run with each batch/plate. Solvent controls should not have induction over the basal level of EROD activity in H4IIE, nor should the carrier solvent inhibit the induction of CYP1A1 in the cells. Over time, significant changes in EROD activity measured in solvent control wells/plates may indicate contamination of carrier solvent stock. If contamination is suspected, solvent should be replaced with a fresh lot and new chemical standards should be prepared using this new solvent.

\section{B. H4IIE Cell Culture}

Routinely performing the H4IIE bioassay requires a stable, consistent source of cells. Initial aliquots of cryopreserved H4IIE cells can be obtained from the American Type Culture Collection (ATCC number CRL-1548). These aliquots are free of Mycoplasma arginini, a common biological contaminant in cell cultures. Mycoplasma contamination may cause adverse effects, such as changes in metabolism, growth, viability, DNA, RNA, and protein synthesis; and morphology (Freshney, 1992). Thus, it is important to ensure that H4IIE cultures are free of mycoplasma contamination in order to avoid unreliable experiment results. Instructions for subculture are based on Bradlaw et al. (1979) and culturing notes are listed in Table 2.

H4IIE cells can be easily cultured on a routine basis with the proper equipment and nutritional components for mammalian cell growth. Cells require a defined growth medium, a suitable growth environment, and routine care. Two recipes for growth media are described in Table 2 . These media provide the nutritional, hormonal, and stromal factors necessary for H4IIE cell growth. Although most of the components of the H4IIE medium are chemi- cally defined, the addition of $10-15 \%$ bovine serum may lead to batch variation in media. Serum is a complex mixture of small and large biomolecules with physiologically balanced growth-promoting and growth-inhibiting activities (Freshney, 1992). Although much is known about the nutritional role of the components in serum, there remain numerous factors whose physiological roles are not fully understood.

The influence of serum on the results of the H4IIE cell bioassay has not been fully explored to date. The high degree of precision among laboratories for this bioassay (see next section) indicates that serum is not a source of great variability when H4IIE cells are used in this specific manner. However, the concentration of serum used in culturing H4IIE cells has been reported to influence the metabolism of drugs such as ibuprofen by cytochrome P-450 enzymes (Menzel-Soglowek et al., 1992). Higher levels of EROD activity are maintained in primary rat hepatocytes cultured in serumfree medium, although there is a selective decline in P-450 activities and toxicity with increased time in culture (Hammond and Fry, 1992). Studies such as these indicate the potential for serum-related variation in CYP1A1 activity in H4IIE. The effect of serum on CYP1A1 induction has been explored in fish cell culture (Hestermann et al., 2000). These authors used the PLHC-1 hepatic tumor cell line derived from the translucent topminnow (Poeciliopsis lucida) and performed their experiments nearly identically to the H4IIE cell bioassay procedures (Hightower and Renfro, 1988). They found the presence of $10 \%$ calf serum in the PLHC-1 medium resulted in reduced relative potencies for TCDD, PCBs 77, 3,3',4,4',5-pentachlorobiphenyl

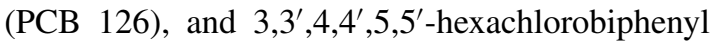
(PCB 169) as compared to cells exposed in serumfree medium (Hestermann et al., 2000). Using radiolabeled TCDD, it was determined that the in the presence of serum, the bioavailability of TCDD is reduced so that less chemical can enter the cells. This finding highlights the importance of using a constant serum concentration when performing the H4IIE cell bioassay or when comparing results among laboratories. Potential variability due to the presence of serum could be eliminated by exposing H4IIE cells to contaminants in the absence of serum, and only using serum-containing medium during routine culturing. This technique has been used in relatively few studies. Alternatively, the development of a serum-free medium (i.e., a fully chemically defined medium) specifically for H4IIE would lead to a highly standardized culture and 
TABLE 2

Culturing Properties for H4IIE Rat Hepatoma Cells

\begin{tabular}{|c|c|}
\hline Property & Description \\
\hline ATCC number & CRL-1548 \\
\hline Organism & Rat (Rattus norvegicus) \\
\hline Tissue & Hepatoma; liver \\
\hline Morphology & Epithelial \\
\hline Growth properties & Adherent \\
\hline Subculturing $^{a}$ & $\begin{array}{l}\text { Remove medium, add fresh } 0.25 \% \text { trypsin solution for } 1 \text { to } 3 \text { min, remove trypsin } \\
\text { and let the culture sit at } 37^{\circ} \mathrm{C} \text { for } 10 \text { to } 15 \mathrm{~min} \text {. Add fresh medium, aspirate and } \\
\text { dispense into new flasks. }\end{array}$ \\
\hline Split ratio ${ }^{a}$ & A subcultivation ratio of $1: 2$ to $1: 4$ is recommended. \\
\hline Fluid renewal ${ }^{a}$ & Every 2 to 3 days. \\
\hline Media for propagation & $\begin{array}{l}\text { ATCC medium: minimum essential medium (Eagle) in Earle's basic salt solution } \\
\text { with } 80 \% \text { nonessential amino acids, } 10 \% \text { fetal bovine serum, } 10 \% \text { bovine calf } \\
\text { serum. } \\
\text { Tillitt Medium (Tillitt et al., } 1991 \mathrm{a} \text { ): Dulbecco's modified Eagle's medium, } 2 \times \\
\text { nonessential amino acids, } 1.5 \times \text { nonessential amino acids, } 1 \mathrm{~m} M \text { pyruvate, } \\
1000 \mathrm{mg} / \mathrm{L} \text { D-glucose, } 2200 \mathrm{mg} / \mathrm{L} \text { sodium bicarbonate, } 15 \% \text { fetal bovine serum. }\end{array}$ \\
\hline Growth environment & $75-\mathrm{cm}^{2}$ Polystyrene flasks in a $37^{\circ} \mathrm{C}$ humidified, $5 \% \mathrm{CO}_{2}$ environment. \\
\hline Culture duration & $\begin{array}{l}\text { Initiate new culture from frozen cells after approximately } 10 \text { passages to reduce } \\
\text { risk of intraspecies cross-contamination, phenotypic drift, or senescence } \\
\text { (Freshney, 1992). }\end{array}$ \\
\hline
\end{tabular}

${ }^{a}$ As described by ATCC—http://www.atcc.org/

dosing environment. However, the use of serum-free media in the H4IIE cell bioassay will likely not be standard practice in the foreseeable future. Drawbacks of serum-free media include greater expense, slower cell growth, and the need for a more strict physicochemical environment than cultures grown in serum-containing media (Freshney, 1992). As mentioned previously, the precision reported among laboratories using the H4IIE cell bioassay does not indicate that serum is a significant source of variation, and for this reason serum will likely continue to be used routinely. Determination of the potential influence of serum on results in the H4IIE cell bioassay would be valuable.

The physical environment for H4IIE cell growth is similar to that for most mammalian cell lines. Cells are maintained in a humidified incubator at $37^{\circ} \mathrm{C}$ in a $5 \% \mathrm{CO}_{2}$ atmosphere (Tillitt et al., 1991a), and are typically grown in $75-\mathrm{cm}^{2}$ polystyrene flasks. Under these conditions, H4IIE cells proliferate rapidly. Subcultivation, or "splitting," of the cell culture is performed on confluent flasks every 4-5 days. In addition to subcultivation, ATCC recommends replacing the medium in the culture flasks with fresh medium every 2-3 days to ensure that the nutritional requirements of the cells are being met. Tillitt et al. (1991a) recommend beginning new H4IIE cultures after nine subcultivations or less to reduce the risk of phenotypic drift, transformation, or senescence in the population.

\section{Plating}

The H4IIE cells are grown and exposed to chemicals or contaminant extracts in tissue culture plates. This ensures proper replication of samples and allows for increased numbers of samples to be tested. In the original H4IIE cell line bioassay, cell monolayers were grown in 60- to 100-mm-diameter petri plates or in smaller culture flasks (e.g., $25 \mathrm{~cm}^{2}$ ) prior to dosing (Bradlaw et al., 1980; Sawyer and Safe, 1982; Bannister et al., 1987). Multi-well microtiter plates are more commonly used in current investigations (Tysklind et al., 1994; Sanderson et al., 1996; Whyte et al., 1998). Plates with 48 or 96 wells have several advantages over single petri plates. Microtiter plates allow many replicates to be tested on the same plate while occupying relatively little space in incubators. The smaller size of the wells means that fewer cells are plated and less media is expended in the plating process. From a safety and disposal standpoint, much lower dosing volumes of contaminants can be used compared to larger petri plates while still achieving the same 
exposure concentration. Probably the single greatest advantage of using multiwell plates is the time savings of the EROD assay in multiwell plate-reading fluorometers (Tysklind et al., 1994; Kennedy and Jones, 1994; also see Section E). These instruments determine the degree of CYP1A1 catalytic activity in all the wells of an entire plate typically in a minute or less. This type of automation greatly increases sample throughput and eliminates much of the variability associated with manual determination of CYP1A1 catalytic activity.

Whether petri plates or multiwell plates are used, steps should be taken to ensure that equal numbers of cells are added to each plate or well in an experiment. Cell protein is measured to normalize CYP1A1 catalytic estimates among wells (see Section E), but equal plating density of cells is the best way to reduce variability in a multiwell assay. The growth characteristics of the cells will be consistent when grown at the same density, and the chemical exposure of the cells will be consistent among wells or plates. H4IIE cells are harvested from cell culture flasks with the aid of trypsin and cell scrapers and resuspended in medium to form a single cell suspension (Honeycutt et al., 1996; Khim et al., 2000). Estimates of cell concentration can be made with a hemocytometer and used to calculate the required cell seeding density. The H4IIE cells may be centrifuged at low speeds $(100-500 \times \mathrm{g})$ and resuspended in media if the cell density needs to be increased. This can be done without harm to the cells. The medium volume and seeding density are dependent on the surface area of the form of petri dish or multiwell plate used (Table 1). H4IIE cells are generally incubated for $24 \mathrm{~h}$ prior to dosing to allow cell attachment to the chamber surface (Tillitt et al., 1991a).

\section{Dosing and Incubation}

H4IIE cells receive a dilution series of the chemical or extract of interest in carrier solvent for determination of a RPF or TCDD-EQ. TCDD standard solutions can be purchased from commercial suppliers (e.g., Accustandard, New Haven, CT; Ultra Scientific, North Kingstown, RI). The number of doses that cells are exposed to typically ranges from 6 to greater than 10 doses prepared at between 3- and 10-fold serial dilution factors. Concentrations of extract at various dilutions can be expressed in terms of gram equivalents [tissue or sediment mass extracted $(\mathrm{g}) \cdot$ solvent carrier volume $(\mu \mathrm{L})^{-1} \cdot$ dilution factor $\left.^{-1}\right]$. When possible, a wide range ( 3 to 4 orders of magnitude) of doses should be used for chemical extracts, where parameters such as maximal CYP1A1 induction and slope are unknown. Accurate TCDD-EQ determination requires that the number of extract doses cover the full CYP1A1 induction range in H4IIE (Figure 3A). An ED50 cannot be calculated without knowing the maximal induction of CYP1A activity caused by a compound or extract. Often this is not known ahead of time. Techniques for dealing with incomplete dose-response curves are discussed in Section F, Data Analysis. Dosing of cells seeded in
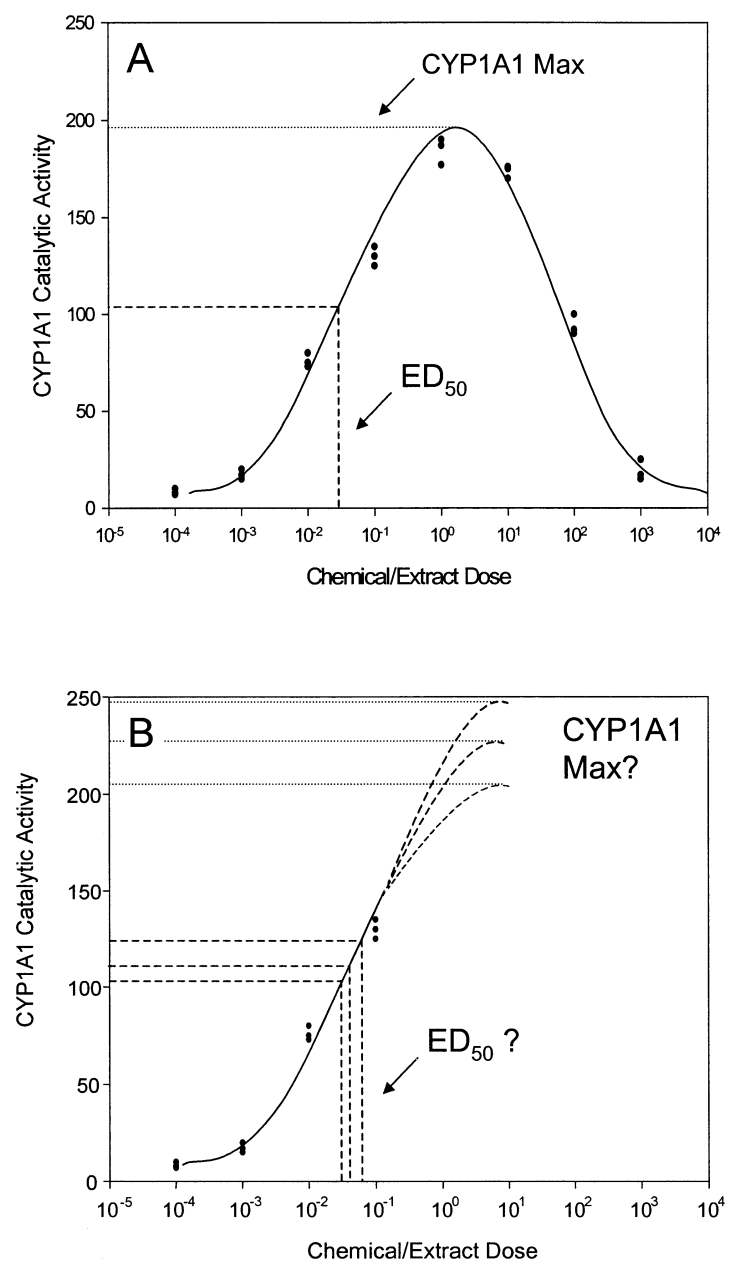

FIGURE 3. (A) Complete dose-response curve of chemically induced CYP1A1 induction and estimated chemical ED50. (B) Incomplete dose-response curve of chemically induced CYP1A1 induction demonstrating both indeterminate maximal induction and chemical ED50. A complete dose-response curve provides the greatest confidence in estimating ED50. 
multiwell culture plates allows for a greater range of doses than petri plates.

Dosing of H4IIE cells is performed under a laminar flow hood using aseptic technique as with routine culturing. Although exposure duration is typically only $72 \mathrm{~h}$, effort should be made to eliminate any influence of bacterial or fungal contamination. Doses of test chemical (2.5-100 $\mu \mathrm{l}$ depending on volume of growth medium) are administered to cells using micropipettes with either plastic (polyethylene) or glass pipette tips. The hydrophobic nature of PHHs has brought into question the use of polyethylene pipette tips. Although no published studies have specifically examined adsorption of PHHs onto polyethylene tips, other hydrophobic chemicals have been observed to bind to plastic pipette tips (Upton et al., 1987; Hyenstrand et al., 2001). Hyenstrand (2001) reported that delivery of a solution of the hydrophobic cyanobacterial toxin microcystin-LR with plastic disposable pipette tips resulted in a loss of $4.2 \%$ per tip operation. Using the same pipette tip, four operations were required to completely saturate a single tip with toxin. This indicates that there is the potential for loss of chemical during dosing of H4IIE cells if plastic tips are used, and that this loss would not be uniform if individual pipette tips were used more than once. Positive displacement pipettes with stainless steel pistons and glass capillary tubes have been used when dosing H4IIE cells to reduce chemical adsorption (Clemons et al., 1998; Whyte et al., 1998). Rinsing the pipette piston with solvent between different chemicals used for dosing is required. However, it is not practical to routinely use single, positivedisplacement pipettes for large-scale use of the H4IIE bioassay such as the Biomonitoring of Environmental Status and Trends (BEST) fish health monitoring efforts (Whyte and Tillitt, 2000). Multichannel pipettes allow simultaneous dosing of wells in multi-well plates: A dilution series of a chemical extract in conical vials is placed in an appropriate sized rack to accommodate the use of the multichannel pipette. Following dosing, vials can be capped and stored for later use.

Isooctane or DMSO are commonly used as chemical carrier solvents in the H4IIE bioassay as mentioned previously. It has been suggested that the amount of carrier solvent used should not exceed $0.5 \%$ of the total solution to eliminate interference or toxicity due to the presence of excess carrier solvent (Bradlaw and Casterline, 1979; Harris et al., 1989). Trivedi et al. (1990) examined the toxicity of DMSO to the human carcinoma cell line HeLa. When the initial number of cells plated was $3 \times 10^{4} / \mathrm{ml}$,
DMSO concentration of $1 \%$ or less had no apparent effect on the rate of proliferation for up to $48 \mathrm{~h}$ of incubation at $37^{\circ} \mathrm{C}$. In incubations up to $72 \mathrm{~h}$, cell growth was repressed by $1 \%$ DMSO. At higher cell plating density $\left(3 \times 10^{5} / \mathrm{ml}\right)$, the effect of DMSO was similar. The effect of other carrier solvents on proliferation of H4IIE cells has not been examined to our knowledge, but Tillitt et al. (1991a) reported no effect of dosing volume on EROD induction in $\mathrm{H} 4 \mathrm{IIE}$ at isooctane concentrations between $0.1 \%$ and $1.5 \%$ of the total volume with incubation for $72 \mathrm{~h}$. This indicates that the commonly used solvent concentration of $0.5 \%$ isooctane should not interfere with the H4IIE cell bioassay, but investigations specifically examining the effects of isooctane or DMSO concentrations on H4IIE cell growth and viability are needed.

Dosed H4IIE cells are incubated for between 24 and $72 \mathrm{~h}$, with the 72-h duration being the most widely used. Incubation time can influence CYP1A1 induction in H4IIE, and this influence is chemical specific. For TCDD, a range of exposure times between 6 and $72 \mathrm{~h}$ had no effect on EROD induction EC50s (Clemons et al., 1997). Incubation time did, however, influence EC50s for 2,3,7,8tetrachlorodibenzofuran (2,3,7,8-TCDF; increase of approximately 9-fold) and PCB 77 (increase of approximately 11-fold) as incubation time increased from 6 to $72 \mathrm{~h}$. It was hypothesized that the shift in EC50 was due to metabolism of the parent compound during incubation (Clemons et al., 1997). Parrott et al. (2000) reported that H4IIE incubation time greatly affected the potency of liver extracts from white sucker (Catostomus commersoni) exposed to bleached-kraft mill effluent (BKME). Cells exposed to extract for periods greater than $24 \mathrm{~h}$ showed decreasing EROD activity with time, again suggesting that cells were able to metabolize some of the CYP1A1 inducing components in the extract (Parrott et al., 2000).

The studies just described indicate that a standard incubation time for chemicals or extracts should be set for the H4IIE cell bioassay when determining extract potency or developing RPFs. The length of exposure should allow for maximal induction of CYP1A1, but not be so long that significant metabolism of inducing compounds takes place. The metabolism of certain inducing chemicals may provide more realism when comparing results from the in vitro assay to in vivo experiments, but in situations where the H4IIE cell bioassay is used solely to estimate the concentration of inducing chemicals in environmental extracts, this metabolism is an interference that should be avoided. An exposure period 
of $24 \mathrm{~h}$ appears to reduce the influence of chemical metabolism, but the majority of published studies using the H4IIE cell bioassay use $72 \mathrm{~h}$ as a standard incubation period. Study results would likely not be affected by the metabolism of AhR-active compounds in an extract. This is true because most studies have used acidified extraction procedures to remove labile compounds. It does, however, appear that an in-depth study of the effects of exposure time in the H4IIE cell bioassay should be conducted to determine the optimal duration for chemical stability and maximal CYP1A1 induction.

\section{E. Measurement of CYP1A1 Catalytic Activity (AHH or EROD)}

Determination of CYP1A1 catalytic activity in chemically exposed H4IIE cells was originally described by Bradlaw and Casterline (1979) and was based on Nebert and Gelboin's (1968b) original method of measuring $\mathrm{AHH}$ activity in mammalian cell culture. In recent years, researchers almost exclusively measure EROD activity as the catalytic endpoint for CYP1A1 measurement in the H4IIE cell bioassay for reasons described in the next paragraph. However, a large amount of highly useful and foundational information came from the measurement of $\mathrm{AHH}$ in H4IIE cells. The AHH assay of CYP1A1 activity measures the conversion of benzo[a]pyrene (BaP) to 3-hydroxybenzo[a]pyrene (Figure 1) and serves as a functional indicator of the amount of CYP1A1 present in the reaction mixture. This reaction requires both the reduced form of nicotinamide-dinucleotide phosphate (NADPH) and molecular oxygen. The assay is initiated after the chemical or extract exposure period by re- moving the overlying medium from the H4IIE cells and rinsing them with a buffer such as phosphate buffered saline ( $\mathrm{pH}$ 7.4). At this point, aseptic technique is no longer necessary and the assay can be performed on the benchtop (this is also true for the EROD assay; see later discussion). Cells are harvested by trypsinization, scraping, or a combination of both (Bradlaw and Casterline, 1979; Sawyer and Safe, 1982). A cellular protein pellet produced after centrifugation (e.g., 10,000 $\times \mathrm{g}$ for $5 \mathrm{~min}$ ) is resuspended in buffer. AHH activity can be measured (Sawyer and Safe, 1982) or the resuspended pellet can be further centrifuged $(105,000 \times \mathrm{g}$ for $60 \mathrm{~min})$ to isolate the microsomal fraction where the P-450 enzymes reside (Nebert and Gelboin, 1968b). The enzymatic activity of AHH is usually measured fluorometrically. The cell homogenate or microsomal fraction is combined with buffer, $\mathrm{NADPH}, \mathrm{MgCl}_{2}$, and benzo[a]pyrene (Table 3 ). The reaction is carried out for $15-30 \mathrm{~min}$ at $37^{\circ} \mathrm{C}$ and is terminated with the addition of a acetone:methanol mixture (Bradlaw and Casterline, 1979; Päivi et al., 1992). A portion of the organic extract is then extracted with $1 \mathrm{~N} \mathrm{NaOH}$ (Sawyer and Safe, 1982) and the fluorescence of this fraction is measured at $396 \mathrm{~nm}$ excitation and $517 \mathrm{~nm}$ emission. Protein determination can be carried out before or after measurement of 3-hydroxybenzo[a]pyrene using the method of Lowry (1951) or Bradford (1976). If protein is measured before the assay, a defined amount of cellular homogenate is used in the reaction (e.g., $0.1 \mathrm{mg} / \mathrm{ml}$ ). Measurement of protein allows standardization of 3-hydroxybenzo[a]pyrene fluorescence to protein content. AHH activity is expressed in units of picomoles 3-hydroxybenzo[a]pyrene formed per milligram of cellular protein per minute of the assay duration ( $\mathrm{pmol} / \mathrm{mg} / \mathrm{min})$.

TABLE 3

Example Reaction Components for Determination of Aryl Hydrocarbon Hydroxylase (AHH) in the H4IIE Cell Bioassay

\begin{tabular}{llll}
\hline Assay reagent & Bradlaw and Casterline (1979) & Sawyer and Safe (1982) & Päivi et al. (1992) \\
\hline Buffer & Tris-chloride & Tris-sucrose & Potassium phosphate \\
& $50 \mathrm{~m} M, \mathrm{pH} 7.5$ & $0.015-0.075 \mathrm{M}, \mathrm{pH} 8.0$ & $25 \mathrm{~m} M, \mathrm{pH} 7.5$ \\
$\mathrm{MgCl}_{2}$ & $3.0 \mathrm{~m} M$ & $2.34 \mathrm{~m} M$ & $3.6 \mathrm{~m} M$ \\
$\mathrm{NADPH}$ & $0.36 \mathrm{~m} M$ & $0.28 \mathrm{~m} M$ & $0.36 \mathrm{~m} M$ \\
$\mathrm{NADH}$ & Not added & $0.33 \mathrm{~m} M$ & $0.42 \mathrm{~m} M$ \\
Albumin & Not added & $540 \mu \mathrm{g}$ & $675 \mu \mathrm{g}$ \\
Benzo[a]pyrene & $80 \mu M$ in methanol & $1.98 \mu M$ & $80 \mu M$ in acetone \\
Final volume & $1 \mathrm{ml}$ & $1 \mathrm{ml}$ & $1 \mathrm{ml}$ \\
Assay temperature & $37^{\circ} \mathrm{C}$ & $37^{\circ} \mathrm{C}$ & $37^{\circ} \mathrm{C}$ \\
Incubation time & $30 \mathrm{~min}$ & $15 \mathrm{~min}$ & $15 \mathrm{~min}$ \\
\hline
\end{tabular}


Determination of EROD activity in the H4IIE cell bioassay became more common in the mid1980s due to the increased safety, decreased cost, and greater efficiency compared to the AHH assay. The EROD reaction produces one product (resorufin), whereas the AHH reaction results in multiple products (Burke and Mayer, 1974; Ronis and Walker, 1985). There are also increased safety concerns and increased expense for safe disposal of reagents in AHH bioassays because assays for $\mathrm{AHH}$ involve use of $\mathrm{BaP}$, a known human carcinogen (da Costa and Curtis, 1995; Williams et al., 1997). The development of multiwell microtiter plate protocols for measuring EROD activity in cells has increased both the speed and cost-effectiveness of the H4IIE cell bioassay, especially when large numbers of samples are to be analyzed (Kennedy and Jones, 1994; Tysklind et al., 1994). It is now common to perform the entire H4IIE cell bioassay, including cell plating, dosing, measurement of EROD activity, and cellular protein, in the same microtiter plate. This method for multiwell plates is described later.

EROD activity describes the rate of the CYP1A1-mediated deethylation of a phenoxazone ether substrate, 7-ethoxyresorufin (7-ER), leading to the formation of the product resorufin that has a free hydroxyl group (reviewed in Whyte et al., 2000a; Figure 1). The H4IIE EROD assay is a modification of the method of Pohl and Fouts (1980). Cell harvesting and preparation of a microsomal fraction were originally performed similar to the AHH bioassay (Sawyer and Safe, 1982; Keys et al., 1986), but now the reaction is generally carried out in the same microtiter plate used for chemical dosing, based on the work of Kennedy et al. (1993). After incubation, plates are washed 2-3 times with distilled water (Tysklind et al., 1994) or with PBS (pH 7.4) if a live cell assay is to be performed (see later discussion; Whyte et al., 1998). Cells are lysed by either osmotic shock from residual distilled water $(\sim 20 \mu \mathrm{l})$ or by quick freeze $\left(-80^{\circ} \mathrm{C}\right)$ and thaw cycle (Tysklind et al., 1994). The main reagents added to the cell suspensions include 7-ethoxyresorufin, dicumarol, and NADPH (added last to initiate reaction; Table 4). Reagents should be held at $37^{\circ} \mathrm{C}$ in a water bath before the EROD assay is performed. Dicumarol is added as an inhibitor of oxidoreductase enzymes (DT-diaphorase or NADPH oxoreductases) that can catalyze the reduction of resorufin thereby reducing the estimation of EROD activity (Lubet et al., 1985). Enzymatic activity can be estimated through the use of batch assays, in which the amount of resorufin produced is measured after a fixed period of time (Clemons et al., 1996), or as kinetic assays, in which resorufin production is repeatedly measured at 60- to 90-s intervals (Tysklind et al., 1994). Kinetic assays yield more data per sample, assure the linearity of the reaction rate, increase confidence in the validity of the EROD estimates as compared to batch assays, and are easily run using automated

\section{TABLE 4}

\section{Example Reaction Components for Determination of 7-Ethoxyresorufin O-Deethylase (EROD) in the H4IIE Cell Bioassay}

\begin{tabular}{|c|c|c|c|}
\hline Assay component & Tillitt et al. (1991a) & Tysklind et al. (1994) & Whyte et al. (1998) \\
\hline Plate size & $\begin{array}{r}15 \times 100 \mathrm{~mm} \\
\text { Petri dishes }\end{array}$ & $\begin{array}{l}\text { 96-Well } \\
\quad \text { microtiter plate }\end{array}$ & $\begin{array}{l}\text { 48-Well } \\
\quad \text { microtiter plate }\end{array}$ \\
\hline Reaction vessel & $\begin{array}{l}\text { Cell suspension aliquots } \\
\text { in separate vessel }\end{array}$ & $\begin{array}{l}\text { Reaction carried out } \\
\text { in dosing plate }\end{array}$ & $\begin{array}{l}\text { Reaction carried out } \\
\text { in dosing plate }\end{array}$ \\
\hline NADPH & $\begin{array}{l}\text { NADPH generator } \\
\text { system }^{a}\end{array}$ & $0.83 \mathrm{~m} M$ & Not added \\
\hline Dicumerol & Not added & $15 \mu M$ & $160 \mu M$ \\
\hline 7-Ethoxyresorufin & $0.6 \mu M$ & $1.7 \mu M$ & $4.87 \mu M$ \\
\hline Final volume & $1250 \mu \mathrm{L}$ & $120 \mu \mathrm{L}$ & $250 \mu \mathrm{L}$ \\
\hline Assay temperature & $37^{\circ} \mathrm{C}$ & $37^{\circ} \mathrm{C}$ & $37^{\circ} \mathrm{C}$ \\
\hline Incubation time & $10 \mathrm{~min}$ & $15 \mathrm{~min}$ & $15 \mathrm{~min}$ \\
\hline Catalytic measurement & Batch & Kinetic (once/min) & Batch \\
\hline Protein assay & Lowry et al. (1951) & Bradford (1976) & $\begin{array}{l}\text { Lorenzen and Kennedy } \\
\text { (1993) }\end{array}$ \\
\hline Approx. assay time & $60 \mathrm{~min} / 12$ plates & $40 \mathrm{~min} / 96$ wells & $18 \mathrm{~min} / 48$ wells \\
\hline
\end{tabular}

${ }^{a} 5 \mathrm{~m} M$ glucose 6-phosphate, $5 \mathrm{mM} \mathrm{MgSO}{ }_{4}, 3.5 \mathrm{~m} M$ NADP, $1.6 \mathrm{mg}$ bovine serum albumin/ml in $0.1 M$ HEPES buffer, pH 7.8 (Tillitt et al., 1991a). 
microtiter plate scanners. The fluorescence of resorufin, the product of the CYP1A1-catalyzed reaction, is measured with an excitation wavelength of $550 \mathrm{~nm}$ and an emission wavelength of $585 \mathrm{~nm}$ (Pohl and Fouts, 1980).

The EROD assay can also be performed on live H4IIE cells (Clemons et al., 1996; Whyte et al., 1998). This method was developed from previous reports on the measurement of EROD activity in intact human cells (Hammond and Strobel, 1992). By allowing the intact cells to provide their own NADPH as a reducing agent for the EROD reaction, the need for externally provided NADPH is significantly reduced or eliminated. The importance of this is that NADPH is the most costly reagent in the assay $(\sim \$ 1.00 \mathrm{USD} / \mathrm{mg}$ or 5 cents/well in 96well plates). In cell suspensions it has been observed that without the addition of NADPH, maximal EROD activity is significantly reduced in the assay (D. Nicks, Columbia Environmental Research Center, Columbia, MO, personal communication). In live H4IIE cells, Clemons et al. (1996) did not report a reduction in maximal EROD activity in the absence of NADPH compared to other reports, but the maximal activity varied (TCDD maximum ranged from 250 to $600 \mathrm{pmol} / \mathrm{mg} \mathrm{P} / \mathrm{min}$ ). A TCDD standard would have to be run with each microtiter plate to control for this variation. The ability of NADPH to penetrate cellular membranes in H4IIE has not been examined. $\mathrm{NADP}^{+}$does not readily penetrate membranes in rat liver microsomes (Takahashi and Hori, 1978), suggesting that NADPH would not permeate into the lumen of the endoplasmic reticulum, the location of CYP1A1, at a fast rate. This may explain why Clemons et al. (1996) did not observe an increase in EROD activity with the addition of NADPH, but it does not agree with the findings in H4IIE cell suspensions. Experiments to determine the degree of NADPH membrane penetration and intracellular concentration in H4IIE should be performed to help optimize the use of this reagent in the bioassay. As of the writing of this review, the majority of published papers use cell suspensions with NADPH added for determination of EROD activity in H4IIE.

Both resorufin and protein standard curves should be generated at the time the H4IIE cell bioassay is run (Figure 4). Fluorescence intensity of resorufin in chemically exposed cells can be compared to a multipoint resorufin standard curve with concentrations ranging from 0.06 to 40 pmol per well. Fluorescence intensity units measured in each well can then be converted to pmol of resorufin formed using a linear regres- sion equation. The concentration of the resorufin stock solution used to prepare the standards should be routinely verified spectrophotometrically (absorbance $=571 \mathrm{~nm}$ ). Commercial sources of the resorufin stock solution include Molecular Probes (Eugene, OR) and Fisher Scientific (Pittsburgh, PA). Reported resorufin molar extinction coefficients used to calculate concentration vary among laboratories. For example, van den Heuvel et al. (1995b) reported a mean molar extinction coefficient of $54.0 \pm 1.1 \mathrm{~cm}^{-1} \mathrm{mM}^{-1}$, and Klotz et al. (1984) reported $73 \mathrm{~cm}^{-1} \mathrm{mM}^{-1}$. The extinction coefficient should therefore be reported along with the resorufin standard curve (Goksøyr and Förlin, 1992).

The rate of resorufin production ( $\mathrm{pmol} / \mathrm{min}$ ) is standardized to cellular protein content. The protein determination methods of Lowry (1951) or Bradford (1976) are commonly used (Table 1). Many microtiter plate methods employ a fluorescencebased protein assay measuring the reaction of fluorescamine with substances containing primary amino groups (Udenfriend et al., 1972). This method was adapted to microtiter plate assays by Lorenzen and Kennedy (1993). The advantage of the microtiter plate fluorescamine assay over other protein measurement techniques used in the H4IIE cell bioassay is that cellular protein is determined on the same instrument and well as resorufin concentrations are measured (Kennedy and Jones, 1994). Fluorescence intensity units (excitation $400 \mathrm{~nm}$, emission $460 \mathrm{~nm}$ ) are converted to milligrams protein based on a seven point bovine serum albumin (BSA; Fisher Scientific, Pittsburgh, PA; Sigma Chemical, St. Louis, MO) standard curve with concentrations ranging from 1.56 to $25 \mu \mathrm{g} / \mathrm{well}$.

Cellular protein content can also be used to normalize the chemical dose to which cells are exposed (e.g., pg TCDD/mg protein) in addition to its use in standardizing catalytic activity of the EROD measurements (Tysklind et al., 1994). Normalizing chemical dose is more pragmatic than simply expressing dose on a molar or mass-per-well basis, but this protein standardization does not take into account cellular growth that occurs over the exposure period (e.g., $72 \mathrm{~h}$ ). If by the end of the exposure period the H4IIE cell growth is halted by contact inhibition (i.e., confluent), protein estimates will be approximately the same among all wells, regardless of differences in the initial plating density of cells. Therefore it is important to ensure equal protein content among wells by verifying that the cell seeding method used provides a uniform initial plating density of cells. 
Resorufin standard curve

(1)

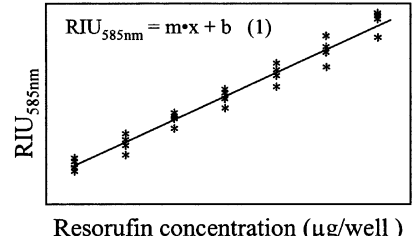

\section{Extract EROD curve}

(2)

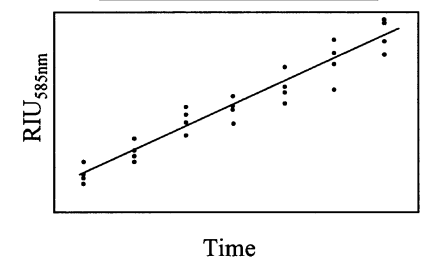

(3)

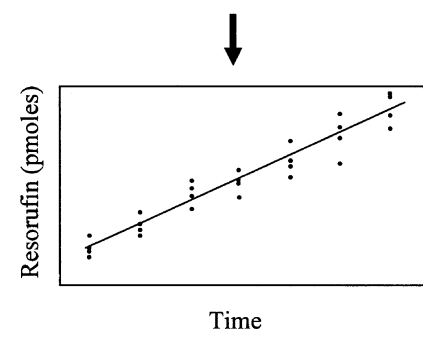

(standardize

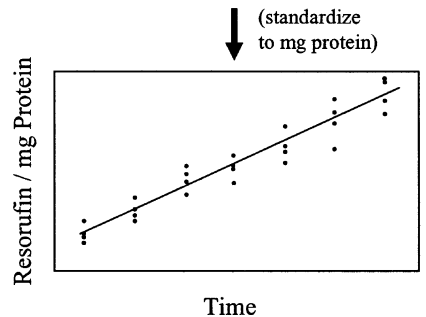

\section{(4)}

Time
Protein (BSA) standard curve

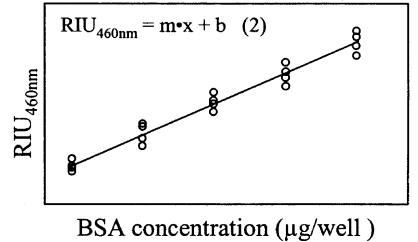

BSA concentration $(\mu \mathrm{g} /$ well $)$

FIGURE 4. General data flow during determination of EROD activity in H4IIE cells exposed to environmental extract.

\section{F. Data Analysis}

Induction data from $\mathrm{AHH}$ or EROD assays are plotted as dose-response curves. Dose-response curves from environmental extracts or pure chemicals are compared to a TCDD standard curve to develop relative potency factors (RPFs) or TCDDEQs* for those test samples (Figure 5). The H4IIE cell bioassay has been used extensively to develop RPFs for individual PHHs and PAHs (Safe, 1990; Willett et al., 1997; Bols et al., 1997), but from a biomonitoring standpoint, the determination of TCDD-EQs in environmental samples is the great-

*The standard notation of TEQs will be used when we discuss toxic potency derived from chemical concentrations and TEF/RPF values. Throughout the text we will use TCDD-EQs to designate toxic potency estimates derived from the H4IIE bioassay. est value of this assay. In keeping with the focus of this review, TCDD-EQs will be discussed, but this section applies equally to the determination of RPFs. TCDD-EQs can be calculated in several ways, including the ratio of the TCDD and test sample ED50s, the ratio of slopes of the linear portion of these dose-response curves, or the ratio of other multipoint estimates (Finney, 1964; Ankley et al., 1991; Putzrath, 1995; Villeneuve et al., 2000a). The assumption of all of techniques for TCDD-EQ determination is that the test extract induces CYP1A1 through the same mechanism as the TCDD standard, and therefore simply acts as a dilution of TCDD (Finney, 1964; Villeneuve et al., 2000a). The method of ED50 comparison is frequently used for H4IIE cell bioassay data due to its simplicity (Jones et al., 1993a; Koistinen et al., 1997; Huestis et al., 1997). CYP1A1 activity is plotted versus the extract dose (semilog plot) and an appropriate regression model 


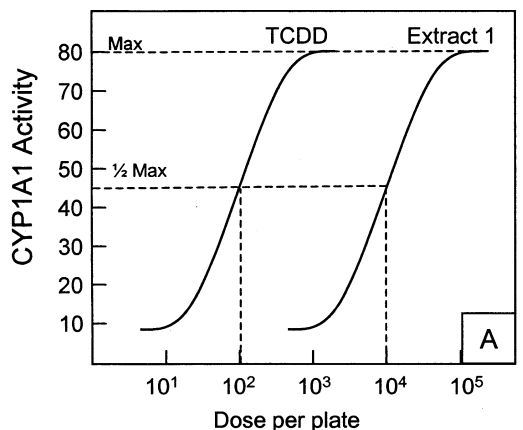

(pg TCDD or gram equivalents Extract)

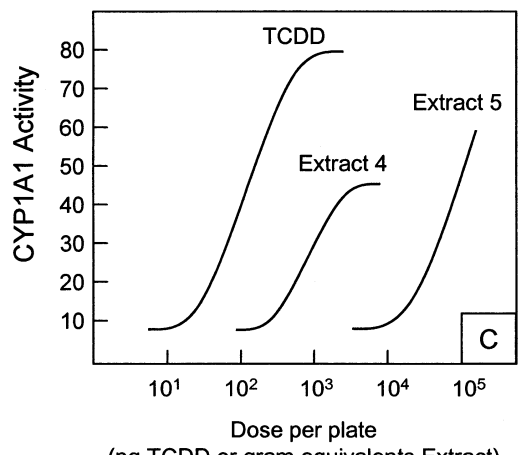

(pg TCDD or gram equivalents Extract)

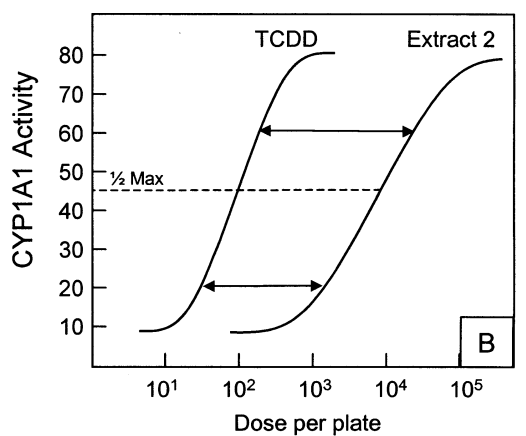

(pg TCDD or gram equivalents Extract)

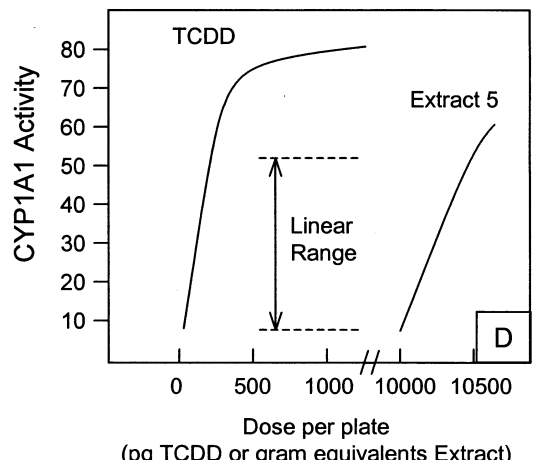

(pg TCDD or gram equivalents Extract)

FIGURE 5. Theoretical dose-response curves generated with the H4IIE cell bioassay.

is fitted to the data (for examples see Finney, 1964; Kerr and Meador, 1996; Oris and Bailer, 1997). The ED50s from the test extract are compared to the ED50 of the TCDD standard to determine the TCDD-EQ. In Figure 5A, it can be seen that the potency of Extract 1 to induce CYP1A1 is 100-fold less than that of TCDD. The calculations are performed based on the description by Sawyer et al. (1984):

$$
\begin{aligned}
& \text { Extract potency } \\
& \begin{aligned}
= & {[\mathrm{TCDD}} \\
\times & {[\text { Extract volume }(\mu \mathrm{l}) /} \\
& \mathrm{TCDD} \text { dose volume }(\mu \mathrm{l})] \\
= & \mathrm{pg} \text { TCDD-EQ }
\end{aligned}
\end{aligned}
$$

Relative potency

$=$ pg TCDD-EQ/sample weight (wet weight, $\mathrm{g}$ )

$=\mathrm{pg}$ TCDD-EQ $/ \mathrm{g}$ (wet weight)

The coefficient of variation (CV) for the estimate of TCDD-EQ is determined additively as described in Tillitt et al. (1991a):

$$
\mathrm{CV}_{\mathrm{TCDD}-\mathrm{EQ}}=\left[\left(\mathrm{CV}_{\mathrm{E}}\right)^{2}+\left(\mathrm{CV}_{\mathrm{S}}\right)^{2}\right]^{1 / 2}
$$

where $\mathrm{CV}_{\mathrm{E}}$ and $\mathrm{CV}_{\mathrm{S}}$ are the coefficients of variation for the extract ED50 and TCDD standard ED50, respectively.

The ED50 comparison method is easy to perform, but is only valid when the dose-response curves are fundamentally identical, differing only in their position on the $x$ axis (Figure 5A). This requires that the dose-response curves for TCDD and the test sample be parallel and attain identical maximal CYP1A1 activity (efficacy). The use of point estimates such as ED50s to determine TCDD-EQs has been criticized in cases where one or both of these conditions are not met (Putzrath, 1995; Villeneuve et al., 2000a). When curves are parallel, point estimates taken from the same position at any point along both the TCDD and sample curves will result in the same TCDD-EQ value. This is not the case when curves are not parallel (Figure 5B). The dose-response curve for Extract 4 is typical of partial agonists, where the maximal response is not observed even at apparently maximal receptor occupancies. Relative to TCDD, the dose-response curve of the partial agonist is shifted to the right. Depending on where the point estimate is taken from on the curve (e.g., EC20, EC50, or EC80), the TCDDEQ of the sample will be different if the slopes of the standard and the extract are not parallel. Tests 
of dose-response curve parallelism are rarely reported in aquatic toxicology studies that use point estimate comparisons (Oris and Bailer, 1997). Even if statistical tests of parallelism are used, Villeneuve et al. (2000a) state that these are not meaningful for examining extract curves where no defined dose unit can be used (i.e., extract doses can only be expressed in terms of their dilution factor or gram equivalents; see Section A). Partial agonists can further complicate accurate TCDD-EQ determination because they occupy a large number of receptors without eliciting a response. This can competitively block the effects of agonists with higher efficacies or full agonists such as TCDD (see Section IIA, Accuracy, for more information).

Another difficulty encountered with the ED50 ratio technique occurs when a dose-response curve does not reach a maximal level of CYP1A1 activity (Figure 5C, Extract 5). In this situation, it is impossible to calculate an ED50. In cases where no maximum CYP1A1 activity is reached, a potential solution may be to test the extract at greater concentration, but this is often not possible. The point estimate comparison method, if used on curves with unequal efficacy or no maximum, would result in ambiguous TCDD-EQs, potentially invalidating the conclusions of a study. To avoid the problems associated with the point estimate method of TCDD-EQ determination, techniques that compare a greater range of data from the dose-response curves are recommended (Putzrath, 1995; Villeneuve et al., 2000a)

The most commonly reported multipoint comparison for calculating H4IIE bioassay-derived TCDD-EQs is a modification of the slope-ratio technique described by Finney (1964). This modified method was originally developed and used by Tillitt et al. (1989) and is described in Ankley et al. (1991) to estimate TCDD-EQs in Lake Michigan Chinook salmon (Oncorhynchus tschawytscha) extracts. H4IIE cells exposed to flesh extracts from these fish did not produce EROD dose-response curves with maximal enzyme induction (i.e., reduced efficacy), preventing ED50 comparisons. To determine a TCDD-EQ using the slope-ratio technique, the TCDD and extract doses are plotted on a linear scale (Figure 5D). The rates of CYP1A1 activity over the initial doses of TCDD or an extract are proportional to the chemical doses. In this firstorder region, the rate of CYP1A1 activity increases almost linearly (highlighted in Figure 5D). A greater slope in this region of the curve indicates a higher CYP1A1 inducing potency for a chemical. By comparing slopes of extract curves to the slope of the
TCDD standard, TCDD-EQs can be estimated, as described by Tillitt et al. (1993):

$$
\begin{aligned}
& \text { Extract potency } \\
& =\text { sample slope }(\mathrm{EROD} / \mu 1 \text { of extract }) / \\
& \text { TCDD slope (EROD/pg TCDD) } \\
& =\operatorname{pgTCDD}-\mathrm{EQ} / \mu \mathrm{l} \text { of extract }
\end{aligned}
$$

Relative potency

$$
\begin{aligned}
= & (\text { pg TCDD-EQ } / \mu \mathrm{l}) \times(\text { extract volume }, \mu \mathrm{l}) / \\
& \text { sample wet weight }(\mathrm{g}) \\
= & \mathrm{pg} \text { TCDD-EQ } / \mathrm{g}(\text { wet weight })
\end{aligned}
$$

The advantages of this technique are twofold: First, it allows the use of a greater range of data from the dose-response curve in the TCDD-EQ calculation. This provides more confidence in estimating the true relative potency of an extract, rather than relying on a single point from the dose-response curve. Second, only the linear portion of the dose-response curve is used in the calculation. Unlike the ED50 comparison method, the slope-ratio technique allows TCDDEQs to be estimated from dose-response curves that do not attain maximal TCDD induction. Thus, data that would have been discarded can provide useful information in a study (note that incidences of incomplete dose-response curves should be reported along with derived TCDD-EQs). These advantages over the ED50 comparison method have increased the popularity of the slope-ratio technique in studies that use the H4IIE cell bioassay (Jones et al., 1993a; Hoke et al., 1994; Ludwig et al., 1996).

An alternative technique that also employs a range of dose-response data to estimate relative potencies has been proposed by Villeneuve et al. (2000a). Although the technique is described for any type of relative potency estimate, this paragraph will discuss its application to TCDD-EQs specifically. To circumvent the problem of nonparallel dose-response curves, TCDD-EQs are determined from multiple points along the effective range of CYP1A1 activity. A relative potency range (RPF range) is determined rather than a single TCDD-EQ estimate (e.g., 1 to $10 \mathrm{pg}$ TCDD-EQ/g). The breadth of RPF ranges indicate the degree of certainty in the TCDD-EQ estimate. For instance, an extract with a broad RPF range may be suitable for general risk assessment applications, but not definite enough for confident comparisons to other extracts (Villeneuve et al., 2000a). To be most effective the RPF range technique requires extract dose-response 
curves to have the same efficacy as the TCDD standard. RPF ranges are calculated by determining effective concentrations along the dose-response regression line for multiple levels of CYP1A1 activity (e.g., ED20, ED50, ED80) induced by an extract. The corresponding values from the TCDD standard curve are used to determine TCDD-EQs at each of the selected points [Eqs. (1) and (2)]. When comparing RPF ranges among extracts, it is necessary to use a standard range of response, arbitrarily defined as, 20 to $80 \%\left(\mathrm{RPF}_{20-80}\right.$ range) of the maximum response achieve for the TCDD standard (Villeneuve et al., 2000a). The RPF range is defined as:

$\mathrm{RPF}_{20-80}$ range $=$ minimum $\mathrm{RPF}_{\mathrm{i}}$ to maximum $\mathrm{RPF}_{\mathrm{i}}$

If equal efficacy cannot be demonstrated, the maximum RPF should be defined as the maximum CYP1A1 response for the sample in question
(Villeneuve et al., 2000a). In addition to the mechanics of the RPF-range technique, the authors include a dichotomous decision-making framework to "guide derivation, critical evaluation, and use of relative potency estimates based on in vitro bioassay results." This framework consists of a series of yes-no questions (e.g., was the observed sample efficacy markedly different from standard efficacy?) that lead to a suggested method of TCDD-EQ determination.

A hypothetical comparison of the three techniques reviewed in this section of our review is provided to allow evaluation of these methods (Figure 6). The TCDD standard curve and the doseresponse curve for $\mathrm{PHH}$ A have the same slope and equal efficacy. In this case, all three techniques are valid and yield very similar RPFs. The curve for PHH B also has equal efficacy, but the slope differs from that of the TCDD standard curve. Although an ED50 can be determined, use of the ED50
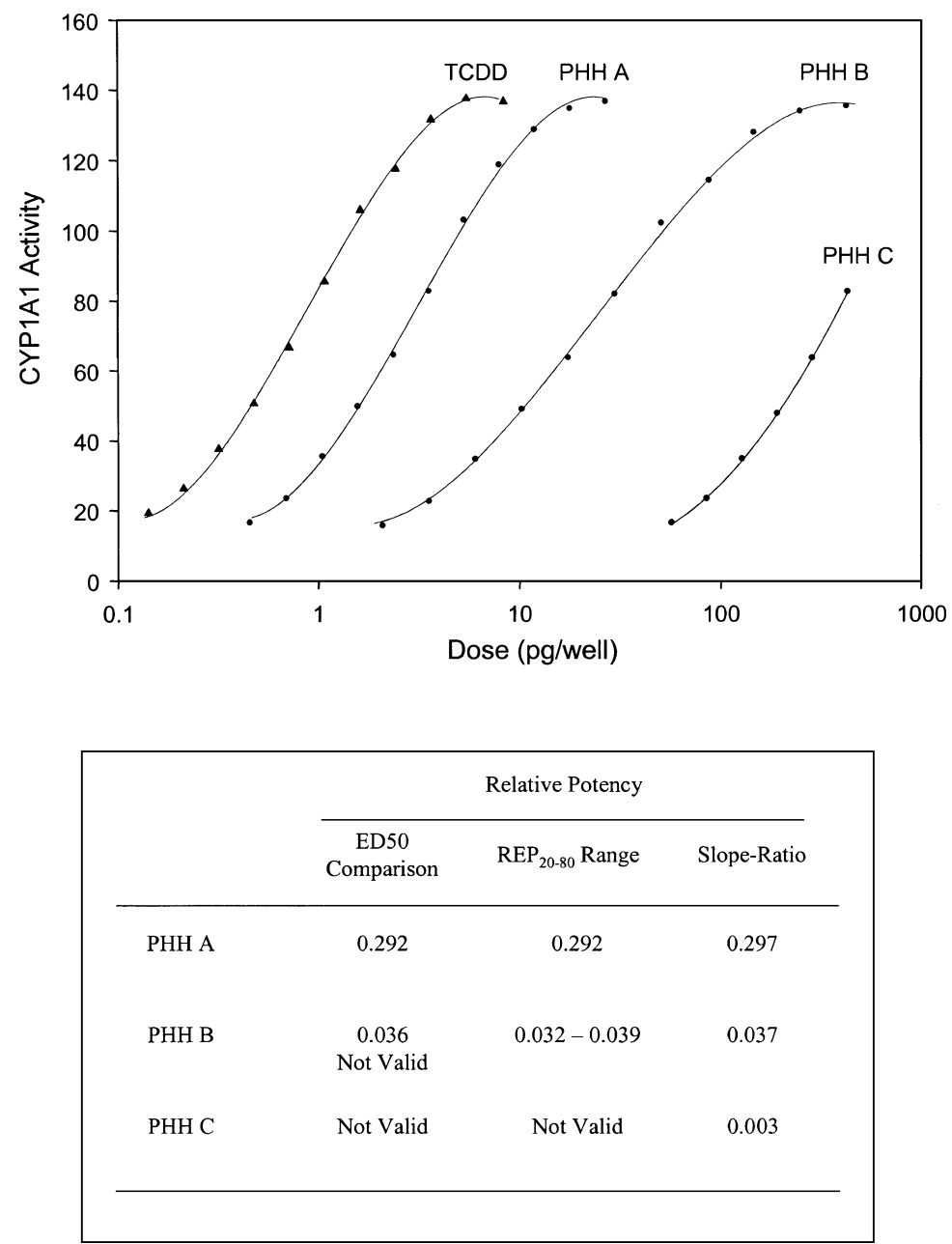

FIGURE 6. Comparison of mathematical techniques used to generate TCDD-EQs from H4IIE cell bioassay dose-response curves. 
comparison technique with this type of doseresponse curve is not recommended because assumptions for the statistical analysis are violated. The $\mathrm{RPF}_{20-80}$ range technique indicates that the RPF for this curve varies depending on the position examined on the curve, but this variation is not great. The RPF determined using the modified slope-ratio technique agrees with the $\mathrm{RPF}_{20-80}$ range. The doseresponse curve for $\mathrm{PHH} \mathrm{C}$ did not attain a maximal level of CYP1A1 activity. Only the slope-ratio technique allows an RPF to be determined for this type of curve. Of the three techniques reviewed, the slope-ratio technique allows the greatest flexibility in determining TCDD-EQs from H4IIE cell bioassay data. This method makes use of the greatest range of dose-response data and can be used to analyze partial dose-response curves. Other methods for estimation of relative potency exist, but these have not yet been applied in the H4IIE cell bioassay as of the writing of this review.

\section{H4IIE CELL BIOASSAY CHARACTERIZATION AND METHOD VALIDATION}

The use of H4IIE cells as a tool to identify the presence of PHHs in environmental samples has undergone many changes and modifications to optimize the effectiveness of the bioassay. This section will review specific analytical performance parameters of the H4IIE cell bioassay. Method validation of the H4IIE cell bioassay is necessary to ensure that the technique is accurate, specific, and reproducible over the specified range that analytes will be tested. A number of publications deal specifically with characterizing the H4IIE cell bioassay (Bradlaw and Casterline, 1979; Tillitt et al., 1991a; Sanderson et al., 1996), and many others have reported performance parameters in their results. The parameters of focus in this section will be accuracy, precision, specificity, limit of detection, limit of quantitation, linearity, and range of the H4IIE cell bioassay. As modifications and optimizations of the H4IIE cell bioassay continue, it is important for researchers to report the performance parameters of the method being used to ensure the validity of their results, to help others interpret the results, and to allow for comparison among laboratories and/or studies.

\section{A. Accuracy}

Accuracy is the measure of exactness of an analytical method, or the closeness of agreement be- tween the value that is accepted as a "true" value and the value found. For the H4IIE cell bioassay, accuracy can be evaluated by comparing the cellular response to extracts of known quantities of chemicals with the actual concentration of those chemicals. In the initial characterization of the H4IIE cell line bioassay performed by the U.S. Food and Drug Administration, Bradlaw et al. (1979) reported good correlation between the predictability of the cell culture system and the chemical identification of toxic dioxin-like components extracted from gelatin samples. Gelatin extracts with high TCDD content produced high AHH activity and samples with negligible amounts of TCDD gave no response in the bioassay. In a more specific measure of accuracy, Tillitt et al. (1991a) conducted spike/bioanalysis studies to assess the ability of the H4IIE cell bioassay to accurately quantitate PHHs in biological samples. Experiments indicated that extracts of chicken eggs spiked with TCDD and PCB 77 produced doseresponse curves of EROD activity that were in good agreement with the dose-response curves seen when the compounds were added directly to the cell cultures. Slopes of the curves for the extracts and pure compounds were not significantly different, indicating no extraction or matrix effect on the response of the bioassay. These experiments clearly demonstrated that the H4IIE bioassay can accurately determine the potency of $\mathrm{PHH}$ extracts.

The accuracy of the H4IIE cell bioassay may be compromised at higher analyte concentrations or in the presence of weak AhR agonists, although this is not commonly observed in this cell culture system. Early experiments by Sawyer and Safe (1982) indicated that concentration plots of several PHHs versus their respective induced AHH activities gave dose-related increases in enzyme activity, which were usually followed by a decrease at higher concentrations of the inducer (Figure 3A). Similar observations have been attributed to cytotoxicity in H4IIE (Bannister et al., 1987), but decreases in enzyme activity in avian cell culture systems exposed to high $\mathrm{PHH}$ concentrations were determined not to be due to loss of cell viability (Lorenzen et al., 1997a). In avian and fish cell culture assays for EROD activity, it has been suggested that this type of bell-shaped dose-response curve may be the result of competitive inhibition of CYP1A activity at high PHH concentrations (Hahn et al., 1993; Kennedy et al., 1995). However, other yet unidentified mechanisms may also play a role (Hahn et al., 1993). A relationship has been suggested between PHH-induced accumulation of highly carboxylated porphyrins and declines 
in EROD activity at high PHH concentrations, but the mechanism involved remains to be determined (Hahn and Chandran, 1996). Some studies have demonstrated not only a decrease in catalytic activity but also a decrease in immunodetectable CYP1A protein at high analyte concentrations (Gooch et al., 1989; Lorenzen et al., 1997a). This supports the use of CYP1A catalytic activity as an accurate estimate of CYP1A protein induction.

A direct comparison of CYP1A1 protein levels to CYP1A1 catalytic activity using the H4IIE cell bioassay has not been done, but it has been suggested that substrate inhibition of H4IIE EROD or AHH activity may result in incorrect induction estimates (Murk et al., 1996). To ensure the accuracy of TCDD-EQs determined with the H4IIE cell bioassay, the extract dilution series should bracket the full dose-response curve. If a decrease in activity is observed at high concentrations, this should be reported with the presentation of TCDD-EQs. In cases where inhibition is suspected (e.g., extracts from areas of high PCB contamination), it may be useful to determine both catalytic activity and immunodetectable protein levels of CYP1A1 on selected samples. If the dose-response curves of CYP1A1 protein and catalytic activity differ significantly, other methods of TCDD-EQ determination should be used. Sanderson et al. (1996) suggest the use of a recombinant H4IIE cell line transfected with a luciferase reporter gene under control of dioxinresponsive elements (DREs) because luciferase activity is insensitive to substrate inhibition in hepatoma cells (Sanderson et al., 1996; Richter et al., 1997). It is important, however, that the stability of the reporter gene is demonstrated over time before this assay can be used routinely like the wild-type H4IIE cell bioassay. It is likely that the H4IIE bioassay will continue to be used for biomonitoring due to its availability and widespread knowledge base. The phenomenon of substrate inhibition can be avoided when using the H4IIE cell bioassay by using serial dilutions of the dosing chemical or extract. Therefore, the accuracy of TCDD-EQ determination using wild-type H4IIE cells should not be influenced in most cases.

The accuracy of the H4IIE bioassay may also be assessed through the use of a positive reference material. In the same way as analytical chemists maintain records of method performance, performance materials may also be used for the H4IIE bioassay. A positive reference material is a sample of an appropriate matrix that has a known amount of dioxin-like activity. The positive control material can be tested with each batch or set of samples from the field. The H4IIE bioassay results from testing of the positive control material are maintained as an ongoing control or reference in the form of a control chart. Deviations of the H4IIE results of the positive control material from the mean values of the control chart can help alert analysts to potential problems in a given batch of H4IIE bioassay results.

\section{B. Precision}

Precision is the measure of the degree of repeatability of an analytical method under normal operation and is usually expressed as the percent relative standard deviation or coefficient of variation (CV) for a statistically significant number of samples. One test of the precision of the H4IIE cell bioassay is to examine repeated TCDD standard curves. Tillitt et al. (1991a) reported the CVs for within bioassay variance associated with TCDD ED50s were small, with an average of $3.70 \%$. Different laboratories have reported among bioassay CVs for TCDD ED50s based on long-term use of the H4IIE cell bioassay. Overall estimates are generally in the range of $25-35 \%$ (Table 5), indicating similar variability among labs. When the actual TCDD ED50 values among labs are standardized to cell number and compared, the values are remarkably similar (Table 5, column 3), considering that several different assay techniques were used and that the estimates cover a period of over, 20 years. Estimates of ED50s for other PHH standards are also very similar among different laboratories (Tillitt et al., 1991a). This demonstrates a high level of reproducibility of the H4IIE cell bioassay among different laboratories over time.

Precision of the H4IIE cell bioassay is also quite high for environmental extracts. Tillitt et al. (1991a) reported that the CVs associated with extract ED50 estimates are generally in the range of 5-15\%, and that the final estimates of TCDD-EQs in these environmental samples had CV values between 10 and $20 \%$. The authors noted that this precision is only observed when a TCDD standard curve is run with each set of environmental samples. This is because TCDD-EQ determinations are relative measures based on comparison to the cells response to TCDD. There will always be subtle differences between each plate of cells and in day-to-day assay conditions that will alter the induction of CYP1A1. It is important to run a TCDD standard curve with each set of environmental extracts to ensure matching cell densities and assay conditions exist for both TCDD standards and extracts. 


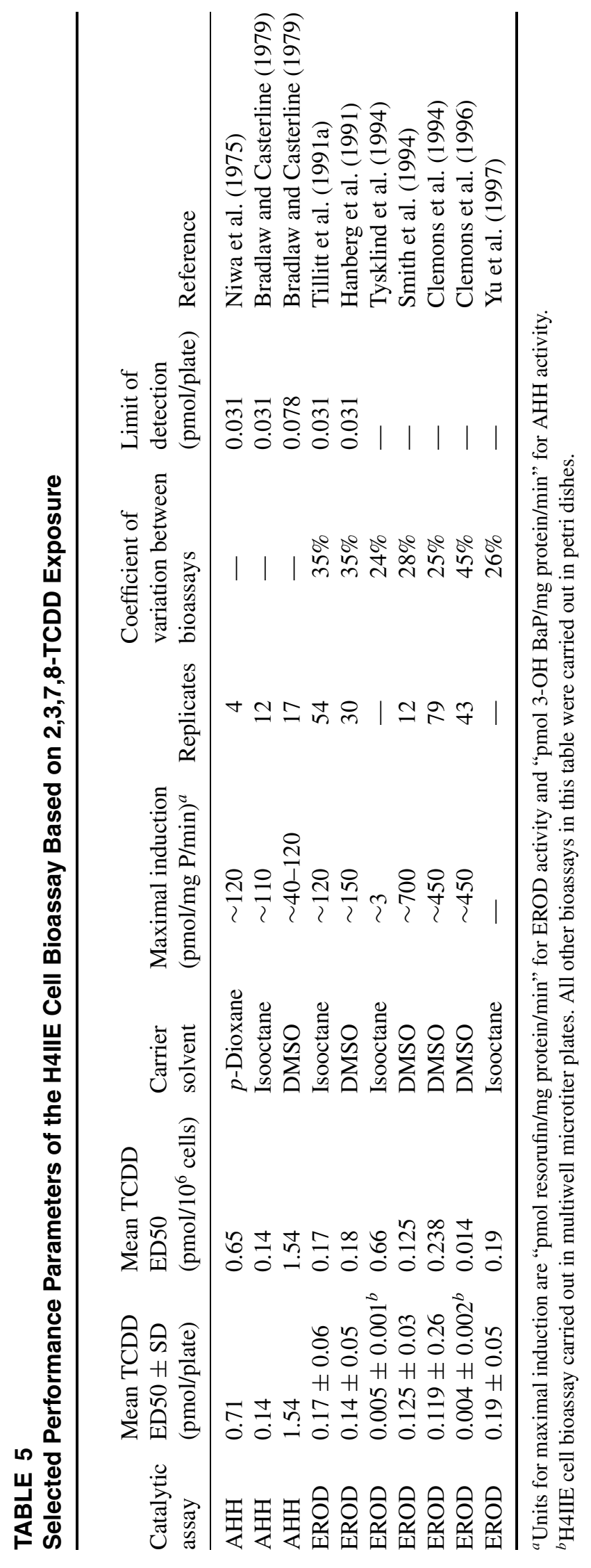




\section{Limit of Detection and Limit of Quantitation}

The limit of detection (LOD) is defined as the lowest concentration of an analyte in a sample that can be determined to be statistically different from a blank (Keith et al., 1983). It is expressed as a concentration in units of standard deviation and is generally based on the IUPAC definition of three standard deviations above the mean of the analytical blank (Winefordner and Long, 1983). This value is derived from statistical parameters easily obtained from the TCDD standard curve. Using the IUPAC model, there is a $0.13 \%$ chance that a signal (i.e., induced CYP1A1) measured at or above the detection limit would be due to random fluctuation of the blank signal. The limit of detection for TCDD in the H4IIE cell bioassay has been very consistently reported at $0.031 \mathrm{pmol} / \mathrm{plate}$ ( $31 \mathrm{fmol}$; Table 5) when the 100-mm petri dish format is used. This is an indication of not only the high sensitivity of the assay to the presence of PHHs, but also supports the excellent precision of the H4IIE cell bioassay over time (described previously). Only rarely have H4IIE detection limits for environmental extracts been reported. Thomas and Anthony (1999) determined an LOD of 0.043 pg TCDD-EQ/g egg wet weight for great blue heron (Ardea herodias) egg extracts analyzed with the bioassay. This is very close to the LOD reported for TCDD ( $0.035 \mathrm{pg}$ TCDD/g tissue) in analysis of fish liver extracts using mass spectrometry (Parrott et al., 2000).

The limit of quantitation (LOQ) is defined as the lowest concentration of an analyte in a sample that can be determined with acceptable precision and accuracy under the stated operational conditions of the H4IIE cell bioassay. An LOQ value of 10 standard deviations above the mean of the analytical blank is recommended (Keith et al., 1983). Based on the values reported in Table 5, the TCDD LOQ for the H4IIE bioassay would be approximately $0.01 \mathrm{pmol}$ TCDD/plate. This should also correspond to the LOQ for extract TCDD-EQs, but the value may be affected by the presence of other chemicals in the extract. In cases where a TCDD-EQ for an extract is below the LOD or LOQ, a general practice is to assign a value of one half of the LOD or LOQ for the TCDD-EQ (Ankley et al., 1993; Giesy et al., 1997).

It is important to determine the potential influence that unknown components of the sample matrix itself might have on CYP1A1 measurement when determining the LOD or LOQ. Extracts of environmental samples (i.e., sediment, tissue, etc.) may contain small biologically active molecules that are not removed during the cleanup procedure. It would be difficult or impossible to reproduce the sample matrix itself, but a field control sample from a similar reference site can be used that is similar to the test sample matrix (e.g., sediment upstream of a PHH contaminated site). This "matrix control" serves two purposes by indicating the potential influence of both small molecules from the extract and the influence of the extraction procedure (e.g., residual extraction solvent in the carrier solvent) in the absence of PHHs or related chemicals. The effect on CYP1A1 induction by the matrix control should also be compared to routine procedural controls and solvent controls.

In the field of drug assay development, the LOD and LOQ are described as the most important parameters for judging the quality and reliability of data at the lower end of the concentration range of interest (Kucharczyk, 1993). Yet very few H4IIE cell bioassay studies report these parameters with a description of how the values were derived. Values for LOD and LOQ are particularly important when examining extracts with very low CYP1A inducing potency. Routine reporting of these parameters in H4IIE studies would provide valuable information to researchers deciding on whether the H4IIE cell bioassay has the required sensitivity for their particular study.

\section{CYP1A1 Activity Range}

Range is the interval between the upper and lower levels of CYP1A induction (inclusive) that have been demonstrated to be determined with precision, accuracy and linearity using the method as written. A number of variables may influence the measured induction of CYP1A1, including plate size, H4IIE cell density, volume of growth medium, chemical carrier solvent, and assay endpoint (EROD or AHH). The variability in activity is revealed by comparing maximal CYP1A1 induction by TCDD among different studies (Table 5). Many factors can influence this maximal induction, and it is therefore difficult to determine the exact reasons for differences among laboratories. Of greater importance for accurate determination of TCDD-EQs is to ensure that the range of TCDD-induced CYP1A1 activity among plates within the same study are not statistically different. Highly variable maxima among TCDD standard curves in an assay would result in different TCDD-EQs for a single extract depending on which TCDD standard is used in the calculation (or reduced accuracy if the mean of several TCDD 
standard curves is used). As described previously, TCDD standard curves in the H4IIE cell bioassay are highly repeatable in terms of linearity and range, and generally do not pose a problem in the accurate determination of TCDD-EQs.

\section{E. Quality Assurance in the H4IIE Cell Bioassay}

The accuracy and consistency of the results from the H4IIE cell bioassay can be ensured through the use of defined quality assurance (QA) methods. A good QA program will identify potential problems before they occur, prevent recurrence of identified problems, and provide confidence in the bioassay results. This is accomplished through the proper replication of assayed samples (e.g., perform triplicate analysis on at least 5\% of samples), comparison of calibration against known standards, proper maintenance of equipment, accurate sample tracking and chain-of-custody records, and documentation at all steps of sample processing. Suggested elements of a good QA program for the H4IIE cell bioassay are listed in Table 6 . This section outlines important H4IIE cell bioassay standard methods that will make certain that the data generated have a high probability of being of acceptable quality.

The QA measures for the H4IIE cell bioassay can be divided into two categories: those measures that assure the quality of the EROD assay data, and those measures that assure the quality of the sample processing. The EROD assay QA measures include generation of TCDD, resorufin, and protein

\section{TABLE 6}

\section{Suggested Elements of a Good Quality Assurance Program for the H4IIE Cell Bioassay}

\begin{tabular}{|c|c|}
\hline Component & Quality assurance suggestions \\
\hline H4IIE maintenance & $\begin{array}{l}\text { - Routinely check cells for mycoplasma or other contamination (see } \\
\text { Section IIB for cell culture procedures). }\end{array}$ \\
\hline TCDD standards & $\begin{array}{l}\text { - Generate a composite TCDD dose-response curve from the average } \\
\text { of four independent determinations. } \\
\text { - TCDD composite curve should be generated for every } 10 \text { extract } \\
\text { samples tested. }\end{array}$ \\
\hline Sample replication & - Assay $5 \%$ of extract samples in triplicate. \\
\hline Controls & $\begin{array}{l}\text { - Include positive control sample extract in triplicate with samples } \\
\text { for H4IIE analysis on each assay date (e.g., tissue extract from } \\
\text { organism containing known concentrations of PHHs demonstrated } \\
\text { to consistently induce CYP1A1 in H4IIE). } \\
\text { - Include appropriate matrix and solvent controls in triplicate for } \\
\text { H4IIE analysis on each assay date. }\end{array}$ \\
\hline Reagents & $\begin{array}{l}\text { - Check concentrations of resorufin, ethoxyresorufin, and NADPH } \\
\text { reagents on each assay date using spectrophotometer. } \\
\text { - Concentrations are deemed acceptable if actual concentration is } \\
\text { within } 10 \% \text { of nominal concentration. } \\
\text { - Record source and lot numbers of all reagents used in laboratory } \\
\text { notebooks. }\end{array}$ \\
\hline Resorufin and protein standards & $\begin{array}{l}\text { - Prepare eight-point resorufin and seven-point BSA (bovine serum } \\
\text { albumin) standard curves with six replicates for each concentration. } \\
\text { - Analyze resorufin and protein standard curves concurrently with } \\
\text { TCDD standards and sample extracts. }\end{array}$ \\
\hline Equipment and instrumentation & $\begin{array}{l}\text { - Routinely inspect and perform preventative maintenance on all } \\
\text { instruments. } \\
\text { - Perform regular calibration of equipment. }\end{array}$ \\
\hline Experimental information and data & $\begin{array}{l}\text { - Record data in bound notebooks with copies maintained in separate } \\
\text { secure area. } \\
\text { - Maintain hard copies of computer data files in project notebook. } \\
\text { - Verify all data reductions independently. } \\
\text { - Archive all computer data files as CD or tape backups. }\end{array}$ \\
\hline
\end{tabular}




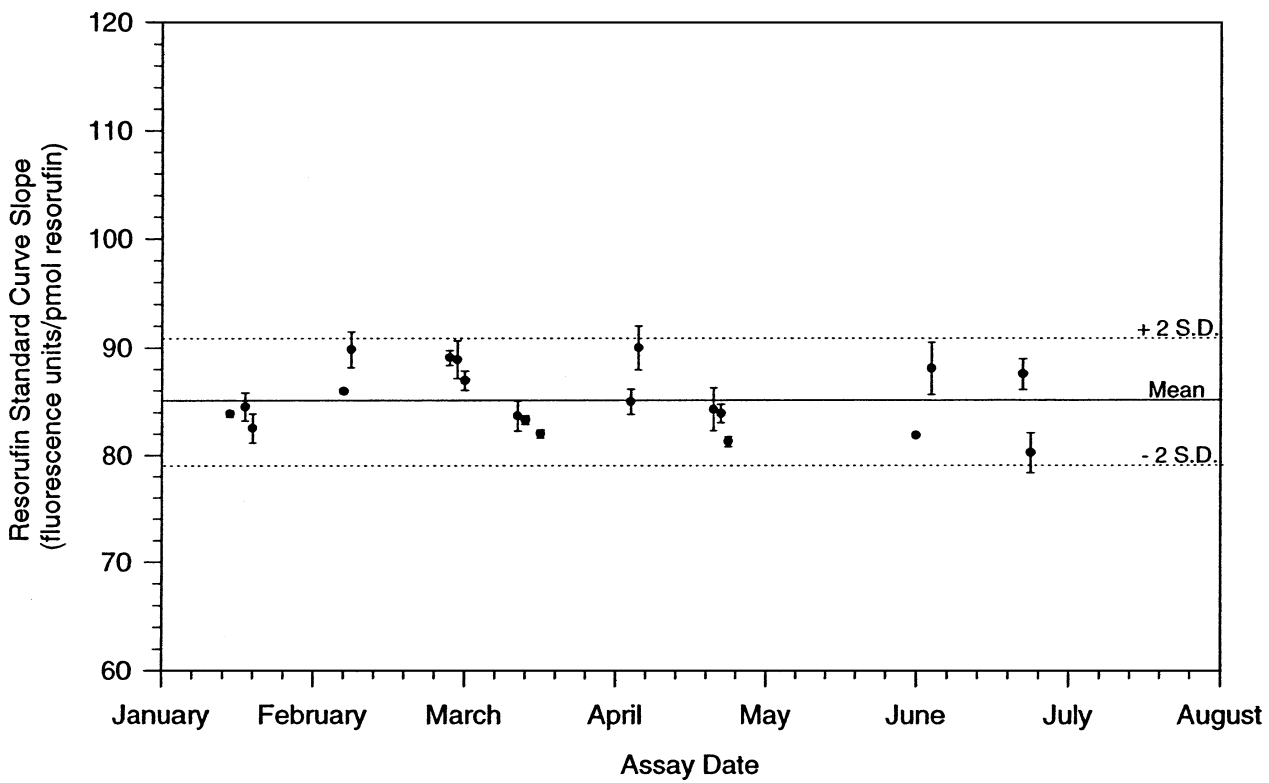

FIGURE 7. Control chart example for resorufin standard curve slope over multiple assays in the H4IIE cell bioassay.

standard curves for each set of samples run on a given day. The parameters from these standard curves are compared with those generated on previous occasions in a control chart (Figure 7). By examining the parameters from the standard curves of each assay, the performance of the measurement system can be demonstrated. The second category, sample-processing QA measures, include running the H4IIE cell bioassay with a positive control material, a negative control material (i.e., matrix con- trol), a reagent or procedural blank, and replicate samples. As with the EROD assay QA measures, control charts can be generated (Figure 8).

The control charts allow for statistical analysis of the parameters measured and establishment of acceptance criteria for these parameters (Taylor, 1981). To effectively use control charts, a series of measurements are taken for the parameter in question (e.g., slope of the resorufin standard curve) and the standard deviation determined.

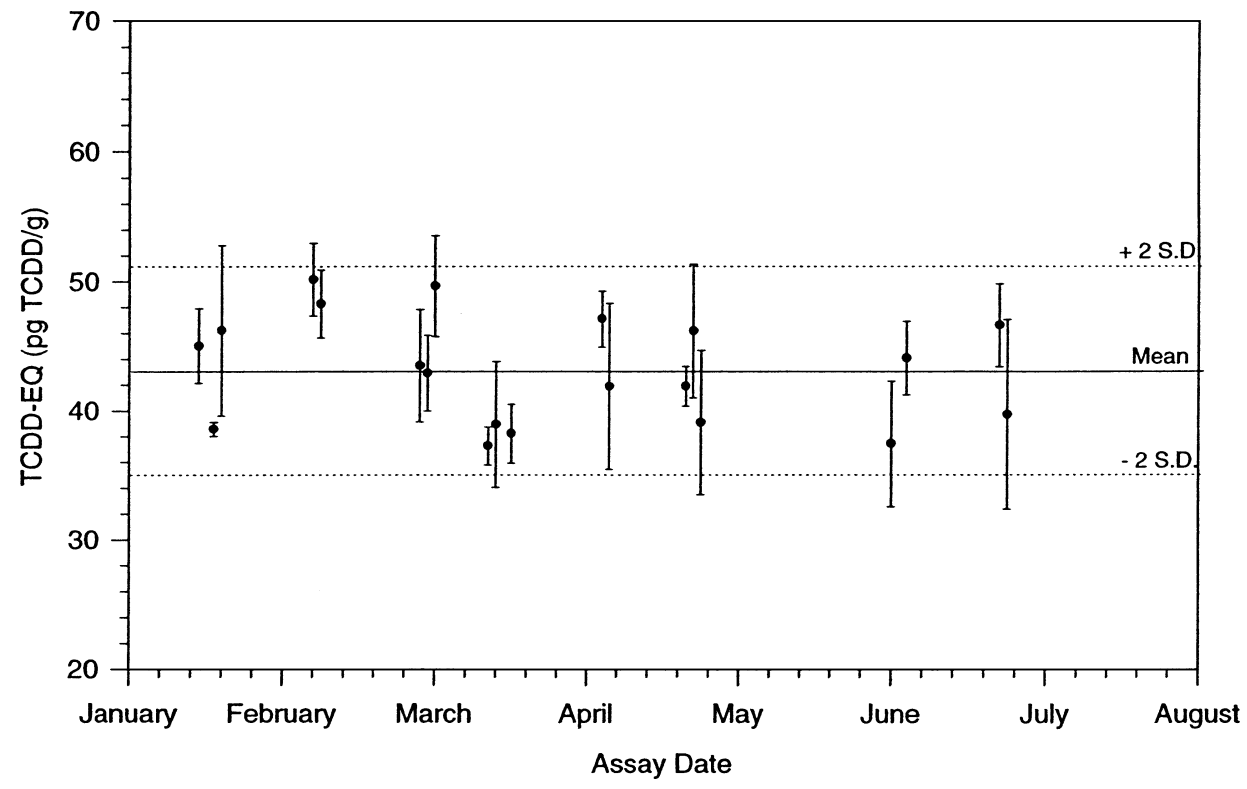

FIGURE 8. Control chart example for positive control material TCDD-EQ over multiple assays in the H4IIE cell bioassay. 
TABLE 7

Acceptance Criteria for Quality Assurance Measures in the H4IIE Cell Bioassay

\begin{tabular}{|c|c|c|c|}
\hline Measure & Parameter & $\begin{array}{l}\text { Acceptance criteria } \\
\text { (within assay) }\end{array}$ & $\begin{array}{l}\text { Acceptance criteria } \\
\text { (among assays) }\end{array}$ \\
\hline TCDD standard curve & Slope or ED50 & $\begin{array}{c}r^{2}>95 \%, p<.05 \\
\mathrm{CV}_{\text {within }}<25 \%\end{array}$ & Within $2 \sigma$ of control chart mean \\
\hline Resorufin standard curve & Slope or ED50 & $\begin{array}{c}r^{2}>95 \%, p<.05 \\
\mathrm{CV}_{\text {within }}<25 \%\end{array}$ & Within $2 \sigma$ of control chart mean \\
\hline Protein standard curve & Slope or ED50 & $\begin{array}{c}r^{2}>95 \%, p<.05 \\
\mathrm{CV}_{\text {within }}<25 \%\end{array}$ & Within $2 \sigma$ of control chart mean \\
\hline Replicate assays & TCDD-EQ & $\mathrm{N} / \mathrm{A}^{a}$ & $\mathrm{CV}_{\text {among }}<50 \%$ \\
\hline Positive control material & TCDD-EQ & $\mathrm{CV}_{\text {within }}<25 \%$ & Within $2 \sigma$ of control chart mean \\
\hline Negative control material & TCDD-EQ & $\mathrm{CV}_{\text {within }}<25 \%$ & Within $2 \sigma$ of control chart mean \\
\hline Reagent blank & TCDD-EQ & Mean $\leq$ LOQ & $\begin{array}{l}\text { Within } 2 \sigma \text { of LOQ control chart } \\
\text { mean }\end{array}$ \\
\hline Replicate samples & TCDD-EQ & $\mathrm{CV}_{\text {within }}<25 \%$ & $\mathrm{CV}_{\text {among }}<50 \%$ \\
\hline
\end{tabular}

${ }^{a}$ N/A, not applicable.

Acceptance criteria (i.e., control limits) are computed from this standard deviation. For example, values of the parameter that fall outside of the two standard deviation limit (95\% of the values) warn of possible trouble, while values that fall outside of the three standard deviation limit usually mean corrective action is needed (Taylor, 1981). Acceptance criteria for within-assay results should also be established (e.g., the $r^{2}$ of the TCDD standard curve should have $p<.05$ and the CV for all TCDD standard curves run that day should be less than $25 \%$ ). Acceptance criteria for quality assurance measures in the H4IIE cell bioassay are listed in Table 7.

\section{F. Summary}

The H4IIE cell bioassay is a reproducible and sensitive bioanalytical tool. This section has reviewed reports of the analytical performance parameters of the H4IIE cell bioassay, highlighting its high level of precision and accuracy, its known limits of detection and quantitation, and the importance of the range of CYP1A1 induction. It is equally important for laboratories using the H4IIE cell bioassay to have a sound quality assurance program to reduce measurement errors and assure results of acceptable quality. These practices are not specific to the H4IIE cell bioassay and are reviewed by Keith et al. (1983). Such a quality assurance program would include the use of well-maintained and reliable equipment, calibration standards, and proper experimental technique. It is important to keep records of TCDD, resorufin, and protein standard curves and monitor these results for any changes over time. Participation in interlaboratory comparisons (e.g., round-robin studies) helps to ensure valid comparisons among studies. Well-designed quality assurance programs for use of the H4IIE cell bioassay help reduce both inter- and intralaboratory variability.

\section{H4IIE CELL BIOASSAY AS A SCREENING TOOL FOR ENVIRONMENTAL CONTAMINANTS}

The H4IIE cell bioassay has two basic purposes in environmental testing: (1) the evaluation of the relative potency of individual, chemicals; and (2) the evaluation of the relative potency of chemical mixtures taken from the environment. We will describe the utility of the H4IIE cell bioassay-derived potency estimates when used in conjunction with environmental chemistry information in Section IV.A. The subsequent section (IV.B) contains a review of the studies in which the H4IIE bioassay has been used to evaluate the overall potency of complex mixtures of chemicals extracted from environmental samples. Last, we discuss the interpretation of the H4IIE cell bioassay results for hazard assessment purposes.

\section{A. TEQs Calculated from H4IIE Relative Potency Factors (RPFs)}

Regulation of groups of PHHs are often based on single "representative" congeners (e.g., TCDD for all PCDD/Fs) or based on the sum concentration 
of all members of a group (e.g., total PCBs; Clean Water Act, U.S. EPA, 1977). These methods are seriously flawed because they ignore the fact that different PHHs in the same group can differ widely in their toxic potency (Tillitt, 1999). Generation of H4IIE TEQs is a fast and simple approach that avoids these difficulties but is only now being considered for risk assessment in the United States (Henningsen et al., 1998). This section briefly reviews the use of RPFs to calculate TEQs, as this topic has been dealt with extensively elsewhere (Safe, 1987; van den Berg et al., 1998; Birnbaum, 1999; Tillitt, 1999).

H4IIE RPFs (often labeled TEFs in early publications) are derived by comparing the activity of AHH or EROD in cells exposed to individual PHHs to the activity in TCDD-exposed cells:

$$
\text { Congener A RPF }=\frac{\mathrm{ED} 50_{\mathrm{TCDD}}}{\mathrm{ED} 0_{\text {Congener A }}}
$$

RPFs derived using the H4IIE cell bioassay serve two general purposes. First, these values can be combined with analytical chemistry data to gen- erate a TEQ, which can then be used for general risk characterization or to validate the assumption of an additive response in cells exposed to a complete environmental extract (TCDD-EQ). Second, H4IIE RPFs for a specific PHH can be combined with mammalian RPFs determined from other in vitro and in vivo response studies to arrive at a consensus TEF value for that PHH (e.g., WHO-TEF values). Determination and use of consensus TEFs are beyond the scope of this article, but the reader is directed to a review by van den Berg et al. (1998) and a series of reviews in Human and Ecological Risk Assessment by Safe (1999), Birnbaum (1999), Tillitt (1999), and Sanderson and van den Berg (1999).

The calculation of a TEQ requires measured concentrations of selected PHHs in an environmental extract and their respective H4IIE RPFs (Table 8). The specific congeners used in the calculation are generally the PHHs determined to be the most potent inducers of CYP1A1 activity in H4IIE. For example, of the 209 PCB congeners, only a small number induce CYP1A1 at detectable levels (Metcalfe and Haffner, 1995), and therefore only concentrations

TABLE 8

Validating the Assumption of Additivity in the TCDD-EQ Model Using H4IIE Relative Potency Factors (RPFs)

\begin{tabular}{|c|c|c|c|c|c|}
\hline \multirow[b]{2}{*}{ Congener $^{a}$} & \multirow[b]{2}{*}{ H4IIE $\mathrm{RPF}^{b}$} & \multicolumn{2}{|c|}{ Concentration $(\mathrm{pg} / \mathrm{g})$} & \multicolumn{2}{|c|}{ TEQ (pg/g) } \\
\hline & & Extract 1 & Extract 2 & Extract 1 & Extract 2 \\
\hline 2,3,7,8-TCDD & 1 & 25 & 30 & 25 & 30 \\
\hline 1,2,3,7,8-PnCDD & 1.13 & 6 & 8 & 6.78 & 9.04 \\
\hline $1,2,3,4,7,8-\mathrm{HxCDD}$ & 0.49 & 0.5 & 0.5 & 0.245 & 0.245 \\
\hline 1,2,3,6,7,8-HxCDD & 0.23 & 4 & 5 & 0.92 & 1.15 \\
\hline $1,2,3,4,6,7,8-\mathrm{HpCDD}$ & 0.09 & 0.5 & 1.5 & 0.045 & 0.135 \\
\hline 2,3,7,8-TCDF & 0.03 & 30 & 35 & 0.9 & 1.05 \\
\hline 1,2,3,7,8-PnCDF & 0.16 & 7 & 10 & 1.12 & 1.6 \\
\hline $1,2,3,4,7,8-\mathrm{HxCDF}$ & 0.33 & 10 & 14 & 3.3 & 4.62 \\
\hline $1,2,3,6,7,8-\mathrm{HxCDF}$ & 0.1 & 3 & 4 & 0.3 & 0.4 \\
\hline $1,2,3,4,6,7,8-\mathrm{HpCDF}$ & 0.01 & 0.75 & 1 & 0.0075 & 0.01 \\
\hline $3,3^{\prime}, 4,4^{\prime}-\mathrm{TCB}$ & 0.00079 & 3000 & 3200 & 2.37 & 2.528 \\
\hline $3,4,4^{\prime}, 5-\mathrm{TCB}$ & 0.0072 & 200 & 250 & 1.44 & 1.8 \\
\hline $2,3,3^{\prime}, 4,4^{\prime}-\mathrm{PnCB}$ & 0.000025 & 30,000 & 46,000 & 0.75 & 1.15 \\
\hline $3,3^{\prime}, 4,4^{\prime}, 5-\mathrm{PnCB}$ & 0.1 & 700 & 750 & 70 & 75 \\
\hline \multirow[t]{4}{*}{$3,3^{\prime}, 4,4^{\prime}, 5,5^{\prime}-\mathrm{HxCB}$} & 0.0014 & 150 & 75 & 0.21 & 0.105 \\
\hline & & & $\Sigma$ TEQ (pg/g) & $110^{c}$ & $130^{c}$ \\
\hline & & & TCDD-EQ (pg/g) & $230^{c}$ & $1400^{c}$ \\
\hline & & & $\mathrm{TEQ} \approx \mathrm{TCDD}-\mathrm{EQ} ?$ & Yes & No \\
\hline
\end{tabular}

${ }^{a}$ Prefixes: $\mathrm{T}=$ tetra, $\mathrm{Pn}=$ penta, $\mathrm{Hx}=$ hexa, $\mathrm{Hp}=$ hepta. Suffixes: $\mathrm{CDD}=$ chlorinated dibenzo- $p$-dioxin, $\mathrm{CDF}=$ chlorinated dibenzofuran, $\mathrm{CB}=$ chlorinated biphenyl.

${ }^{b}$ From Clemons et al. (1994, 1996).

${ }^{c}$ To two significant digits. 
of these congeners are included in the TEQ calculation. The PHH congeners that are strong inducers of CYP1A1 (i.e., have high AhR binding affinities) are approximate isostereomers of TCDD, as determined from in vitro quantitative structureactivity (QSAR) data, EROD and AHH measurements in H4IIE, and toxicity (LD50) in mice and rats (Bandiera et al., 1984; Safe et al., 1986, 1989; Denomme et al., 1986; Kafafi et al., 1993). Predictions of other CYP1A1 inducers based on structure have been tested using the H4IIE cell bioassay (Liu et al., 1993; Hewitt et al., 1998). It should be noted that not all CYP1A1 inducers in H4IIE are structurally similar to TCDD. For instance, several PAHs (Willett et al., 1997) and sulfur-containing benzimidazole compounds (Backlund et al., 1999) can cause CYP1A1 expression in H4IIE.

Published H4IIE RPFs span two decades, beginning with an initial set of PHH RPFs based on AHH induction (Bradlaw et al., 1980). RPFs for the major classes of CYP1A1 inducers (PHHs) are compiled in Tables 9 and 10. The most complete set of RPFs for PHHs are reported in a series of papers by Safe and coworkers (Sawyer and Safe, 1982; Bandiera et al., 1984; Mason et al., 1986) based on AHH induction. Published RPFs for an individual congener can differ by several-fold depending on the study examined (Tables 9 and 10).

To examine the variability in H4IIE RPFs and its relation to assay technique, the $\mathrm{CV}$ was determined for individual chemicals where the RPF had been determined more than three times (data not shown). RPFs for individual chemicals were quite variable among studies, with high $\mathrm{CV}$ values for PCDDs, PCBs, and PCDFs. For PCBs and PCDDs, this variability did not appear to be attributed to specific techniques used to determine RPFs (e.g., removal of AHH derived RPFs or examination of isooctane versus DMSO as carrier solvents did not consistently reduce the $\mathrm{CV}$ ). For PCDFs, AHHderived RPFs were generally higher than ERODderived RPFs, and their removal from the CV calculation did reduce the variability to some degree, but not greatly. Despite this variability, an examination of the rank order of RPFs among studies reveals very similar patterns among labs. For instance, examination of a selected set of six PCDD RPFs from Table 9 determined by Bradlaw et al. (1979, 1980), Schrenk et al. (1991), and Tillitt et al. (1991) revealed an almost identical rank order of potency for these compounds. The rank order of PCB congeners in Table 9 is also generally similar among the different studies. Variation that is present is most certainly due to differences in H4IIE culturing, assay conditions, and possibly impurities in the chemical standards discussed in Section II and not due to within assay variation. Coefficients of variation for ED50s used to calculate RPFs for individual congeners within experiments are generally below $20 \%$ (Tillitt et al., 1991a; Tysklind et al., 1994; Clemons et al., 1997). It is therefore important in studies where TEQs are to be compared to TCDD-EQs that the bioassay conditions for TCDD-EQ determination closely resemble those used for the original generation of the RPFs. This will ensure that the PHHs in an environmental extract will elicit a biological response under the same conditions used during exposure of H4IIE cells to individual PHH congeners. In cases where H4IIE RPFs are used only to generate TEQs from analytical chemistry data, the selection of appropriate RPFs becomes more difficult. Improvements over time in detection limits for H4IIE EROD induction and the ability to obtain more reproducible dose-response curves suggest greater confidence in more recently published RPFs (Sanderson et al., 1996). The sets of PHH RPFs determined in the, 1990s are less complete than those published in the, 1980s, mainly because recent studies have focused on determining RPFs for only the most potent CYP1A1-inducing congeners (i.e. congeners that will contribute the greatest amount to the total TEQ; Table 8 ). For this reason, the use of recently published RPFs may provide more accurate TEQs, but it appears that a research priority should be the generation of a complete set of RPFs for highly active $\mathrm{PHH}$ and PAH congeners using the current H4IIE cell bioassay protocol.

TEQs are determined by multiplying the concentration of each congener by its respective RPF to give TEQ values specific to each PHH (Table 8). The individual TEQ value for a PHH represents the equivalent concentration of TCDD that would induce the same CYP1A1 activity. Normalizing each congener concentration to a TCDD concentration allows the summation of the individual TEQs to generate a total TEQ in that extract ( $\sum$ TEQ). TEQs can be used to rank environmental extracts by their dioxin-like content. Comparing mean TEQs in environmental samples collected from different regions can help prioritize areas of concern (Tillitt et al., 1991b; Rattner et al., 1994; Whyte et al., 1998; van den Berg et al., 1998). The toxicological significance of TEQs is discussed in Section IV.C.

H4IIE cells can also be dosed with the complete environmental extract to generate a TCDDEQ (Section IIF). If the analytical measurement of PHHs in an extract include all of the major CYP1A1inducing compounds present, and these compounds 


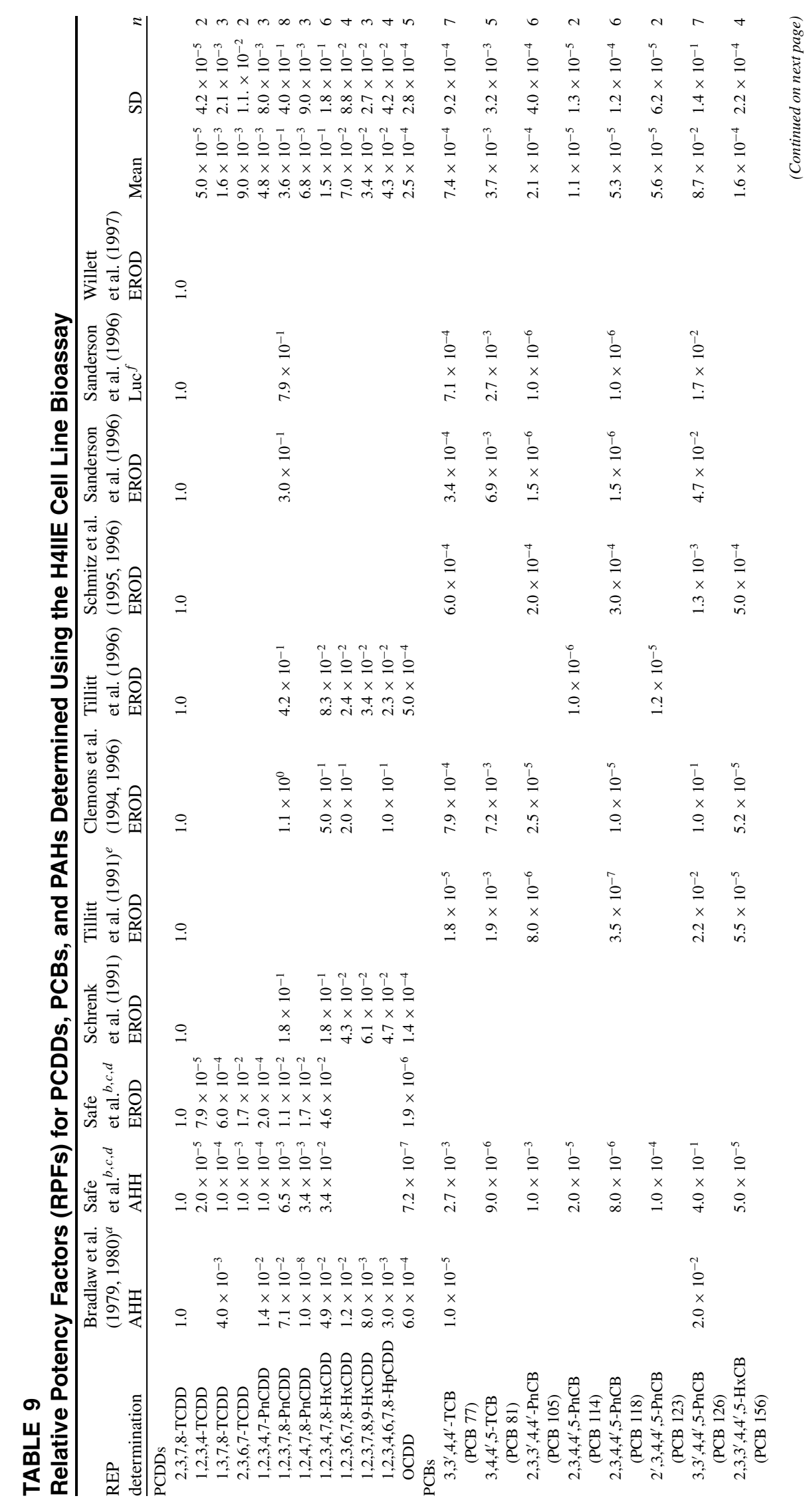




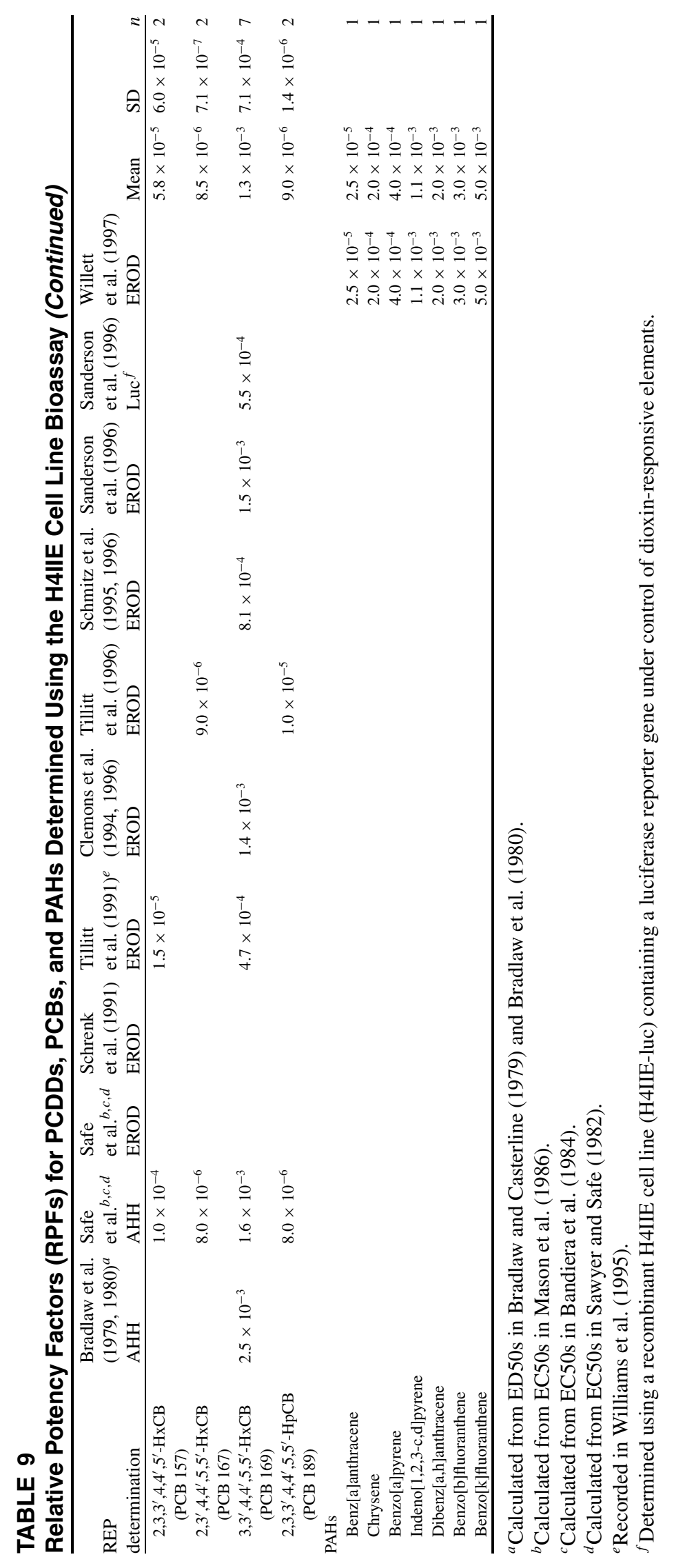




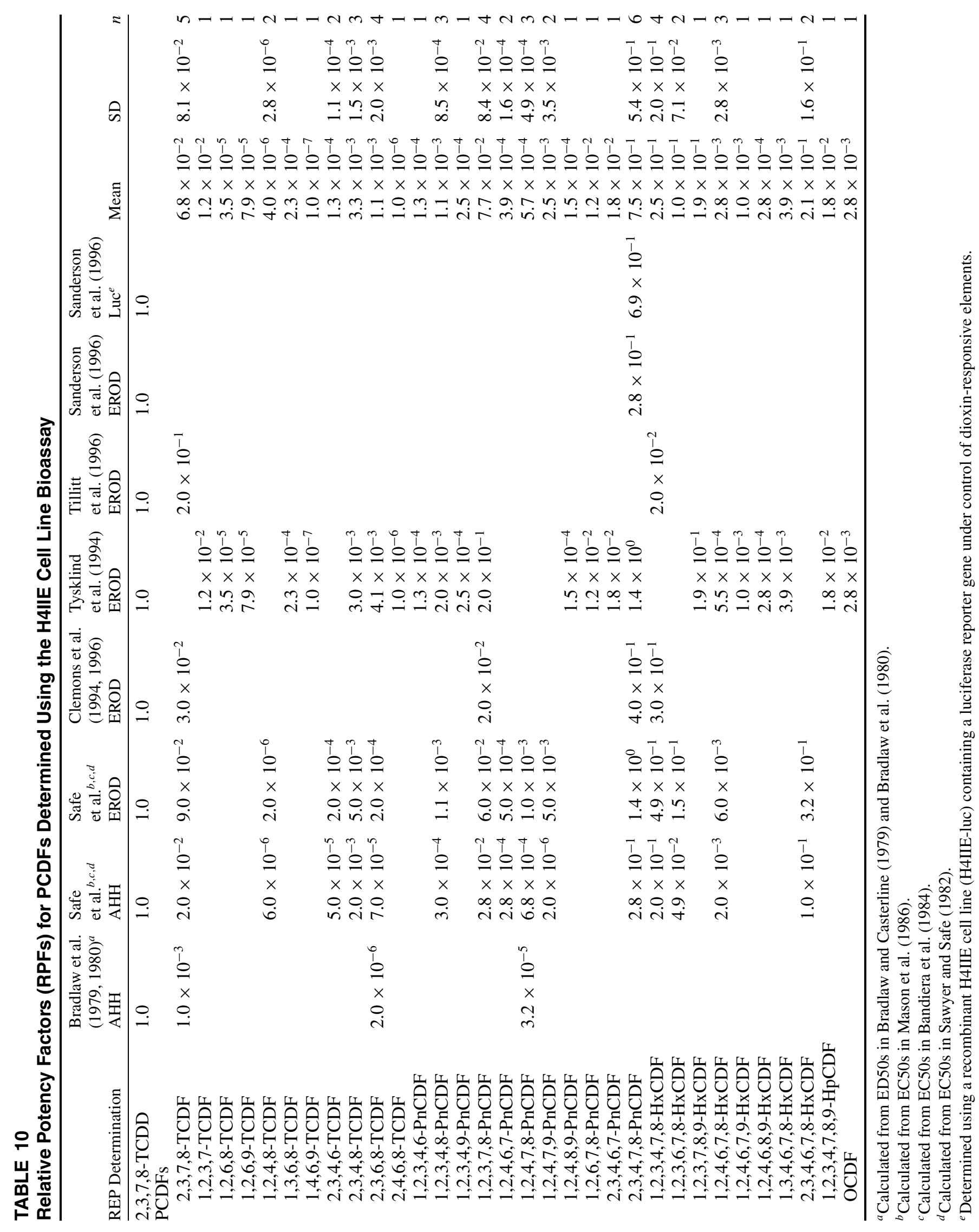


induce CYP1A1 additively, then the calculated TEQ and the bioassay-derived TCDD-EQ should be relatively equal (Table 8, Extract 1). The term "relatively equal" is used to stress the fact that there is inherent variability in a biological system such as the H4IIE cell bioassay. Because of this variability, even a two- to threefold difference in the TEQ and TCDD-EQ for an environmental extract could confirm an additive response to $\mathrm{PHH}$ exposure. Factors to consider when evaluating additivity include the number of replicates for an extract, the individual chemicals used in the TEQ calculation, and differences between the methods used to derive the H4IIE RPFs and the TCDD-EQ. With these considerations in mind, if the TEQ and TCDD-EQ for an extract differ by orders of magnitude, a number of possible explanations exist (assuming no analytical measurement error). A TCDD-EQ that is significantly greater than its corresponding TEQ (Table 8, Extract 2) may indicate that (1) other CYP1A1inducing compounds are present in the extract that were not measured (Till et al., 1997), or (2) the PHHs measured are not acting through an additive mechanism, but rather two or more PHHs present are inducing CYP1A1 synergistically to give a greater overall level of induction (Schmitz et al., 1996). A TCDD-EQ that is orders of magnitude less than its corresponding TEQ may indicate a less-thanadditive response in the H4IIE cells due to the chemical mixture present. A less-than-additive response has been demonstrated with binary combinations of PCB congeners (e.g., PCB 153) and TCDD in the H4IIE bioassay. Certain congener combinations can result in less-than-additive EROD induction (Hahn et al., 1993; Sanderson et al., 1996; Clemons et al., 1998), but PCB/TCDD ratios need to be greater than, 20,000:1. Despite potential chemical interactions, additivity is generally observed in the H4IIE cell bioassay (Schrenk et al., 1991; Willett et al., 1997; Whyte et al., 1998). A number of field investigations that used the H4IIE cell bioassay are summarized in Table 11, and in studies comparing TEQs to TCDD-EQs, both additive and nonadditive responses in the H4IIE cell bioassay are reported. The next section will look in detail at the application of the H4IIE cell bioassay to field investigations and biomonitoring efforts.

\section{B. H4IIE Toxic Equivalents (TCDD-EQs) in Field Studies and Biomonitoring}

The H4IIE bioassay is a useful tool for evaluating the amount of biologically active PHHs accu- mulated in samples collected from the wild. TCDDEQs account for the varying biological potencies of all of the different PHHs in an environmental extract. In addition, several studies have reported correlations between TCDD-EQs in wildlife extracts and adverse effects in those populations (Section IV.C). Therefore, TCDD-EQs indicate both exposure to and potential toxicity of PHHs. However, the use of TCDD-EQs to predict toxicity in non-mammalian species should be approached with caution. Although the presence of the AhR has been demonstrated in a range of vertebrates, including fish, birds, and amphibians (reviewed in Hahn, 1998), there is some evidence that certain PHH congeners do not induce the same AhR-mediated effects in all species. For instance, differences in CYP1A inducing potency for certain mono-ortho PCB congeners between fish and mammals have been demonstrated (reviewed in van den Berg et al., 1998). This has led to the suggestion that for hazard assessment purposes, TCDD-EQs and RPFs should be generated using species-specific cell lines for the organism in question (Clemons et al., 1996, 1997; Kennedy et al., 1996; van den Berg et al., 1998). A recent review by Hahn (2002) includes a comparison of the relative sensitivities of in vitro bioassays for dioxin-like compounds. The systems examined for CYP1A activity included the H4IIE cell bioassay, a human hepatoma cell line (HepG2), three hepatic fish cell lines (PLHC-1, RTL-W1, and RTH-149), and chick embryo hepatocytes. TCDD EC50 values for each system were within the same order of magnitude (0.01), excluding the HepG2 cell line, which was approximately 10-fold higher than the other systems. This suggests that the different systems would respond similarly to dioxin-like chemicals, but as stated above, this is not the case for all PHH congeners. These theoretical considerations in mind, relationships between TCDD-EQs and the injurious effects of dioxin-like chemicals have been demonstrated successfully in a number of non-mammalian species (see Section C).

From a hazard screening perspective the TCDD-EQ model offers a useful tool to estimate the degree of PHH exposure and potential effects. There are four major advantages that the H4IIE bioassay has over analytical methods used to determine the potency of PHHs in environmental samples. First, because the H4IIE bioassay detects PHHs based on a common mechanism of action for these chemicals, the combined presence of all CYP1A1-inducing compounds present in an extract is measured. The H4IIE cell bioassay can assess these chemicals even at concentrations below analytical detection limits 
and it assesses chemicals that may not be on your list of targeted analytes. Second, by examining all CYP1A1-inducing chemicals in an extract simultaneously, the H4IIE bioassay integrates interactions among the different PHHs present in the extract (e.g., synergism or antagonism). Third, the H4IIE cell bioassay is routinely more rapid than analytical chemical measurements of the same set of analytes, especially dioxins and furans. Fourth, the H4IIE cell bioassay is considerably less expensive (10-25\%) than the cost of analysis of all the chemicals which are measured by the bioassay. Because of these advantages, the H4IIE cell bioassay has been used extensively to assess the potency of PHH-containing extracts from many trophic levels in the wild and from abiotic matrices such as sediment and water. For vertebrate species, a scan of Table 11 reveals the derivation of H4IIE TCDD-EQs in 22 species of fish, 14 species of birds, and 4 species of mammals. These studies have been conducted in both aquatic and terrestrial environments worldwide.

Field studies have used the H4IIE cell bioassay to make relative comparisons of TCDD-EQs among environmental samples or among collection sites (Table 11). Aquatic species, mainly fish, have been examined in a variety of environments. Studies have used the H4IIE bioassay to identify areas where fish have accumulated high concentrations of TCDD-EQs relative to fish from reference locations. These regional comparisons have revealed PHH contamination in fish from industrial regions of the Great Lakes (Zacharewski et al., 1989; Giesy et al., 1995; Tillitt et al., 1996) and in fish inhabiting areas near pulp and paper mill effluents (van den Heuvel et al., 1996; Whyte et al., 1998). In one of the few studies that report TCDD-EQs in aquatic invertebrates, McDonald et al. (1994) and Kennicutt et al. (1995) reported 10-fold greater TCDD-EQs in clams from the heavily PCB-contaminated Winter Quarters Bay, Antarctica, as compared to clams collected from a uncontaminated reference location (Table 11). Winter Quarters Bay, directly adjacent to the McMurdo Research Station, is known to have extensive areas of submerged abandoned equipment and waste (Kennicutt et al., 1995). Concentrations of TCDD-EQs in the clam tissues were correlated with tissue PCB concentrations and confirmed the accumulation of toxic chemicals in the biota of McMurdo Sound.

The H4IIE cell bioassay has been used extensively to determine differences in PHH contamination among avian populations (Table 11). A series of investigations in the Great Lakes has revealed high concentrations of TCDD-EQs in populations of birds inhabiting the Fox River and Green Bay, WI (Tillitt et al., 1989, 1991b, 1992, 1993; Jones et al., 1993b, 1994; Ludwig et al., 1996). Where concentrations of TCDD-EQs in birds from both reference and contaminated sites are reported, relative levels of PHHs can be approximated based on mean concentrations. Comparisons of "baselinenormalized" TCDD-EQs rather than absolute values reduces the influence of different H4IIE bioassay techniques (e.g., EROD vs. AHH-derived TCDDEQs; Zacharewski et al., 1989). Double-crested cormorant (Phalacrocorax auritus) eggs and chicks collected at Little Gull Island, Green Bay, had mean TCDD-EQs roughly three- and ninefold higher, respectively, than eggs and chicks of the same size from the Apostle Islands, Lake Superior (Jones et al., 1994). Similarly, mean TCDD-EQ in Forster's tern (Sterna forsteri) eggs from Green Bay were approximately ninefold higher than eggs from a reference lake in Wisconsin (Tillitt et al., 1993). A six-fold increase in black-crowned night heron (Nycticorax nycticorax) embryo TCDD-EQ mean was recorded in birds from Green Bay compared to a reference lake in Virginia (Rattner et al., 1994). The significance of the identical relative levels of TCDDEQs in both cormorant and tern eggs is difficult to interpret, but may be related to similar maternal diets of birds in these locations. In all three species of birds, TCDD-EQs concurred with residue analysis in the same tissues reported as TEQs or $\sum$ PCBs (Table 11). Biological effects of these concentrations of TCDD-EQs and PHHs in fish-eating waterbirds is discussed in Section C. The H4IIE cell bioassay has also been used to estimate PHH contamination of bird populations in Europe such as white-tailed sea eagles, Halieetus albicilla (Koistinen et al., 1997) and osprey, Pandion haliaetus (Hanberg et al., 1991).

Field studies can use the H4IIE cell bioassay exclusively as a screening tool to locate populations of PHH-contaminated organisms, but often, analytical chemistry data are presented alongside TCDD-EQs. This additional information can be used to determine the classes of chemicals that are the major contributors to elevated TCDDEQs, thereby supporting hypotheses of contaminant sources or suggesting new ones. Concentrations of TCDD-EQs are often related to direct concentrations of PHHs or to the overall relative potency of measured PHHs determined as TEQs (Table 11). When H4IIE-derived RPFs and analytical chemistry data are available, TCDD-EQs should be compared to TEQs developed from those H4IIE-derived RPFs. 


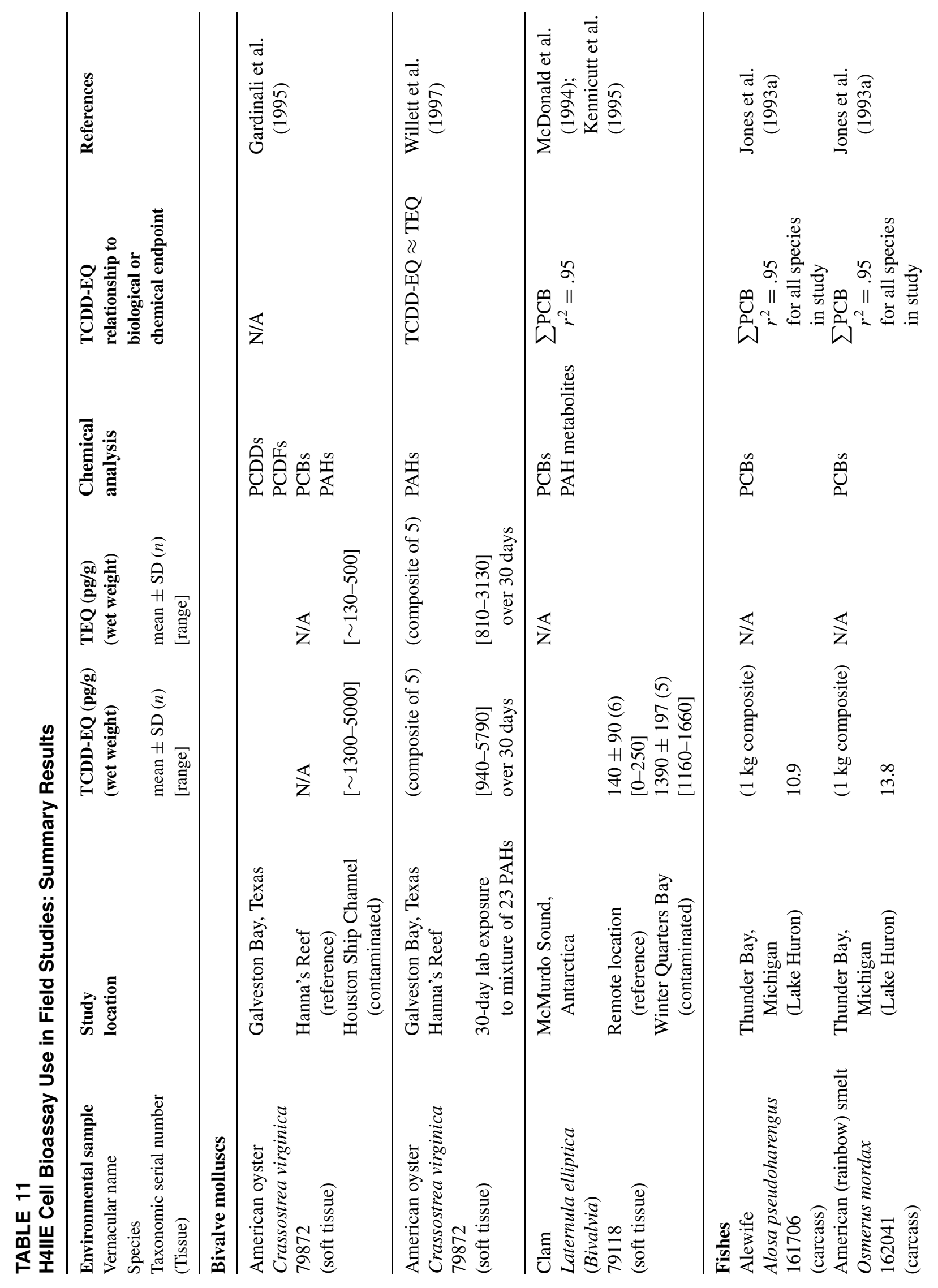




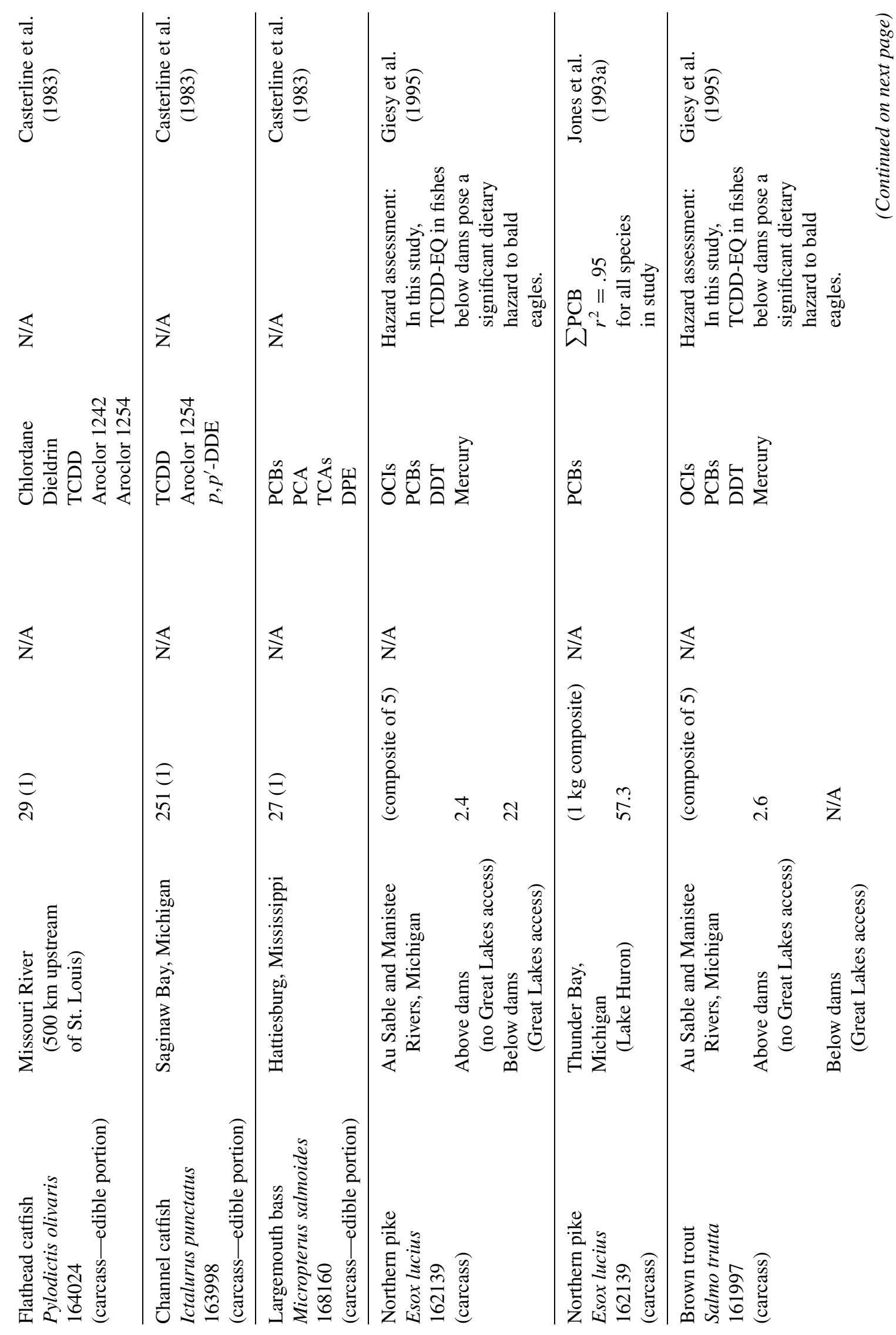




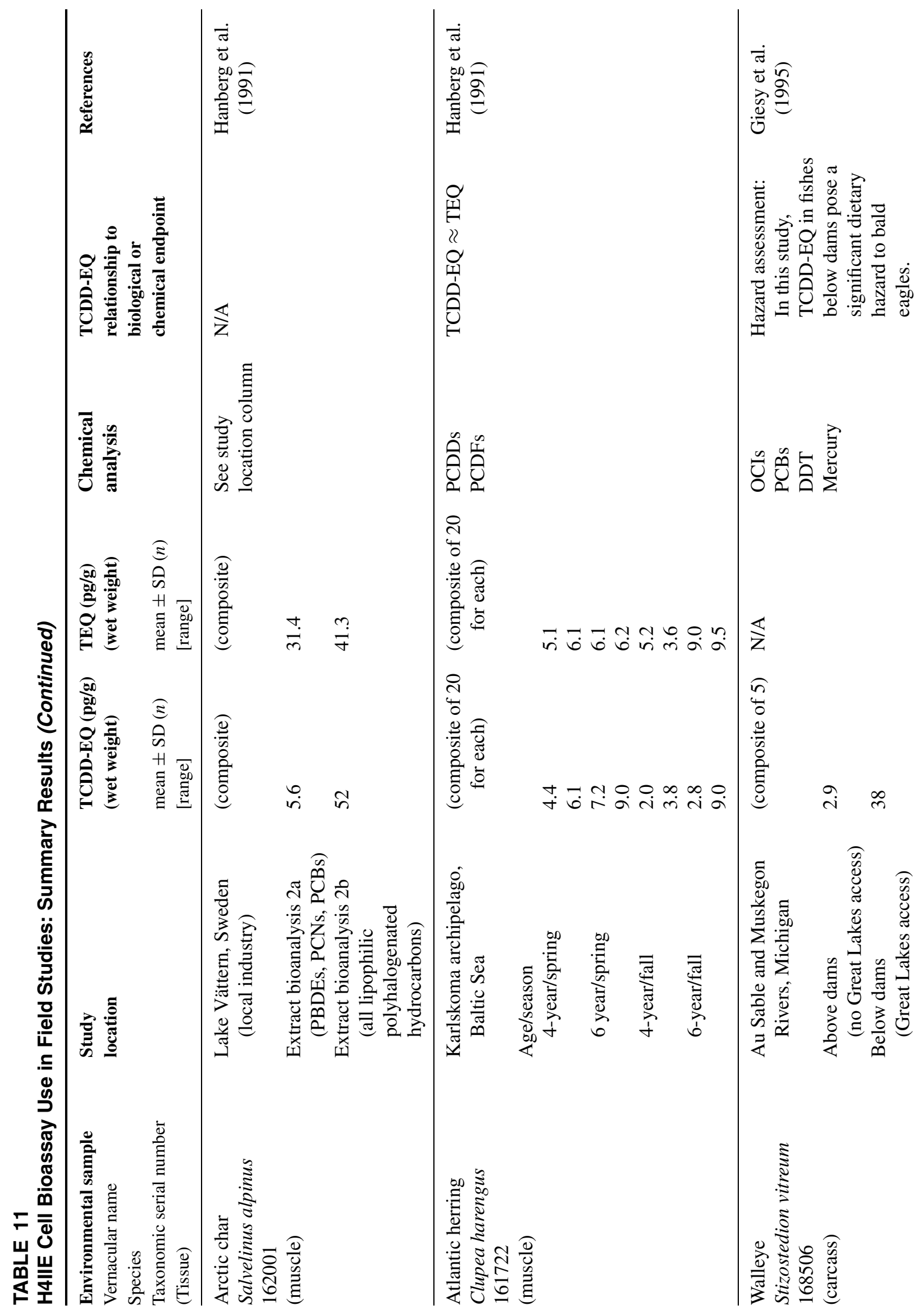




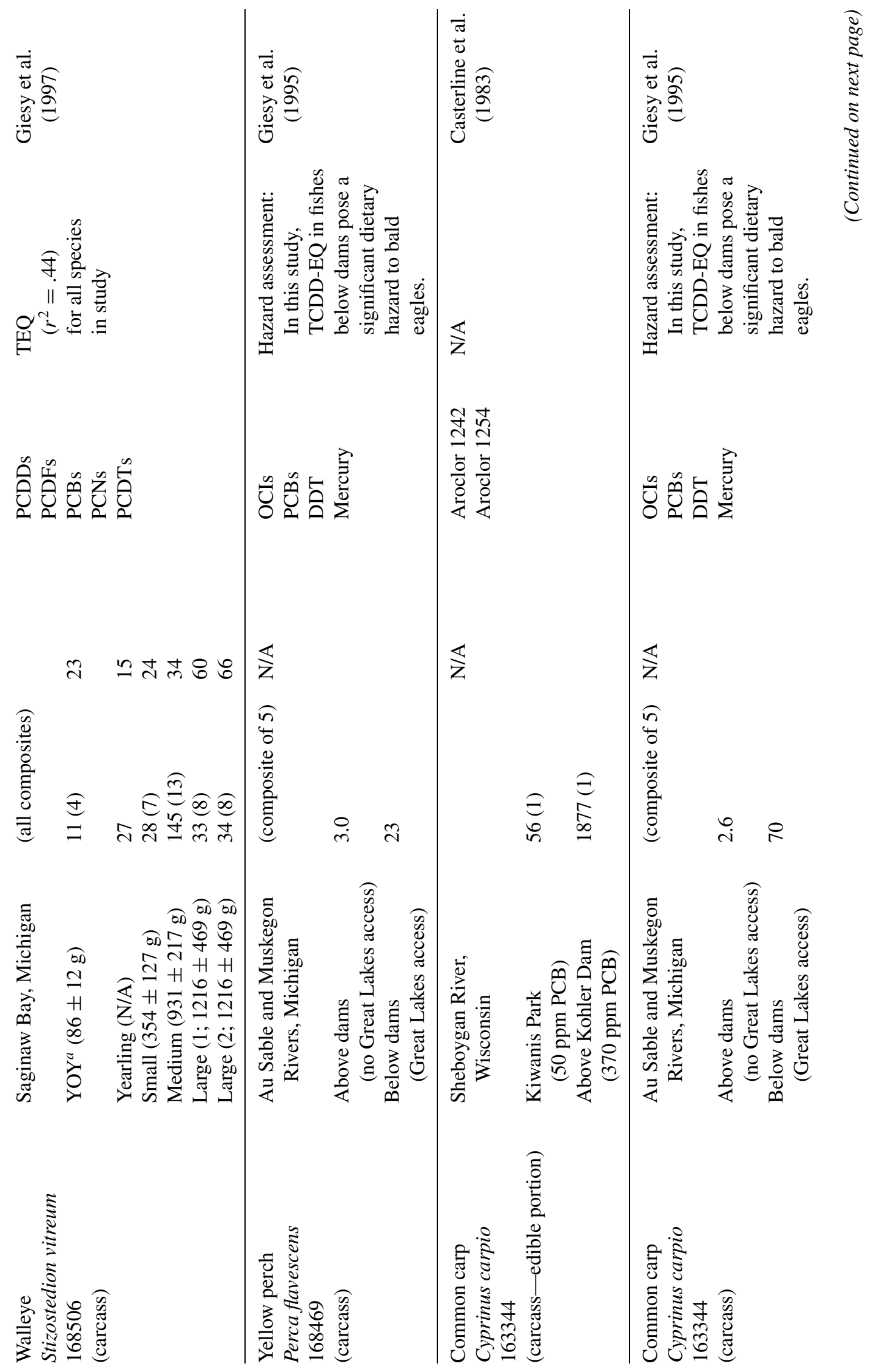




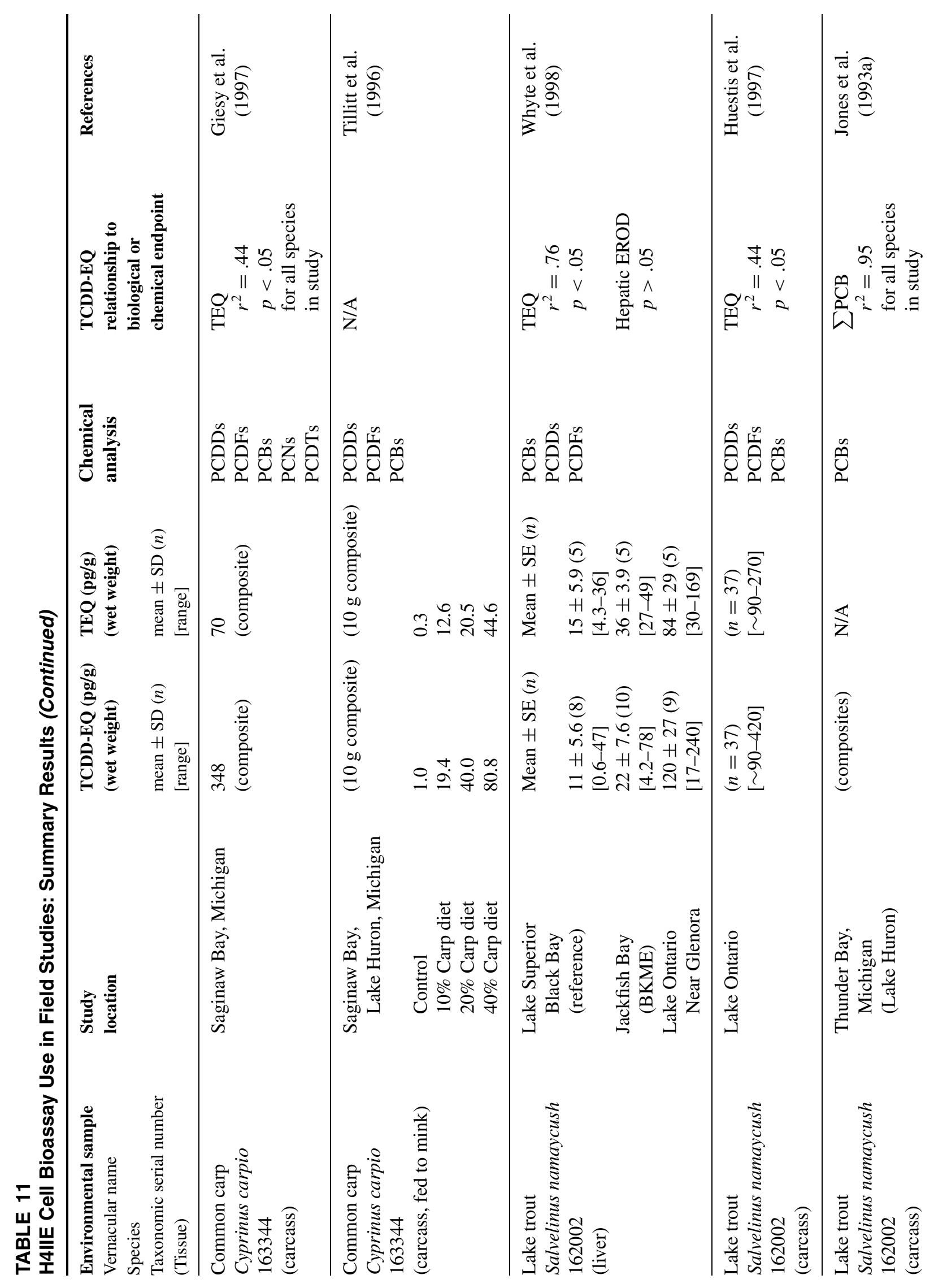




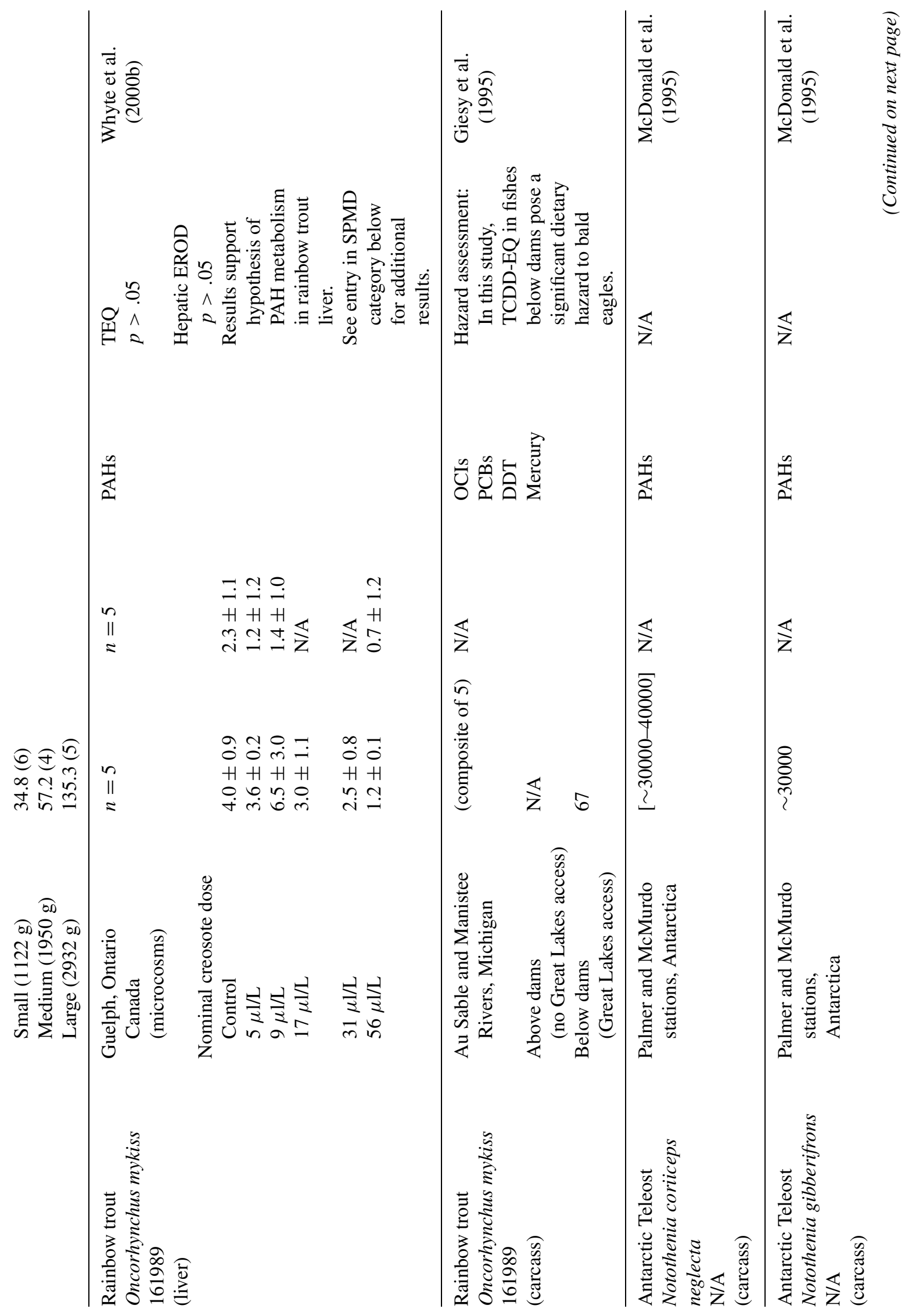




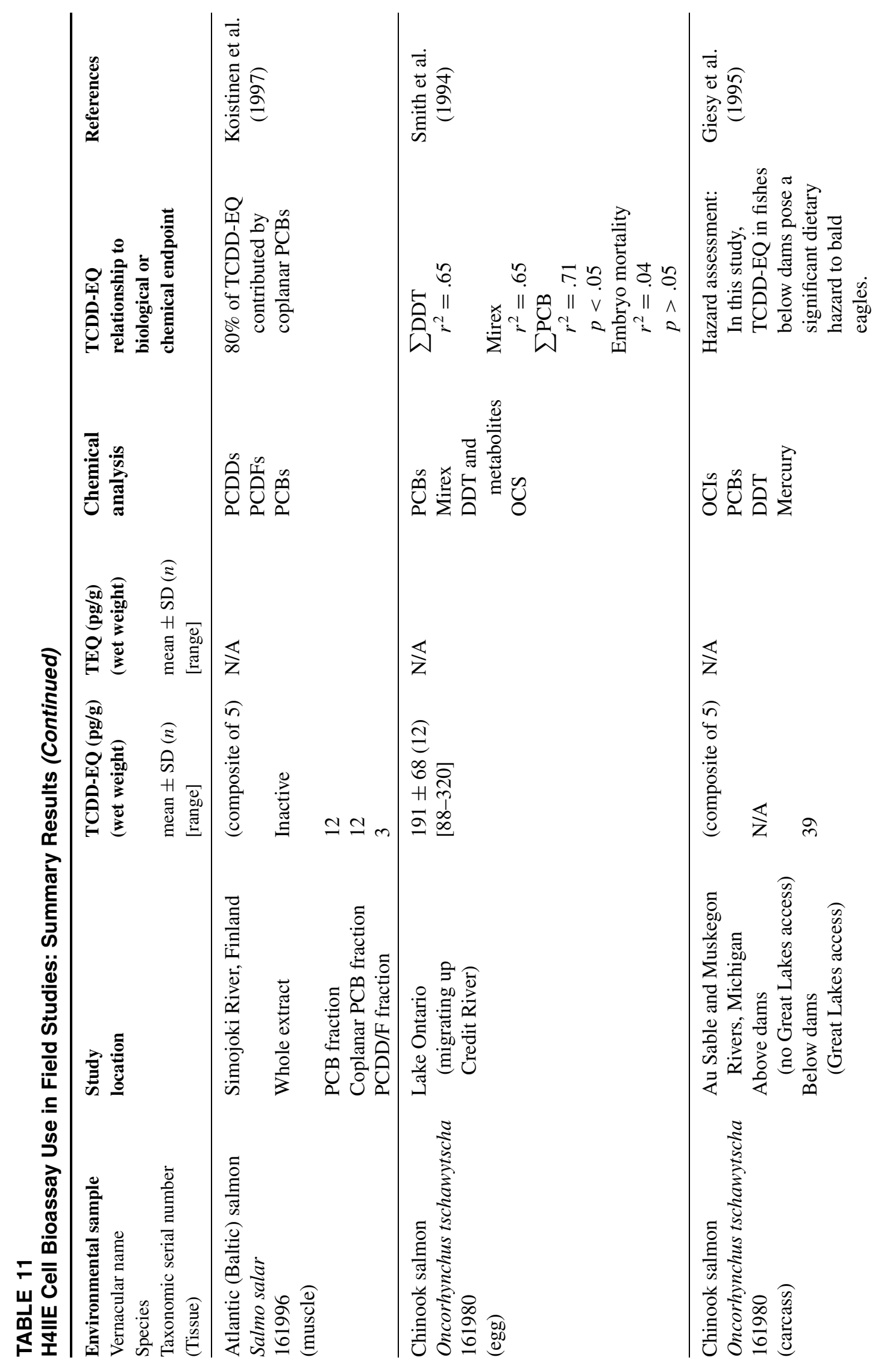




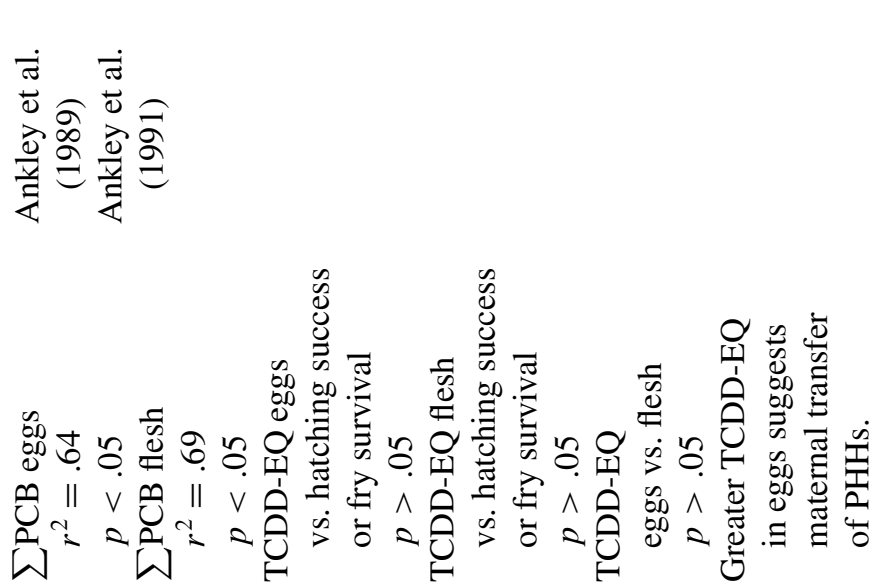

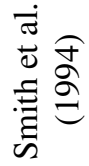

บิ

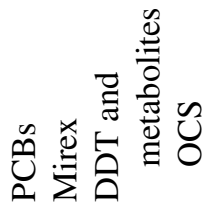

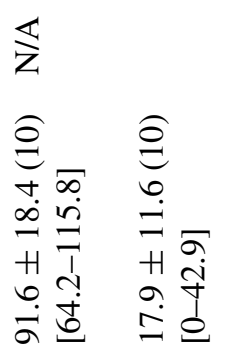

$\overleftrightarrow{\mathrm{z}}$

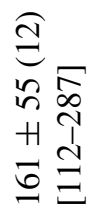

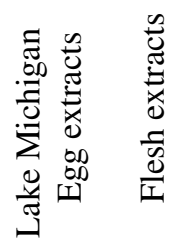

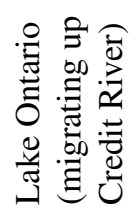
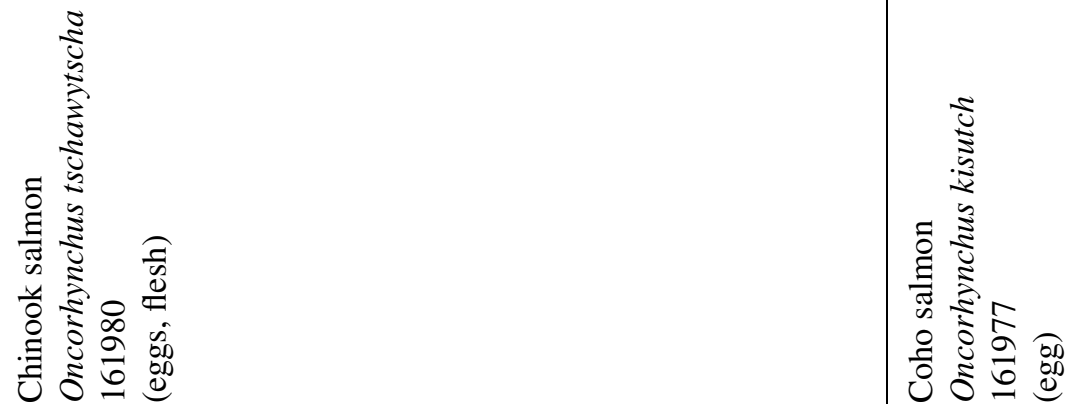


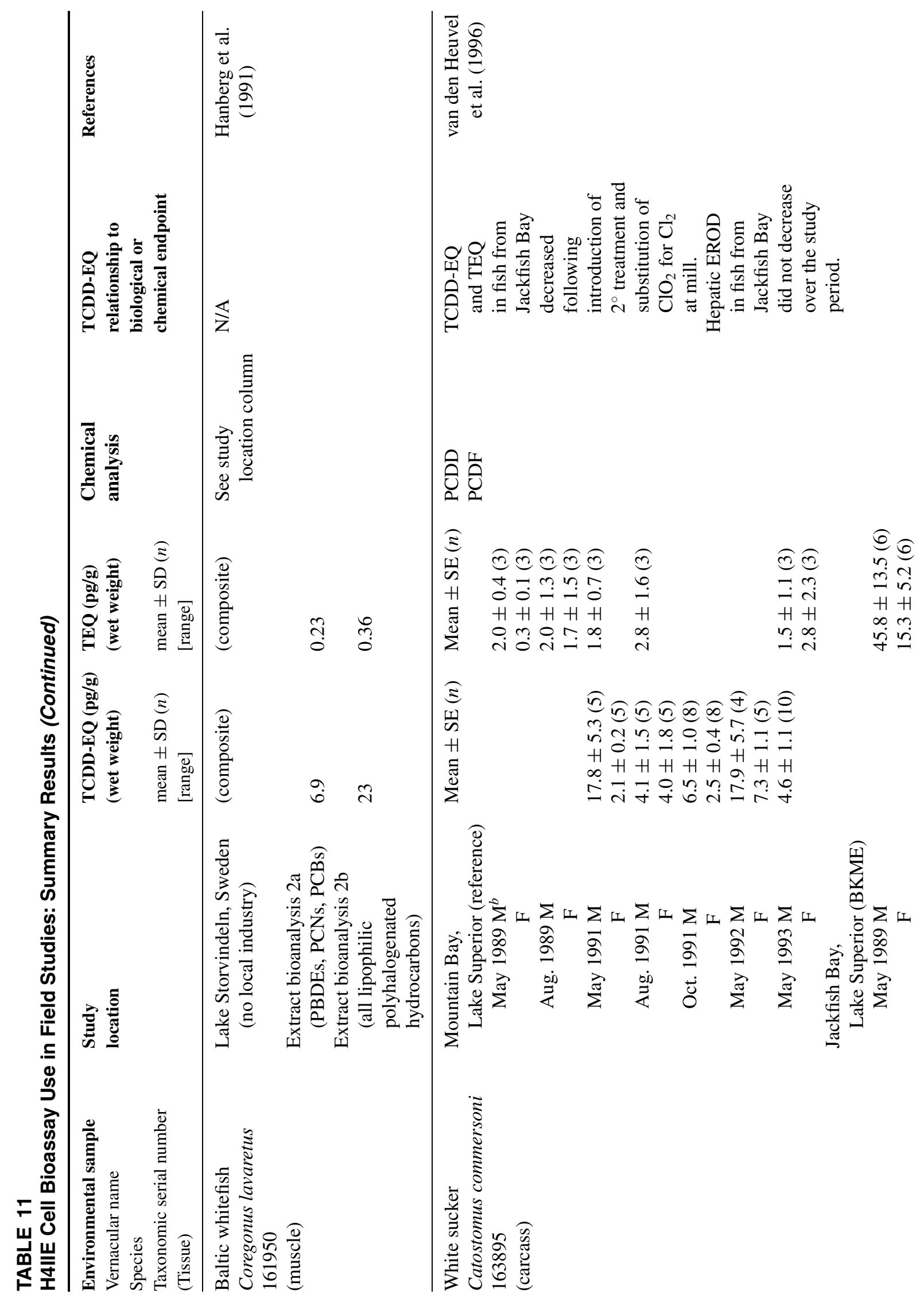




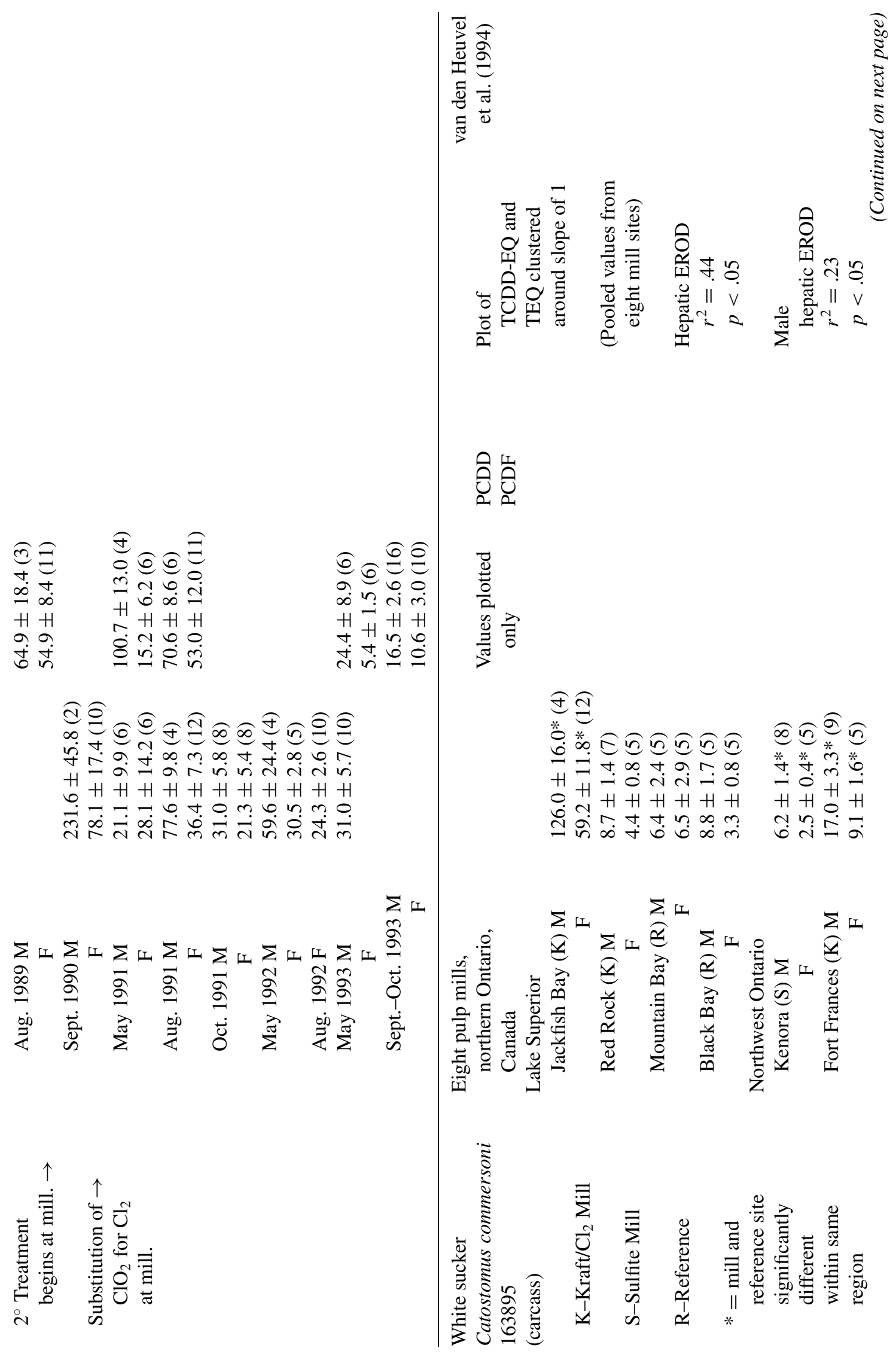




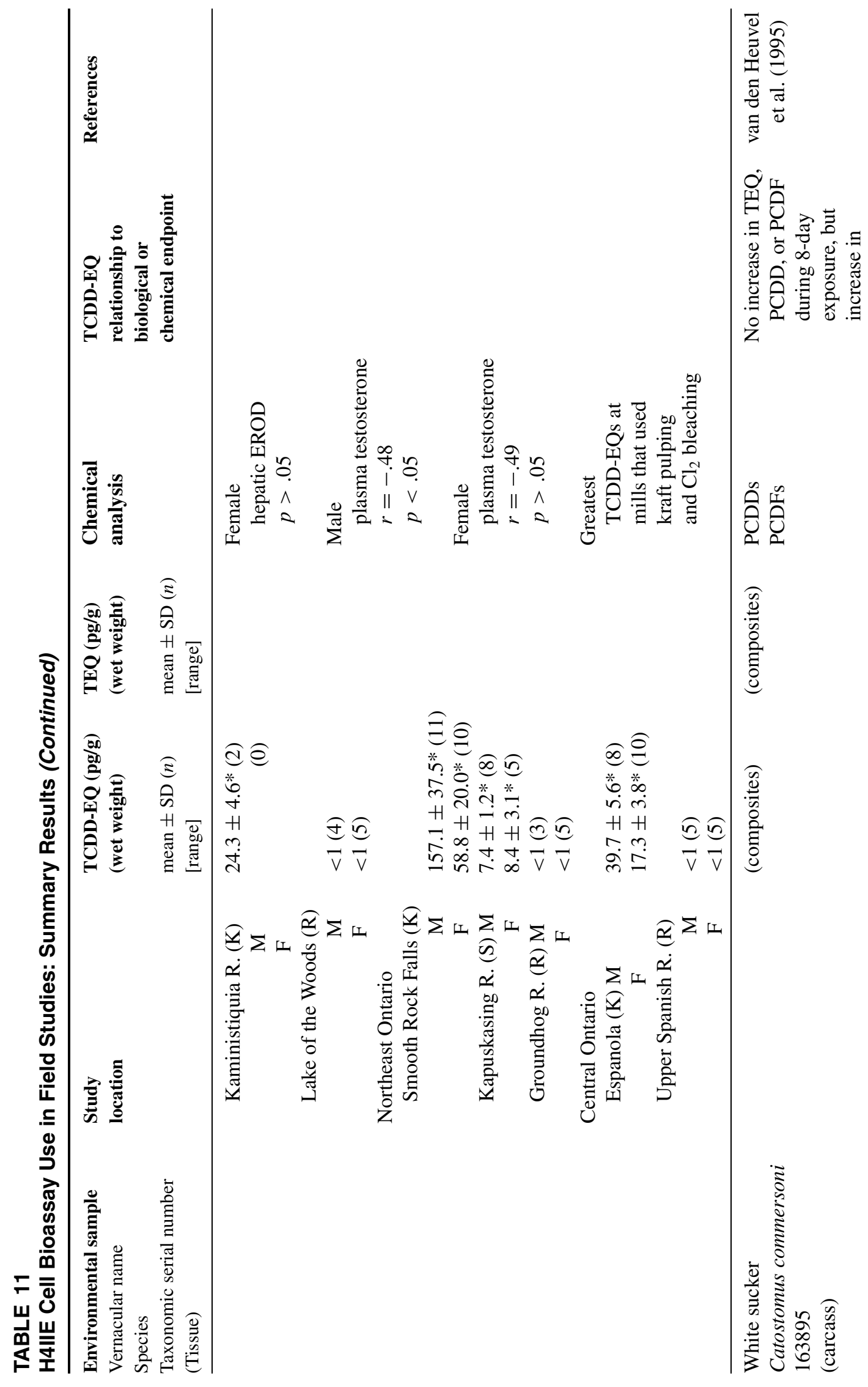




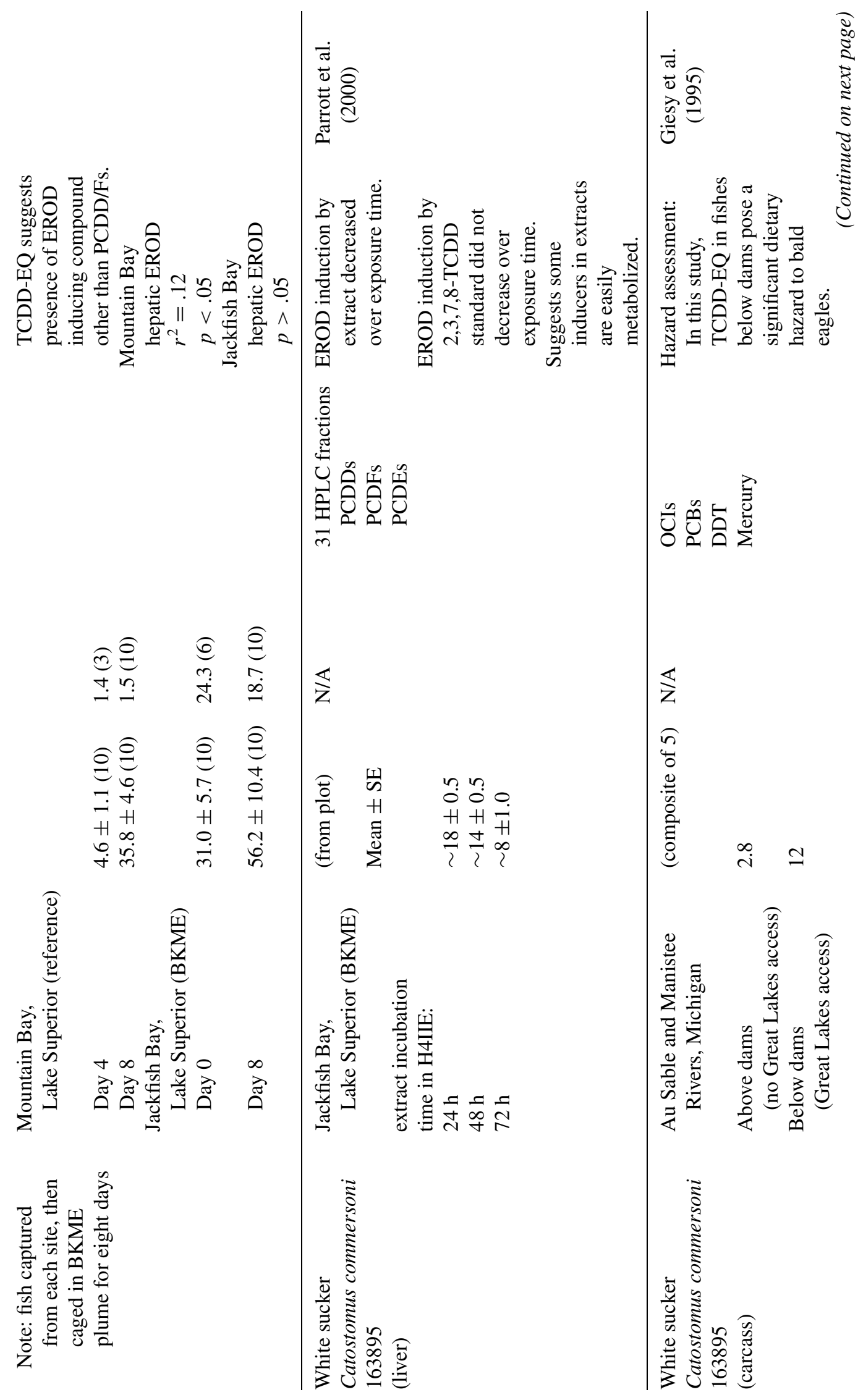




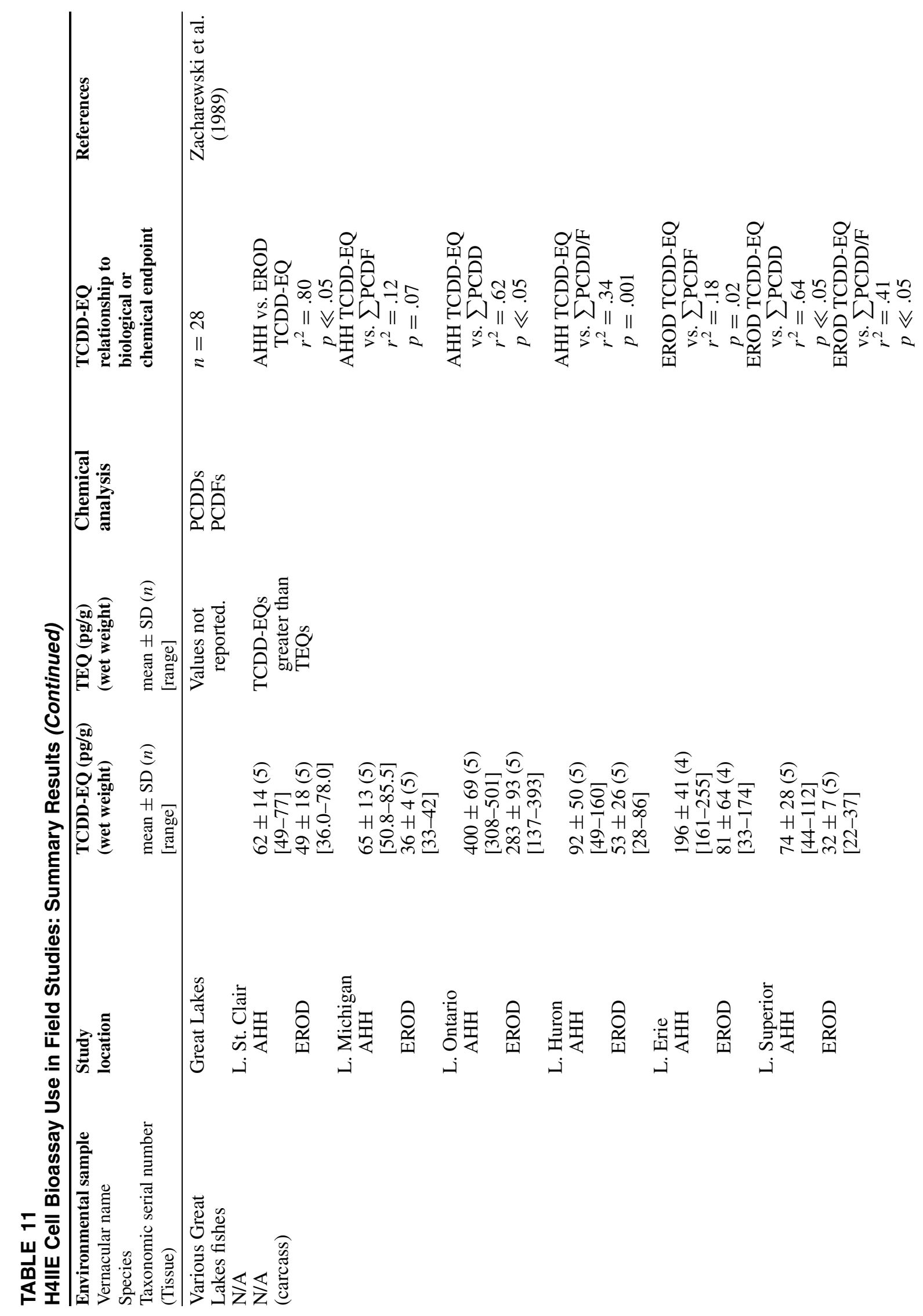




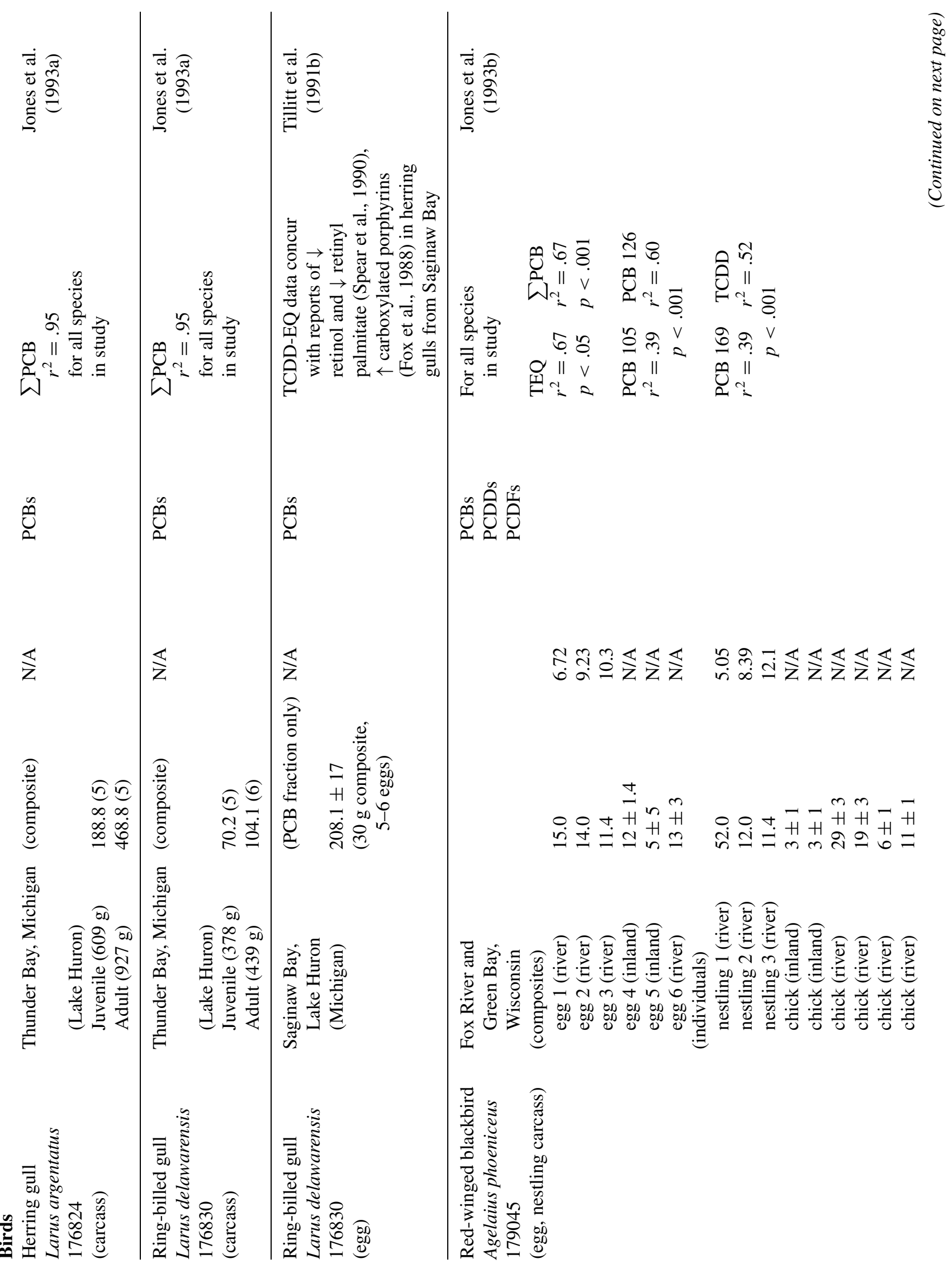




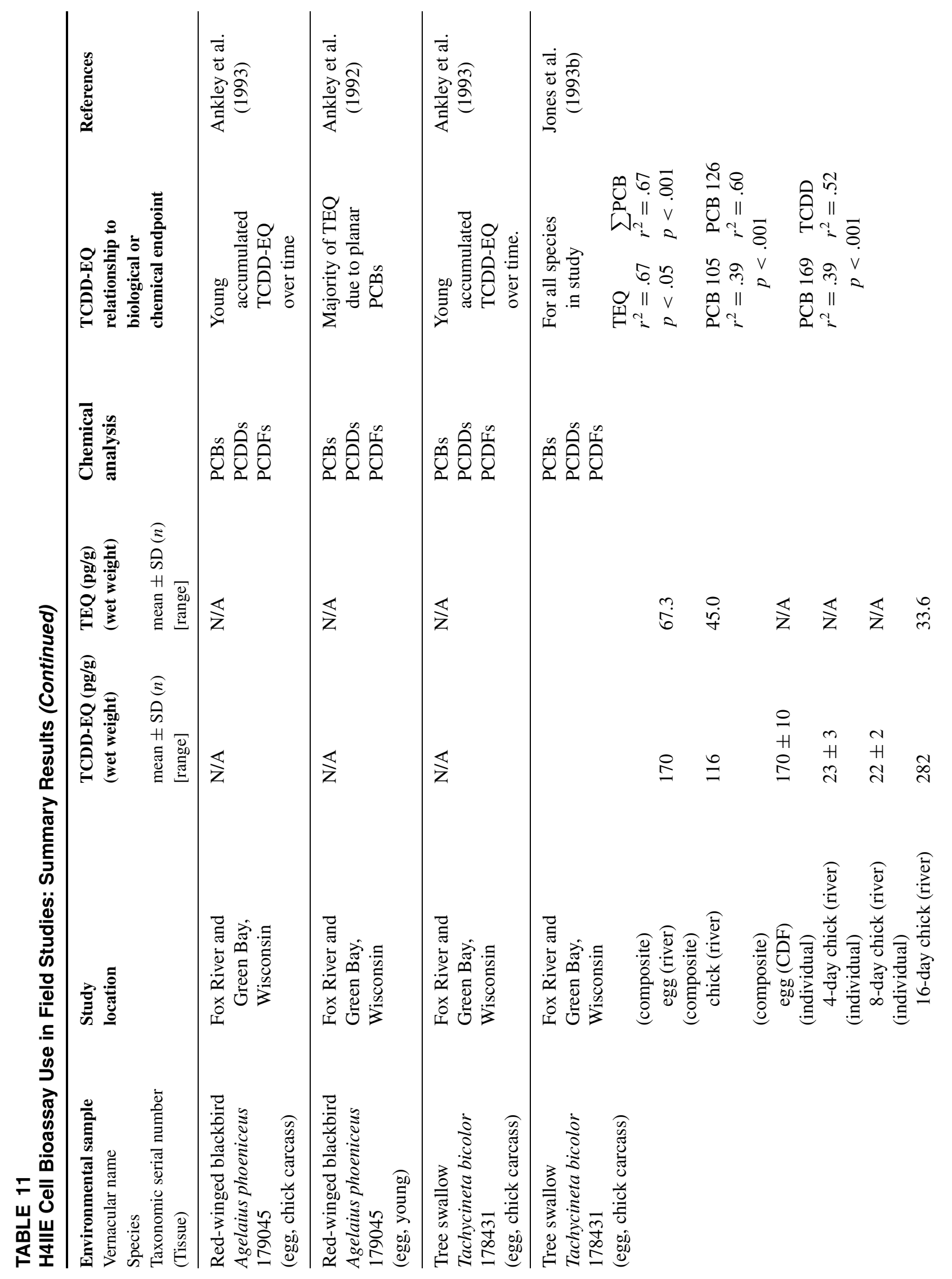




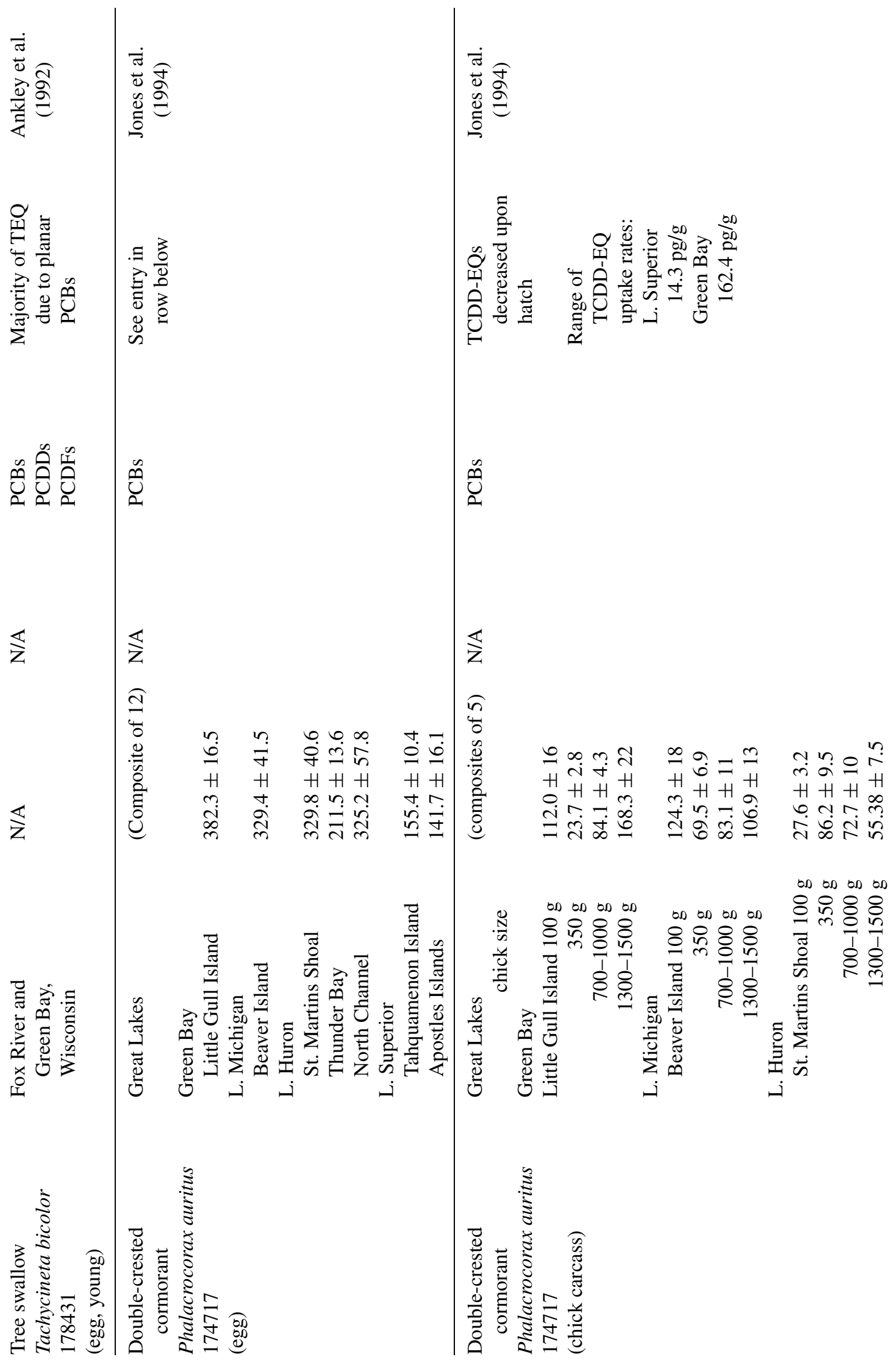




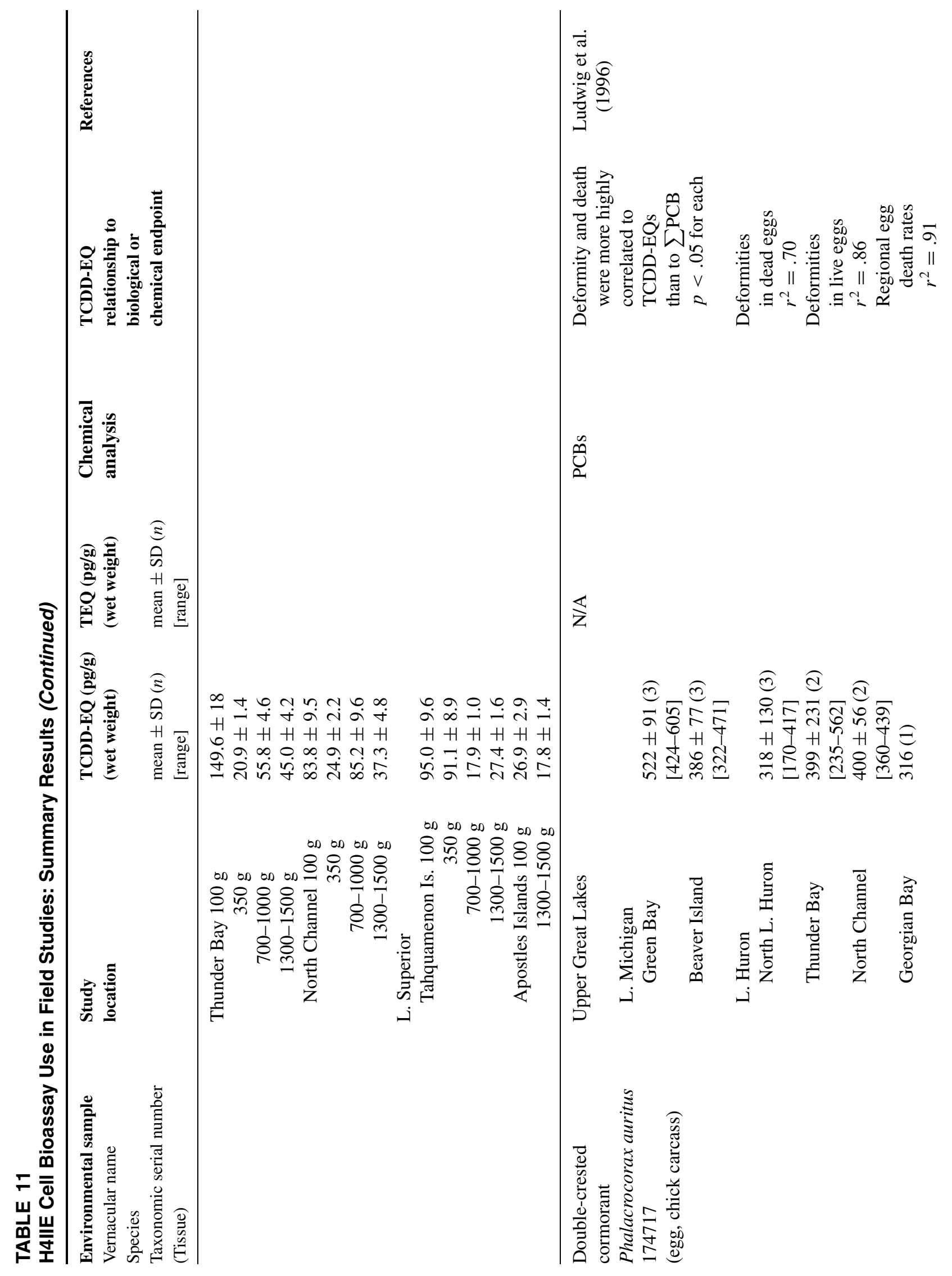




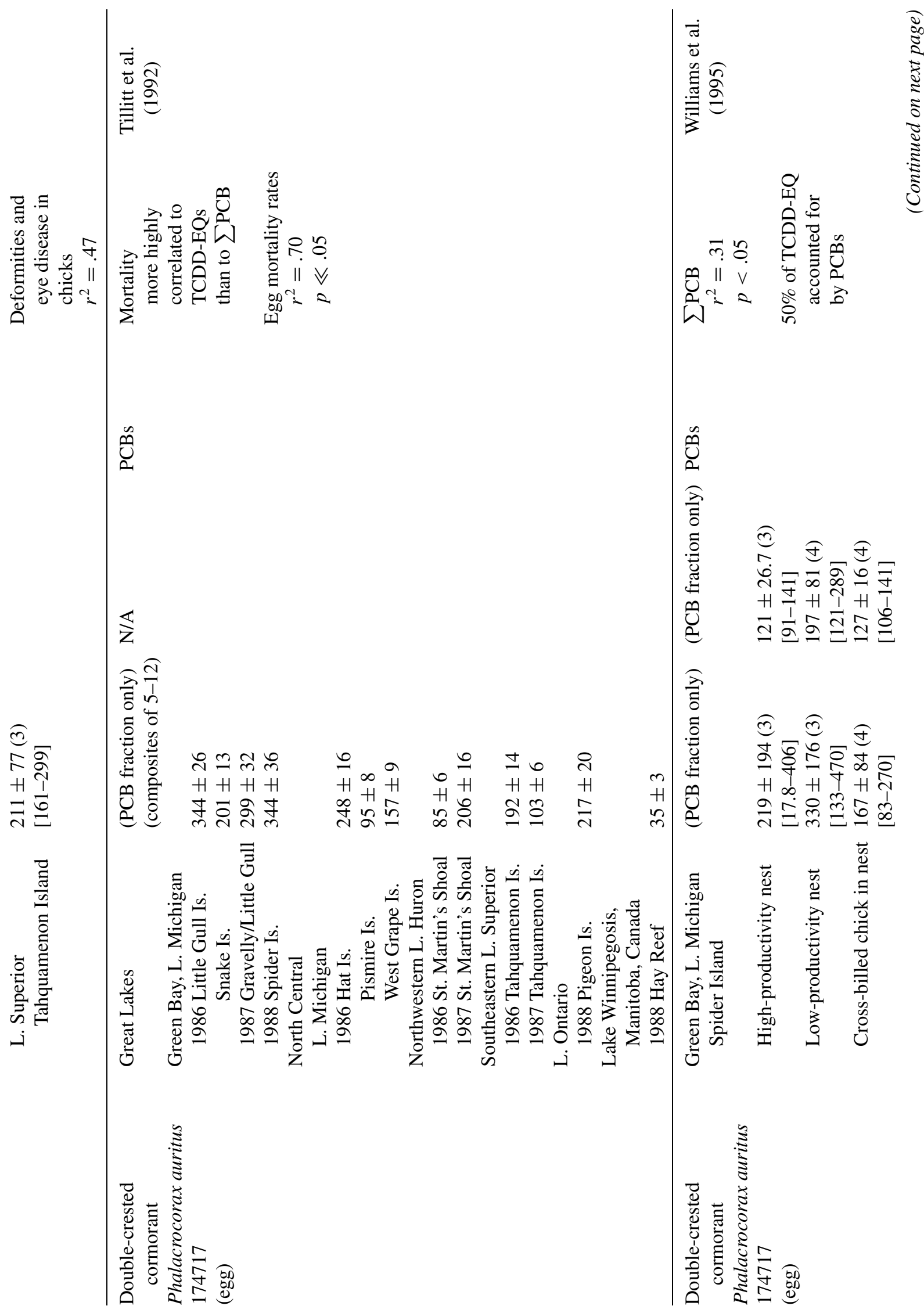




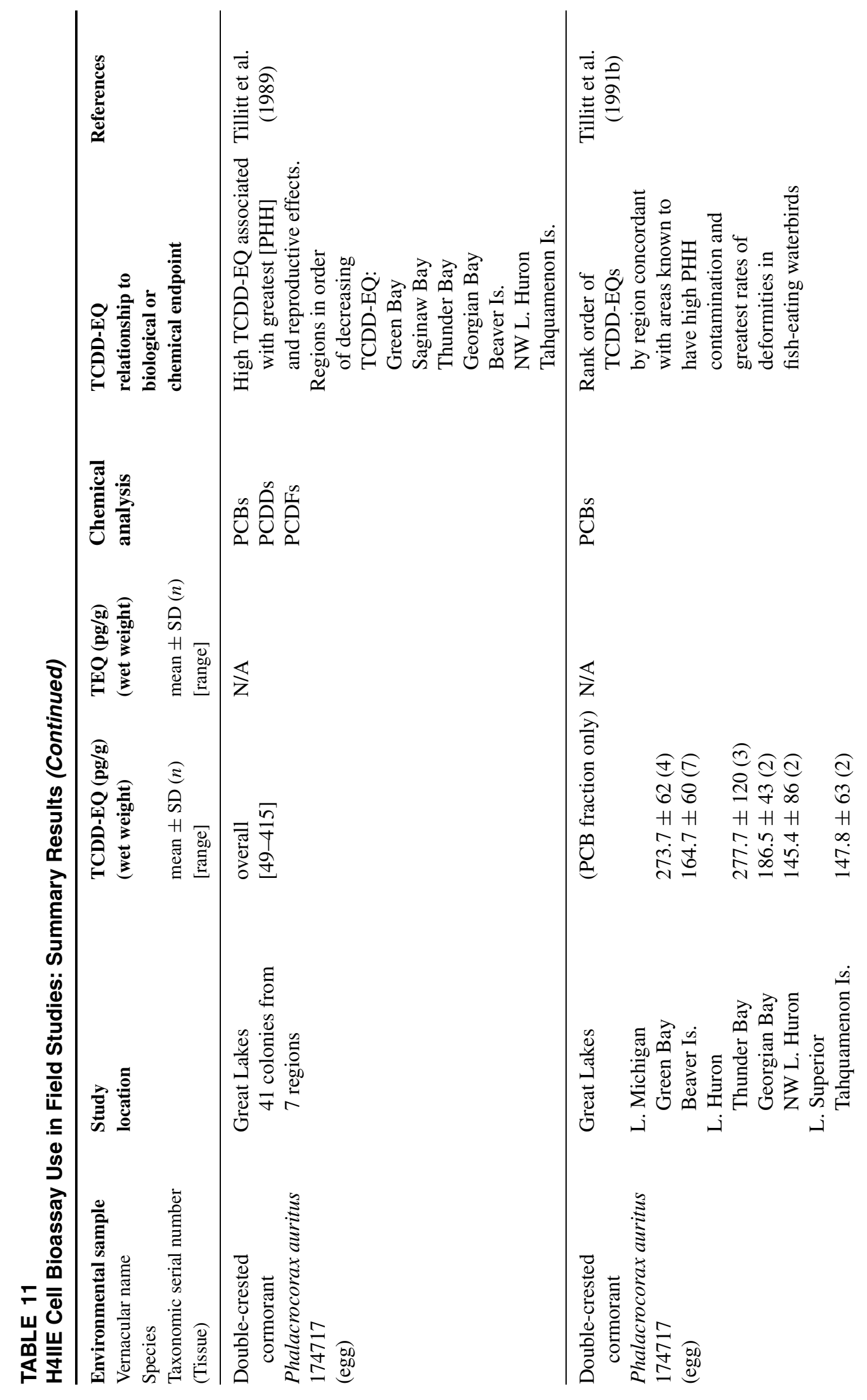




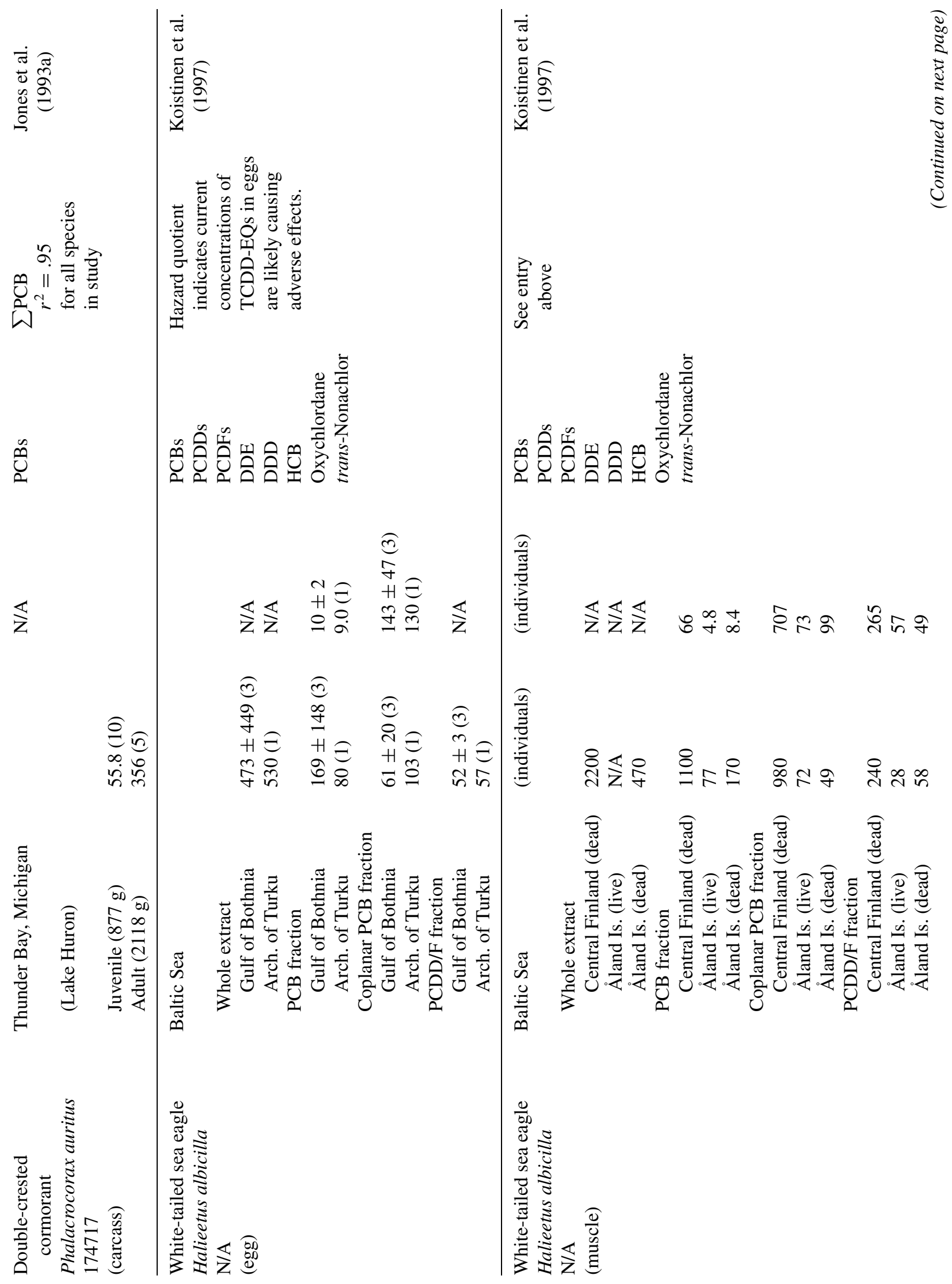




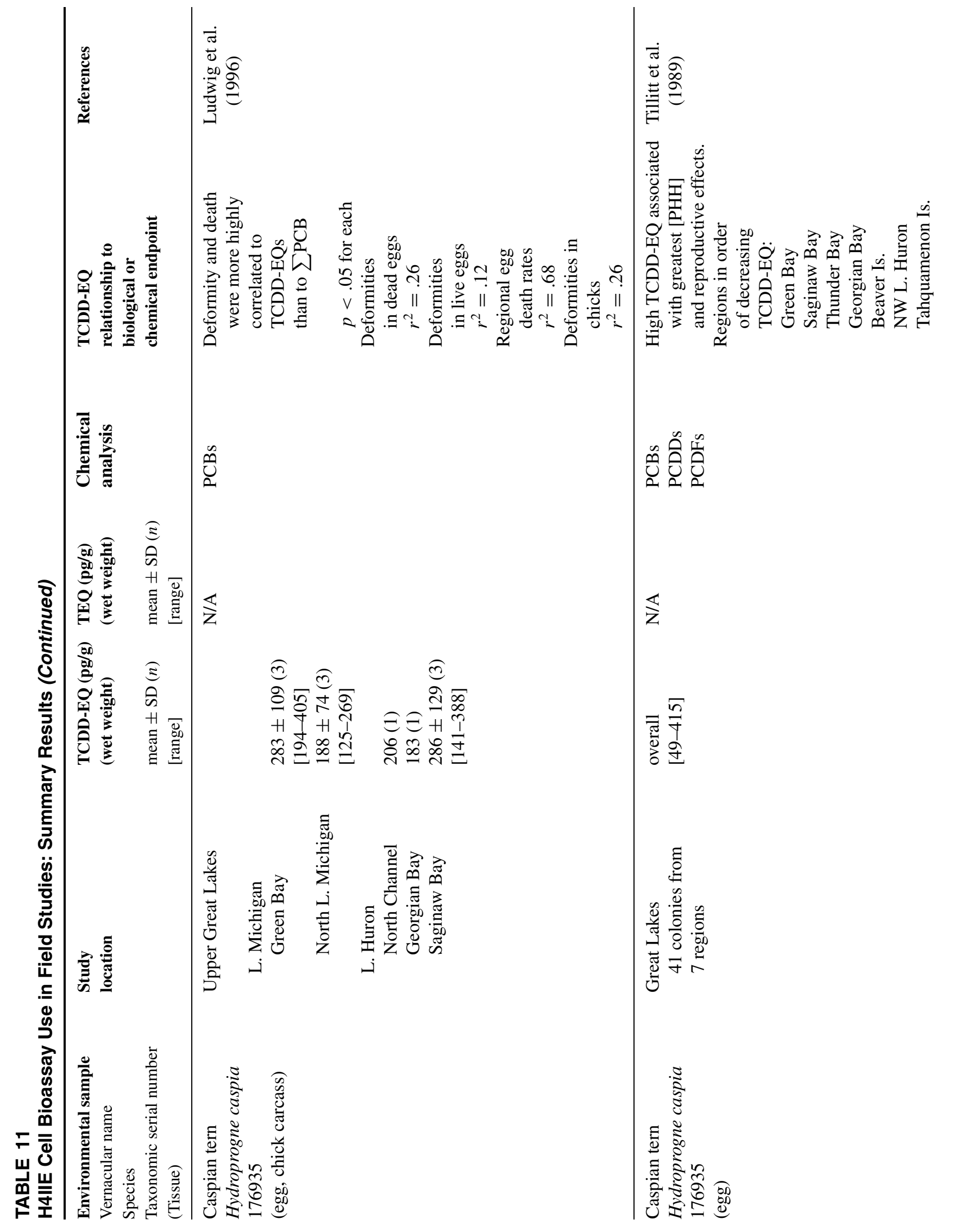




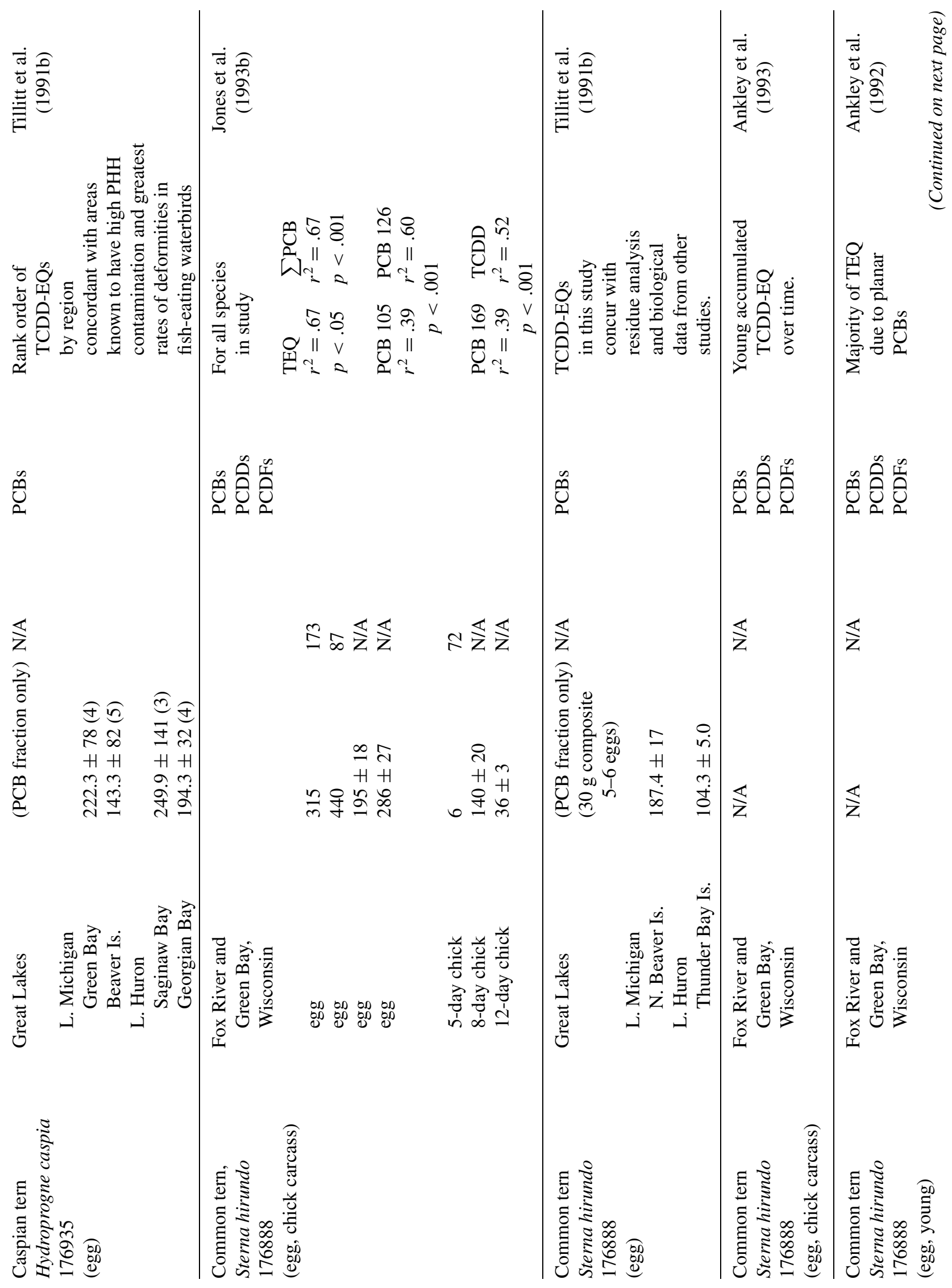




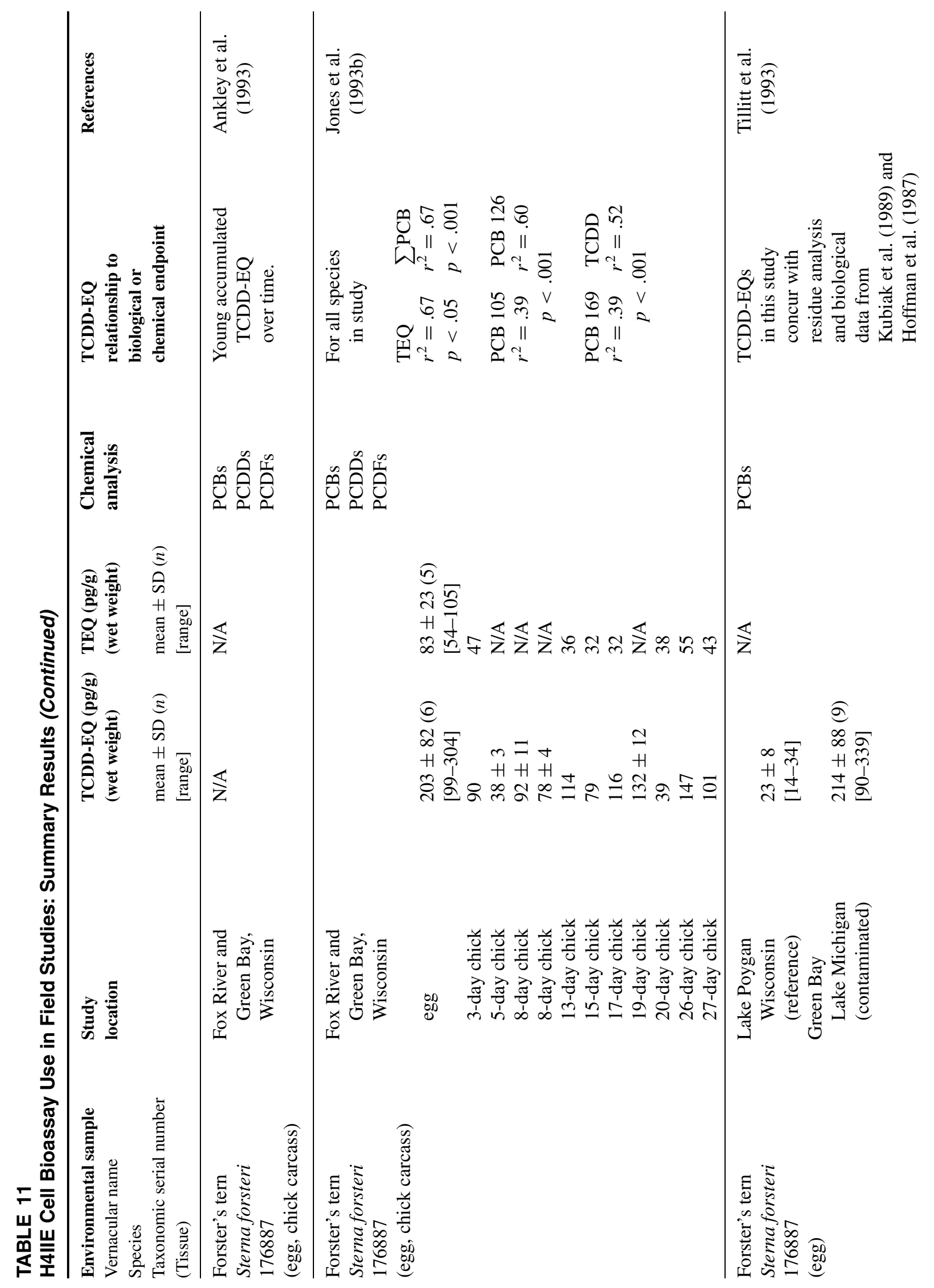




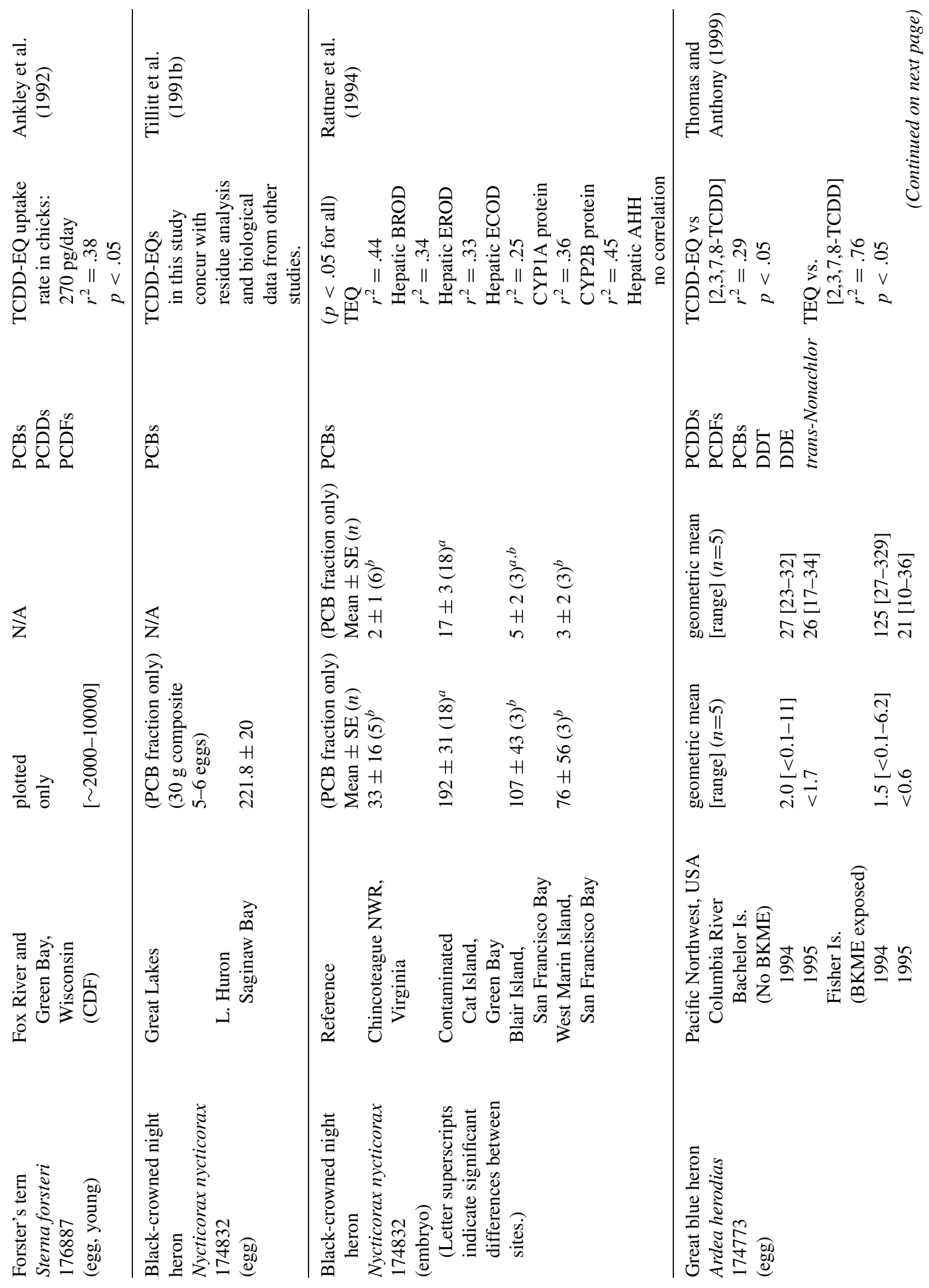




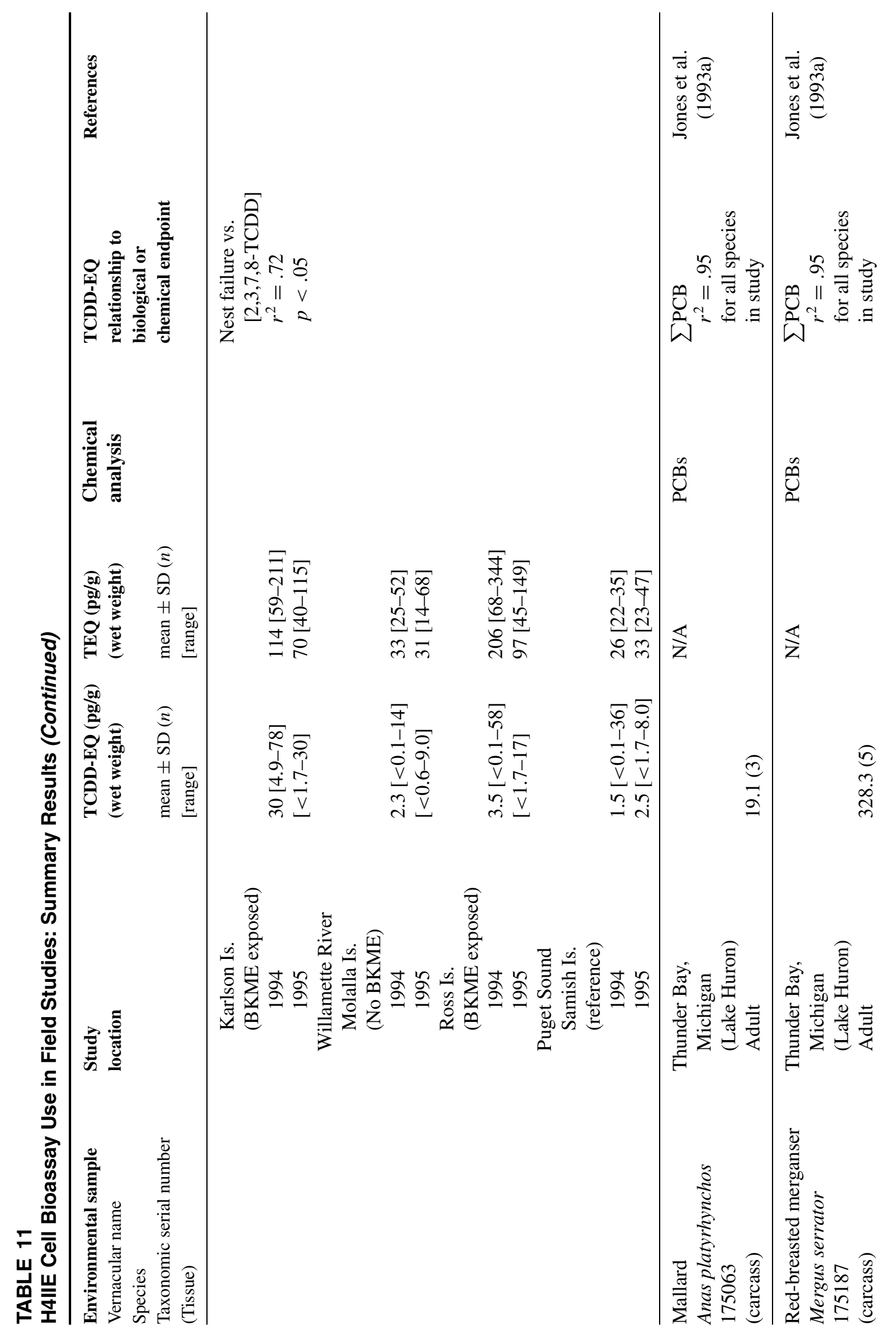




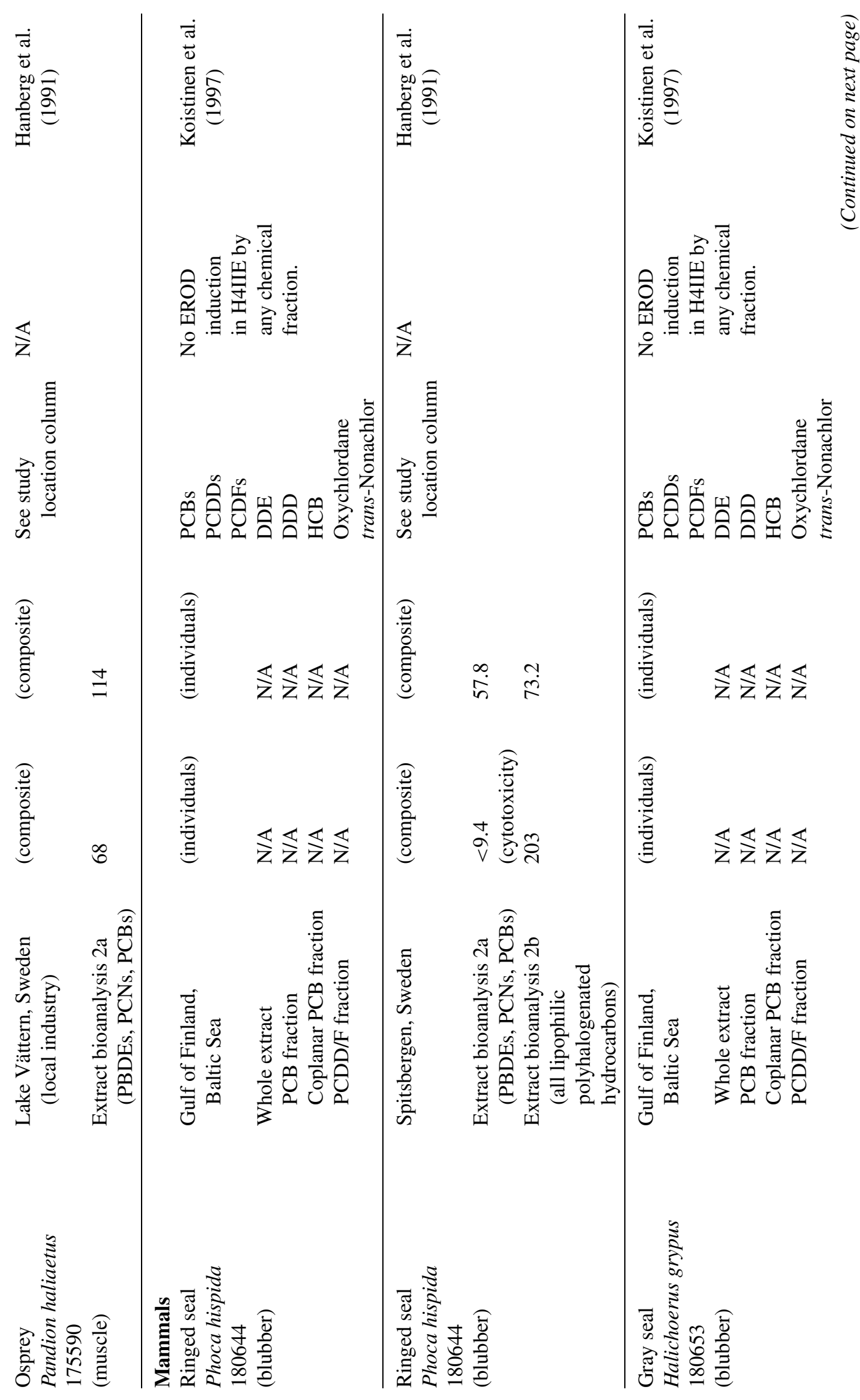




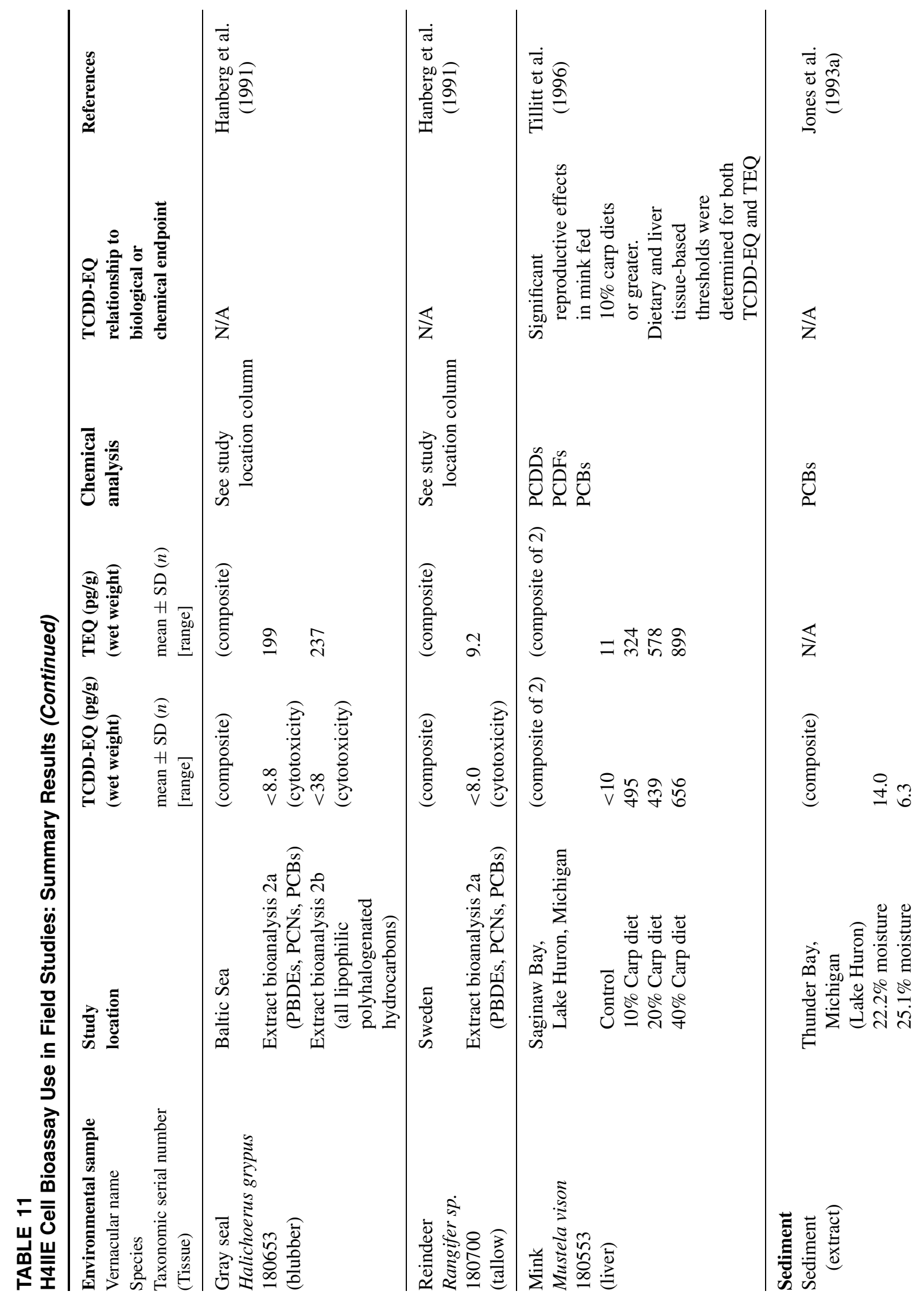




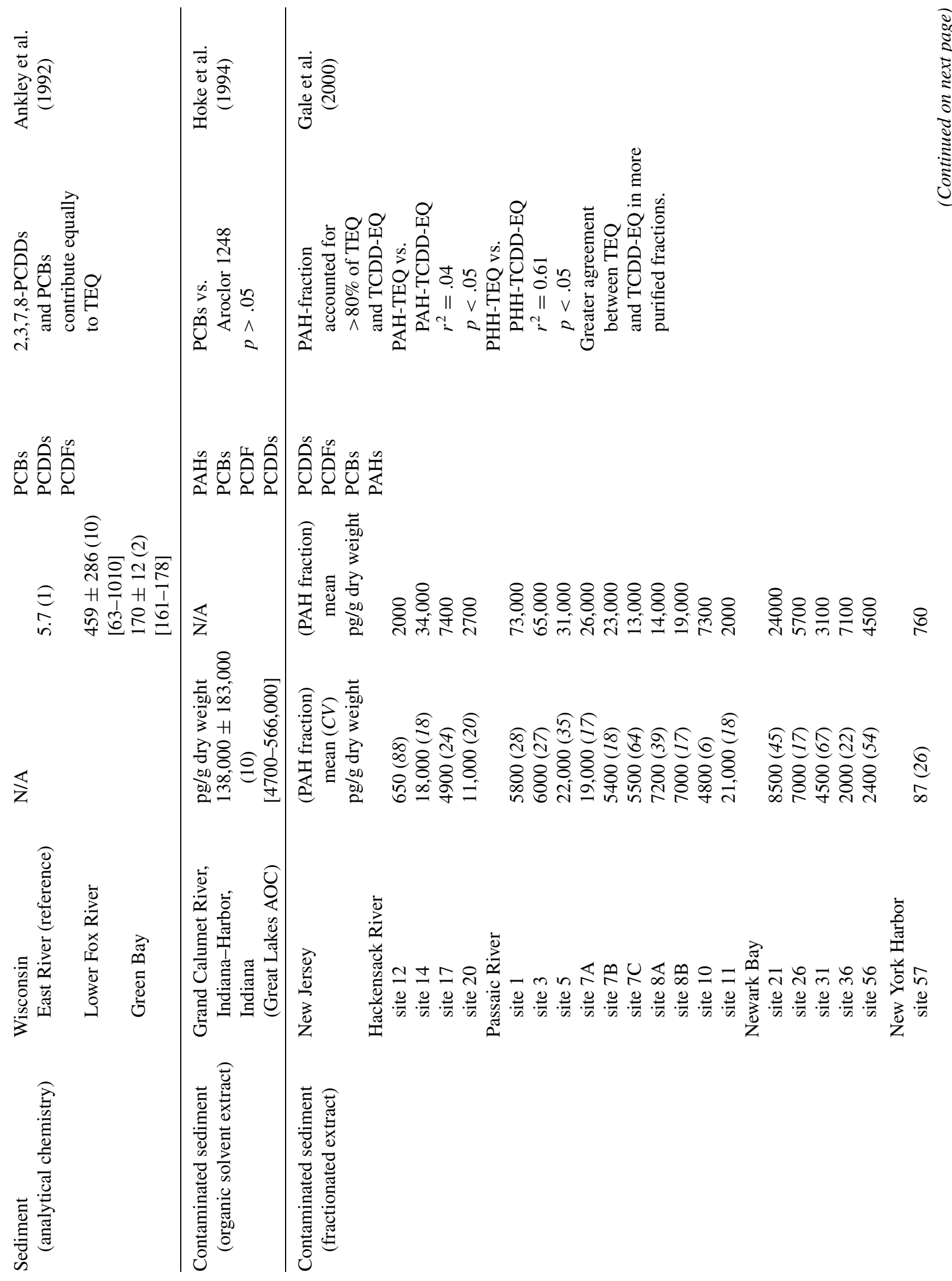




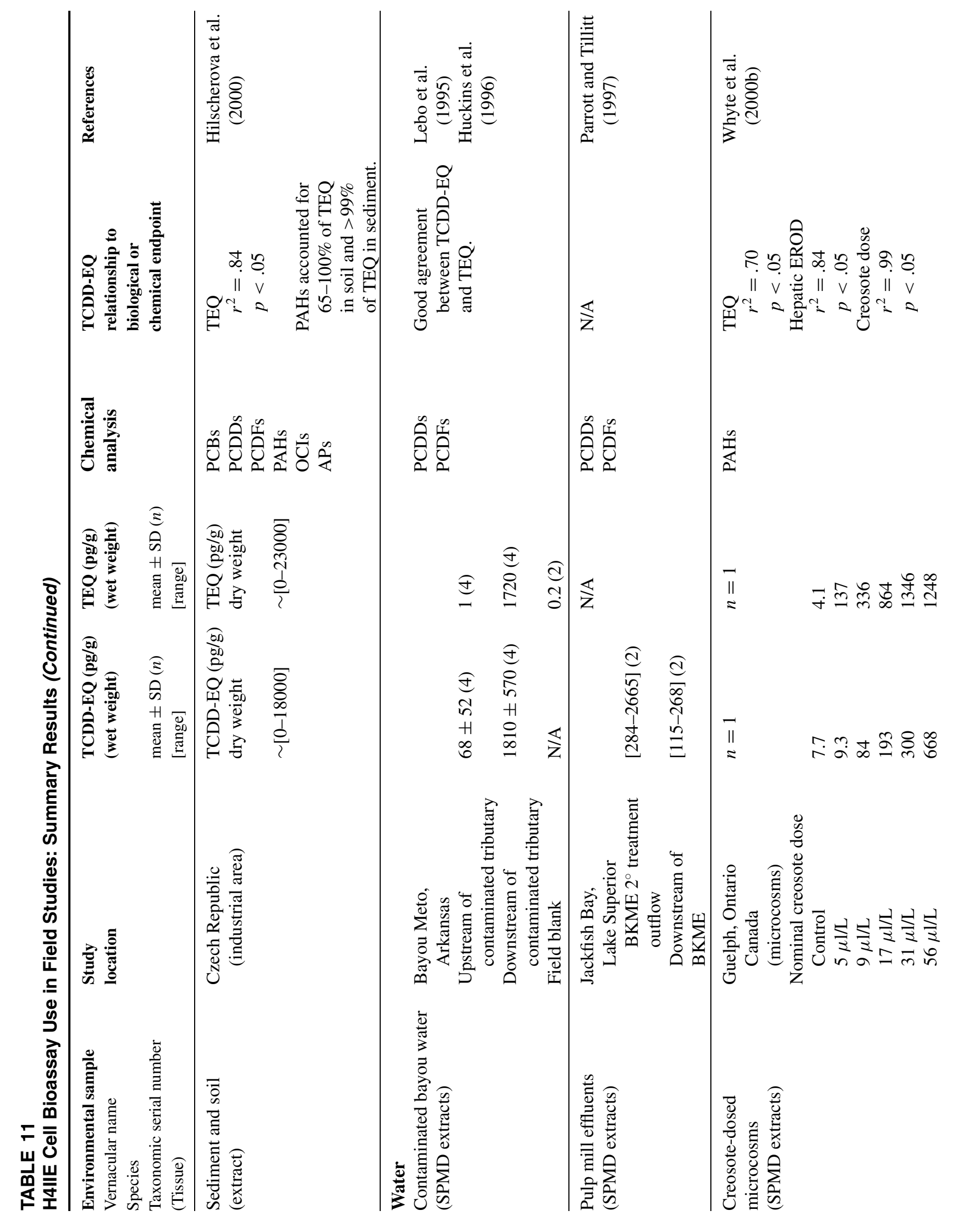




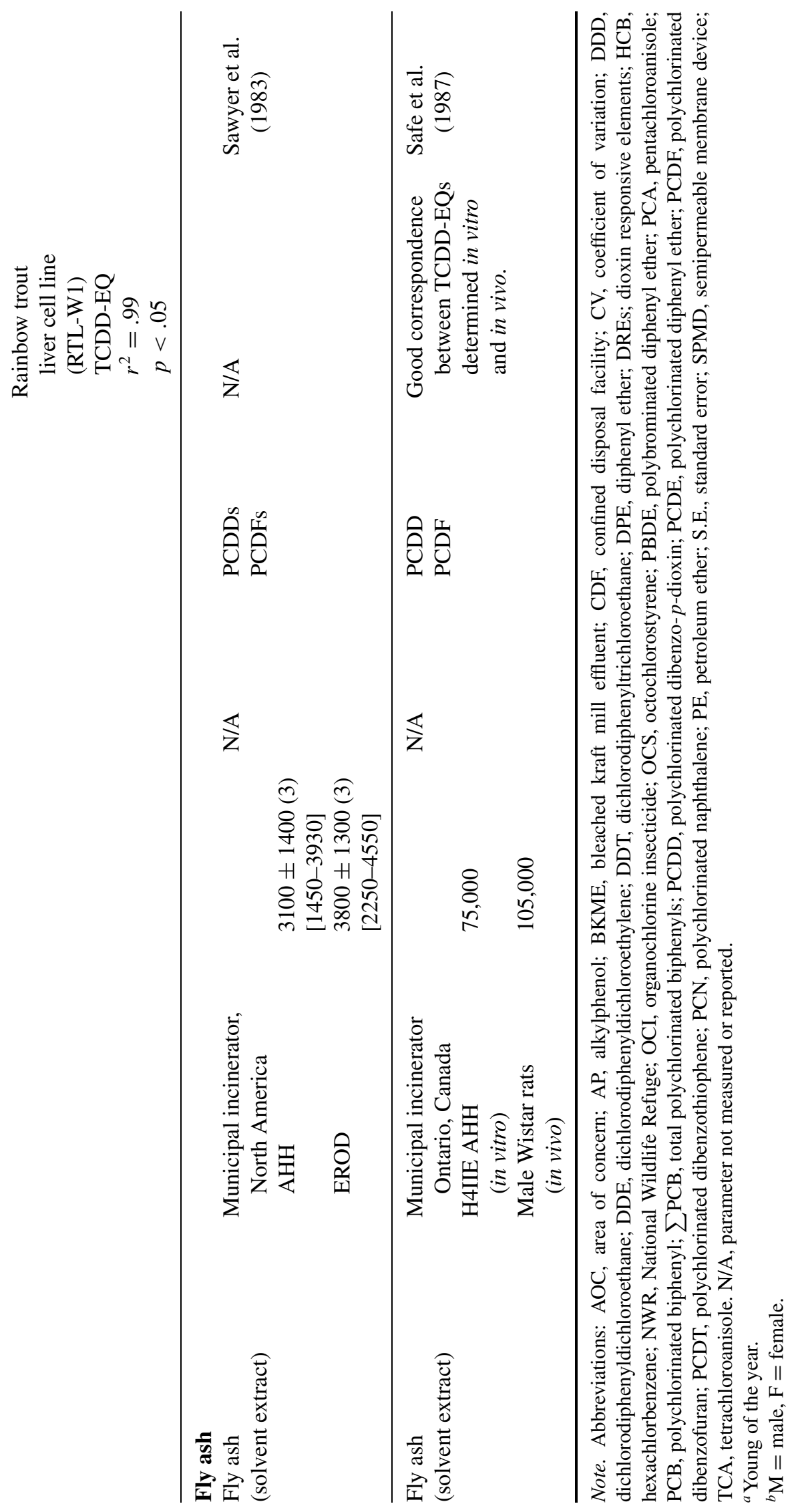


Significant correlations exist between analytical measurements of PHHs/PAHs and TCDD-EQs in eleven out of twelve studies reviewed (Table 11). Concentrations of PCBs were considered a priori to be the dominant contributor to TCDD-EQs in several studies in Lake Michigan, and indeed strong correlations existed between total PCB concentrations and TCDD-EQs in fish and birds from this region (Ankley et al., 1991; Jones et al., 1993a, 1993b; Williams et al., 1995). This is supported by earlier work, where it was determined that planar PCBs accounted for over $90 \%$ of the TEQs in Forster's tern (Sterna forsteri) eggs from Green Bay, Lake Michigan (Kubiak et al., 1989). Other major contributors to TCDD-EQs in extracts from Great Lakes wildlife are PCDDs and PCDFs. Zacharewski et al. (1989) reported significant correlations between TCDD-EQs in Great Lakes fish composites and concentrations of $\sum$ PCDDs and $\sum$ PCDFs. These TCDD-EQs were greater than their corresponding TEQs, suggesting that other inducing chemicals (such as non-ortho PCBs) were present in the extract. In a series of field investigations and caging experiments in the vicinity of bleached kraft pulp mills around Lake Superior, comparisons of TCDD-EQs, TEQs, and analytical measurements of PCDDs and PCDFs in white sucker and lake trout (Salvelinus namaycush) extracts suggested the presence of CYP1A1 inducing compounds other than just PCDD/Fs (van den Heuvel et al., 1994, 1995a, 1996; Whyte et al., 1998; Parrott et al., 2000). By combining the in vitro results of the H4IIE bioassay with in vivo measures of CYP1A1 activity, the authors were able to surmise that the unidentified compounds were potent CYP1A1 inducers, relatively water soluble, and rapidly metabolized and excreted (van den Heuvel et al., 1995a; Whyte et al., 1998). In areas of complex contamination such as these, the use of both analytical and biological measures of suspected EROD inducing compounds can play a critical role in pinpointing the source of contamination in an environment. If resources permit, PCDDs, PCDFs, and planar PCBs with the highest TEFs should all be measured in environmental extracts. This would allow a more precise determination of contributing congeners to the overall TEQs/TCDD-EQ.

Caution should be exercised when making conclusions based on correlations between contaminant concentrations and TCDD-EQs. Smith et al. (1994) noted that TCDD-EQs in Chinook salmon (Oncorhynchus tschawytscha) eggs were strongly correlated not only with $\sum$ PCB $\left(r^{2}=.71, p<.05\right)$, but also with $\sum \operatorname{DDT}\left(r^{2}=.65, p<.05\right)$ and mirex $\left(r^{2}=.65, p<.05\right)$. These two insecticides are not reported to bind to the AhR to induce CYP1A1 (Vodicnik et al., 1981; Delescluse et al., 1998), and therefore they would not contribute to the TCDDEQ. In fact, $p, p^{\prime}$-DDE had no effect on CYP1A1 induction in H4IIE cells over a wide range of concentrations (Tillitt, 1989; Tillitt et al., 1991a). It is likely that heavily polluted regions will have a number of contaminants with elevated concentrations, although only a portion of them would be inducers of CYP1A1. It should be noted here that a correlative relationship between two variables, particularly in an environmental study, does not define a causal relationship between the variables. Causality in environmental toxicology is determined by a set of criteria (Fox, 1991) that includes correlation between the causative agent and an effect, but is certainly not defined by it. Comparing TCDD-EQs to TEQs to estimate the major EROD-inducing chemicals in an extract is more straightforward.

Relationships between TCDD-EQ and TEQ values that support the additive model of CYP1A1 induction in H4IIE have been observed in several studies. Some of these studies include PAHcontaminated American oysters, Crassostrea virginica (Willett et al., 1997), PHH-contaminated Atlantic herring, Clupea harengus (Hanberg et al., 1991), common carp, Cyprinus carpio (Giesy et al., 1997), and BKME-exposed lake trout, Salvelinus namaycush (Whyte et al., 1998). In other cases, however, bioassay-derived TCDD-EQs and TEQs are significantly correlated, but the ratio of the corresponding values is not equal to one. These differences may be due to additive or less-than-additive interactions among PHHs, as described in Section IV.A. In general, TEQs and TCDD-EQs have been significantly correlated, as can be seen in 15 of 16 (94\%) of field studies where both measurements were reported (Table 11).

In cases where a one-to-one correspondence was not observed, the ratio of TCDD-EQs to TEQs was generally greater than 1 , suggesting the presence of unaccounted-for EROD inducers in extracts presented to H4IIE. It is important to remember, however, that deviations from additivity may not be due to chemical interactions, but due to limitations of the bioassay itself. It is estimated that the resolution of the H4IIE cell bioassay is not sufficient to conclude that TCDD-EQ-to-TEQ ratios with values between 0.5 and 2.0 are different from one (Giesy et al., 1997). Furthermore, H4IIE RPFs can best be described as "order-of-magnitude" estimates, and therefore we would not expect TEQs and TCDD-EQs to follow an exact 1:1 relationship 
in the majority of cases. These are important considerations when making statements about deviations from strict additivity. Even when complex models are employed, the relationship between TCDD-EQs and TEQs is difficult to interpret. Giesy et al. (1997) employed a mass-balance approach to determine if all of the CYP1A1 inducing chemicals in complex mixtures of fish extracts were accounted for. This technique involved correcting TCDD-EQ concentrations for estimated recovery, considering potential nonadditive interactions based on estimates of PCB antagonism, and approximations of contribution to TCDD-EQ from polychlorinated naphthalenes (PCNs), polychlorinated diphenyl ethers (PCDEs), and polychlorinated dibenzothiophenes (PCDTs). Although the authors were able to conclude that PCNs, PCDTs, and PCDEs were not responsible for a TCDD-EQ-to-TEQ ratio greater than 1 , the identity of CYP1A1-inducing chemical in the extract remained undetermined. This information is only presented to reveal the complexity of nonadditive results; in general additivity is supported in the majority of studies that employ the H4IIE cell bioassay (see Section IV.A).

Temporal comparisons of TCDD-EQs in wildlife or abiotic samples can also be carried out. Changes in extract TCDD-EQs over time can be used to monitor the success of remediation efforts or to track PHH body burdens at different life stages in a species. The H4IIE bioassay was used to measure TCDD-EQs in liver extracts from white sucker exposed to pulp mill effluents over a fouryear period (van den Heuvel et al., 1996). Following the introduction of effluent secondary treatment and a transition from chlorine to chlorine dioxide bleaching at the mill, concentrations of TCDD-EQs and PCDD/Fs declined. As mentioned previously, in vivo measures of hepatic EROD in white suckers in this study did not decrease, suggesting that PCDD/Fs are not the dominant CYP1A1 inducing compounds in BKME (van den Heuvel et al., 1996). The effects of bioconcentration and bioaccumulation of PHHs can be observed by monitoring TCDD-EQs in tissues of organisms at different ages. In general, concentrations of TCDD-EQs in organisms from a concentrated area increase with body mass, reflecting the accumulation of PHHs over an organisms life (Ankley et al., 1993; Jones et al., 1993a). An exception to this accumulation pattern is seen in fast-growing chicks of fish-eating waterbirds. Studies have reported that concentrations of PHHs and/or TCDD-EQs are greater in the eggs of terns (Sterna forsteri, Sterna paradisaea, Sterna hirundo) and black-crowned night herons (Nyctico- rax nycticorax) than in newly hatched chicks, indicating a drop in $\mathrm{PHH}$ concentration after hatch (Scharenberg, 1991; Ankley et al., 1993; Rattner et al., 1996). It is suggested this effect is due to growth dilution of PHHs as the chick body mass increases (Scharenberg, 1991; Jones et al., 1994). Growth is so rapid during the early life stages that although the absolute mass of PHHs increases over time, this accumulation is not detectable on a concentration basis alone. For this reason it is important to report TCDD-EQs in juvenile organisms as both concentration and absolute mass. For example, a regression analysis of TCDD-EQ mass versus age in Forster's tern nestlings from the Fox River estimated a TCDD-EQ uptake rate of 270 pg/d (Table 11; Ankley et al., 1993).

Concentrations of TCDD-EQs at different trophic levels can indicate the transfer of biologically-active PHHs through the food chain. Jones et al. (1993a) investigated biomagnification of TCDD-EQs in the Great Lakes ecosystem. TCDDEQs increased with trophic status through sediment, forage fish, piscivorous fish, and piscivorous birds. This suggests that the major route for TCDD-EQ accumulation in this ecosystem is the food chain (Jones et al., 1993a). The observed bioaccumulation of TCDD-EQ is consistent with what is known about transfer of PHHs to the top of an aquatic food chain (Fisher, 1995). Species with similar food habits had similar levels of TCDD-EQs. Other studies have also suggested the potential for the biological potency of PHHs to increase with each trophic transfer (Hanberg et al., 1991; Koistinen et al., 1997). The biological hazard associated with this increase is uncertain (Section C).

Most TCDD-EQ determinations are conducted with biological matrices, but extracts of water and sediment can also be tested with H4IIE cell bioassay (Table 11). The biological significance of the TCDD-EQ in abiotic matrices, such as soil, sediment, water, or air, is impossible to evaluate. This is because the complex processes of environmental transport are chemical specific. Thus, the concentrations of TCDD-EQs developed for abiotic matrices are of limited value and may only be compared within a matrix and contaminant source area, on a relative basis. This is the same caution which exists for TEQs developed for abiotic matrices (van den Berg et al., 1998). Concentrations of TCDD-EQs in sediment are generally greater compared to biological extracts because of the greater number of AhR ligands in sediments. Sediments contain chemicals which are not found in biota. For example, PAHs are readily found in sediments, especially in 
urban or industrial areas, while PAHs are only found in small concentrations in fish due to metabolism. There are other compounds that may be found in sediment but are not transferred to the biotic components of the aquatic food chain. The lack of transfer of chemicals can occur for a variety of reasons, but the net result is lower numbers of compounds and lower concentrations of many compounds in biota (such as fish) compared to underlying sediments. Additionally, the high organic content of sediment and the fact that TCDD-EQs are typically expressed relative to dry weight of sediment tend to elevate TCDD-EQs in sediment (Hoke et al., 1994; Gale et al., 2000).

Concentrations of TCDD-EQ in water samples are difficult to detect without concentrating samples. Several studies have used lipid-containing semipermeable membrane devices (SPMDs) to sequester PHHs and PAHs from surrounding water and then expose H4IIE cells to dialyzed extracts of the lipid (Lebo et al., 1995; Parrott and Tillitt, 1997). TCDDEQs in abiotic matrices from different locations can serve as a valuable screening tool for the presence of CYP1A1-inducing compounds and direct research efforts to the most heavily contaminated regions. The biological significance of these measurements is unclear, as stated earlier, and should only serve for relative comparisons.

\section{H4IIE-Derived TCDD-EQs as a Tool for Hazard Assessment}

Results of the H4IIE cell bioassay can be categorized based on concerns due to dioxin-like effects. The bioassay integrates the total of the dioxin-like chemicals present in environmental extracts. The amounts of chemicals present in environmental samples are not delineated with this assay. Chemical-specific risk assessments require traditional analytical chemistry data on individual chemicals. However, data from the H4IIE cell bioassay can be used to conduct hazard ranking of sites in a study or monitoring program. TCDDEQs are mechanistically well suited to predictions of toxic effects in organisms. The relationship between H4IIE-derived TCDD-EQs, PHHs, and detrimental effects was first explored by Safe and coworkers by demonstrating correlations between the in vitro response of H4IIE and the in vivo toxicity in rats after administration of selected PHHs (reviewed in Safe, 1990). Since that time, several authors have used the H4IIE cell bioassay in field situations to determine the relationship between TCDD-EQ es- timates in organisms and the hazard to their health and reproductive well-being.

The strongest evidence linking adverse symptoms of PHH exposure to TCDD-EQs comes from studies of colonial fish-eating waterbirds nesting in polluted environments. In the Great Lakes, populations of gulls (Larus argentatus, Larus delawarensis), double-crested cormorants, and Caspian terns have exhibited unusually high embryo mortality rates, deformities at birth, and altered reproductive behavior (Tillitt et al., 1989, 1993; Ludwig et al., 1995). Greater than average concentrations of PHHs in the tissues of these birds are believed to be a major contributing factor in these effects (Kubiak et al., 1989; Brunström, 1990). Results from the H4IIE bioassay have strongly implicated PHHs in extracts from eggs and tissues of these birds to increased incidence of toxic effects. Tillitt et al. (1989) determined TCDD-EQs in eggs of double-crested cormorants from 41 colonies throughout the Great Lakes. When colonies were ranked according to their TCDD-EQs, the greatest values were found in egg composites from areas with high $\mathrm{PHH}$ concentrations and the most severe reproductive effects. Although not a direct cause-and-effect relationship, the results of this study suggest at least a partial role of PHHs in the reproductive impairments of double-crested cormorants in the Great Lakes (Tillitt et al., 1989). These results have been supported by subsequent studies that strongly relate elevated TCDD-EQs to deformities, biochemical changes (decreased retinol, increased porphyrins), reproductive failure, and death in different species of birds from this region (Table 11 summaries: Tillitt et al., 1991b, 1992, 1993; Ludwig et al., 1996). Extracts of double-crested cormorants from Green Bay, Lake Michigan, have also been tested for their toxicity to developing embryos (Powell et al., 1997). These in vivo studies confirmed the toxicity of the $\mathrm{PHH}$ mixtures as predicted by the H4IIE bioassay. Together these studies conclude a causal relationship did exist among PHH contaminants and adverse reproductive effects in colonial waterbirds in Green Bay and the Great Lakes.

TCDD-EQs have been found to be a better predictor of detrimental effects than certain direct measurements of PHHs (Tillitt et al., 1992; e.g. PCBs; Ludwig et al., 1996). This is expected, because TCDD-EQs can integrate the potential for AhRmediated effects of all PHHs in an extract and the interactions among them. Tillitt et al. (1992) found the potency of PCB-containing extracts of doublecrested cormorant eggs correlated with cormorant reproductive success at those same colonies in the 
Great Lakes. These studies demonstrate the broad utility of H4IIE cell bioassay in environmental hazard assessment and screening.

The H4IIE bioassay has been applied less extensively in hazard assessment for fish populations. Contaminants such as PHHs are believed to be partly responsible for adverse reproductive impacts on salmonid populations in the Great Lakes and the Baltic Sea (Paasivirta et al., 1995; Fitzsimons, 1995; Palace et al., 1998). Ankley et al. (1991) used the H4IIE cell bioassay to determine TCDD-EQs in PCB-containing extracts of female Chinook salmon (Oncorhynchus tschawytscha) flesh and egg samples from Lake Michigan (Table 11). The concentration of TCDD-EQs in eggs was five times higher than in maternal flesh samples, while total PCBs were only 2.5 times greater. This suggested that maternally transferred PCBs had an enhanced potency relative to the PCBs in the muscle tissue, possibly due to greater transfer of more toxic planar PCBs to the eggs (Ankley et al., 1991). Only PCB concentrations in eggs were found to be significantly correlated with hatching success, but there did appear to be a TCDD-EQ threshold of $100 \mathrm{pg} / \mathrm{g}$, above which hatching success was significantly reduced. The TCDD LD50 values for lake trout eggs from a variety of exposure methods are as follows: injection studies, $50 \mathrm{pg} / \mathrm{g}$; waterborne exposure, $47 \mathrm{pg} / \mathrm{g}$; and maternal transfer, $59 \mathrm{pg} / \mathrm{g}$ (Walker et al., 1996). These values are quite comparable to the threshold suggested by Ankley et al. (1991).

Smith et al. (1994) determined H4IIE-derived TCDD-EQs in coho salmon (Oncorhynchus kisutch) and Chinook salmon eggs collected from the Great Lakes. Eggs were reared under laboratory conditions, and TCDD-EQ estimates were compared to embryonic mortality and organochlorine contaminant concentrations in these fish. Mortality that was observed between hatch and swim-up stages did not correlate with TCDD-EQ, total PCB, or organochlorine insecticide concentrations. This corroborated the findings of Ankley et al. (1991), suggesting that PHHs are not the singular factor causing the lack of reproductive success in Great Lakes salmonid populations in the 1990s. Current studies are examining the potential for PHHs to act in concert with decreased levels of vitamin B1 (thiamin) observed in Great Lakes and Baltic Sea salmonid eggs to influence the reproductive success of these species (McDonald et al., 1998).

Mammalian populations have been examined less extensively than birds and fish, but one study in particular has provided some of the most important evidence for the effects of PHHs in top preda- tors. Mink (Mustela vison) are highly sensitive to the effects of PHHs (Aulerich et al., 1973, 1985; Tillitt et al., 1996). This was clearly demonstrated when farm-raised mink were fed diets containing increasing proportions of Saginaw Bay carp (Cyprinus carpio). The TCDD-EQs in control diets and diets containing $10 \%, 20 \%$, and $40 \%$ carp were 1.0 , $19.4,40.0$, and $80.8 \mathrm{pg} / \mathrm{g}$, respectively (Tillitt et al., 1996). Reproductive toxicity was observed in all of the carp treatment groups (Heaton et al., 1995). Reduced body weights of kits born to females occurred in the $10 \%$ and greater carp diet treatments, and the $40 \%$ carp diet resulted in a significant decrease in the number of live kits born to females. The mink reproductive no-observed-adverse-effect level (NOAEL), determined in the 10\% carp diet treatment group, was $19.4 \mathrm{pg} / \mathrm{g}$ TCDD-EQ (Tillitt et al., 1996). From the results of this study, it is clear that mink are more sensitive to PHH-induced reproductive toxicity than most other species that have been tested (Peterson et al., 1993).

The H4IIE cell bioassay has also been used to develop "hazard quotients" (Giesy et al., 1995; Koistinen et al., 1997). The relative hazard of TCDD-EQs in organisms can be calculated by dividing the concentration of these TCDD-EQs by an estimated no-observable-adverse-effect concentration (NOAEC; Koistinen et al., 1997). A value of 1 would indicate that a population is just at the threshold for adverse effects and values greater than 1 would indicate a probability that adverse effects could occur. Giesy et al. (1995) measured TCDDEQs, organochlorine insecticides, PCBs, and mercury in composite samples from eight different fish species that serve as prey for bald eagles (Haliaeetus leucocephalus). These fish were collected above and below hydroelectric dams on three Michigan rivers, with fish residing below the dams having access to the Great Lakes. By combining the hazard quotient technique with biomagnifications factors for accumulation of TCDD-EQ from fish to eggs of bald eagles, it was determined that the TCDDEQs in fish below the dams presented a significant hazard to bald eagles (i.e., hazard quotients were all greater than 1). This technique has also been used by Koistinen et al. (1997) to conclude that TCDD-EQs in white-tailed sea eagle eggs are likely causing adverse effects in the Baltic populations of these birds. The hazard quotient technique can be applied to any species for which a TCDD (or TCDD-EQ) NOAEC has been determined. NOAECs from closely related surrogate species may also be used (Giesy et al., 1995). A note of caution for this approach is required. The assumption that must be made with this 
use of TCDD-EQs can be great. The trophic transfer of dioxin-like chemicals is chemical specific, so the use of TCDD as the model compound for trophic transfer coefficients may lead to inaccuracies in the resultant hazard quotients. Thus, caution must be taken in the interpretation of these exercises.

The results of the H4IIE cell bioassay represent all of the PHHs present in an extract. These chemicals have a range of bioaccumulation or biomagnification potentials and for this reason, a chemicalspecific risk assessment is not possible. However, if the potencies of TCDD-EQs as measured by the H4IIE cell bioassay were evaluated as if they were derived from TCDD alone, then relative hazard categories may be developed. These hazard categories can be based upon the toxicity of dioxin-like contaminants to a species most sensitive life stage, the developing embryo or fetus, and the expected potential for biomagnification. Toxicity reference values (TRVs) of TCDD in fish and wildlife range from $35 \mathrm{pg}$ TCDD/g egg in fish based on lake trout early life stage (ELS) mortality (Walker et al., 1994), to $100 \mathrm{pg}$ TCDD/g egg for avian embryo lethality taken from a feeding study with ring-necked pheasants (Nosek et al., 1993). Reproductive toxicity in mink occurs at $60 \mathrm{pg} \mathrm{TCDD} / \mathrm{g}$ liver in the adult mink (Tillitt et al., 1996). Taken together with the degree of biomagnification expected for TCDD, a hazard category may be developed. The use of TCDD biomagnification values simply provides a reference point from which to make relative screening categories. The biomagnification factor of TCDD from forage fish into predatory fish is approximately 1.0 (Jones et al., 2001). The biomagnification factor of TCDD from fish into the eggs of fish-eating birds is approximately 20 (Braune and Norstrom, 1989), and the biomagnification factor of TCDD from fish into mink livers is approximately 11 (Tillitt et al., 1996). Hazard categories may be developed from simple division of the toxicity reference values by the biomagnification factors (TRV/BMF). Fish health may be expected to be impaired when TCDD-EQs in fish are $35 \mathrm{pg} / \mathrm{g}(\mathrm{TRV} / \mathrm{BMF}=35 / 1)$. Avian reproductive health may be expected to be impaired when TCDD-EQs in fish are $5 \mathrm{pg} / \mathrm{g}$ (TRV/BMF $=$ 100/20), while mammalian wildlife reproductive health can be expected to be impaired when TCDDEQs in fish are $5 \mathrm{pg} / \mathrm{g}(\mathrm{TRV} / \mathrm{BMF}=60 / 11)$. The TRV estimated by Tillitt et al. (1996) for dietary concentrations of TEQs in fish to protect mink reproductive health was $4.4 \mathrm{pg} \mathrm{TEQ} / \mathrm{g}$ fish. Thus, based on the potential for reproductive impairment and these biomagnification factors, H4IIE cell bioassay values in fish greater than $5 \mathrm{pg}$ TCDD/g may be screened as hazardous to avian and mammalian wildlife that consume fish.

\section{SUMMARY: ADVANCES AND FUTURE DIRECTIONS FOR THE H4IIE CELL BIOASSAY}

The H4IIE cell bioassay has proven utility both as a screening tool for dioxin-like chemicals in organisms from the wild, and as a means of estimating the hazard posed to organisms exposed to PHHs. This technique has several advantages over the analytical measurement of PHHs in samples, but conclusions from studies can be strengthened when both bioassay and analytical chemistry data are presented together. Often, the bioassay results concur with biological effects in organisms and also support direct measures of PHHs. For biomonitoring purposes and prioritization of PHH-contaminated environments, the H4IIE bioassay is faster and less expensive than analytical measurements. The H4IIE cell bioassay can be used in combination with other biomarkers such as in vivo measurements of CYP1A1 induction (Whyte et al., 2000a) to help pinpoint the sources and identities of dioxin-like chemicals. The number of studies that measure H4IIE-derived TCDD-EQs continues to increase, resulting in subtle improvements of the method and interpretation over time.

\section{A. Reporter Gene Systems for TCDD-EQ Determination in H4IIE}

The development and distribution of recombinant cell lines, including the H4IIE cells, that use a luciferase reporter gene has also become increasingly popular. Although the H4IIE cell bioassay is widely used in research investigations, reasonable concern exists over the difficulties discussed in this review, such as inhibition of CYP1A1 activity at high ligand concentrations and incomplete concentration-response curves. Measurement of CYP1A1 protein rather than catalytic activity has been suggested one way of dealing with these problems (Hahn et al., 1996), but these methods require greater time investments than the catalytic assay. Recently, a recombinant H4IIE cell line has been produced that contains a luciferase gene of the firefly (Photinus pyralis) regulated by dioxinresponsive elements upon interaction with the AhR (Sanderson et al., 1996). Exposure of the cells to AhR agonists activates the production of luciferase, which is quantified by measuring the light 
production after addition of the substrate luciferin (Hamers et al., 2000). The increased expression of luciferase is measured using a luminometer. The cell line, named H4IIE-luc, is reported to be threefold more sensitive to TCDD than wild-type H4IIE (Sanderson et al., 1996). This increased sensitivity of H4IIE-luc cells may allow full concentrationresponse curves to be generated with lower concentrations of extract, avoiding cytotoxicity and CYP1A1 inhibition seen in wild type cells at high PHH concentrations. Hamers et al. (2000) state that AhR activation in H4IIE-luc cells by easily metabolized compounds such as PAHs can be distinguished from the response to more persistent compounds such as PHHs. PAH-induced luciferase production can be measured $6 \mathrm{~h}$ after exposure, but is no longer detectable after $24 \mathrm{~h}$ of exposure, presumably due to metabolic breakdown of the inducers. For PHHs, induction of luciferase is still present after $24 \mathrm{~h}$ and longer. The cells are reported to yield stable EC50 values for TCDD over long periods of cell culture.

A recently described fluorescence-based cell bioassay may offer methodological and cost advantages over the H4IIE and H4IIE-luc bioassays. Nagy et al. (2002a,b) describe the development and optimization of a recombinant mouse hepatoma cell line (Hepa1c1c7) that responds to AhR-agonists with the induction of enhanced green fluorescent protein (EGFP). The expressed EGFP fluoresces directly without the need for additional reagents, allowing rapid and inexpensive "real-time" measurement of reporter gene activity. Such fluorescence-based assays need to be well characterized before they can be used routinely for biomonitoring studies.

The wild-type H4IIE cell bioassay remains more widely used than luciferase bioassays, at present. Reasons for this include the extensive historical use of the wild-type assay and the availability of the recombinant cells. However, as the H4IIEluc continues to undergo adaptations, the technique will likely gain in popularity. To date, the use of H4IIE-luc in several field studies has been reported (Murk et al., 1996; Khim et al., 2000; Hamers et al., 2000; Hilscherova et al., 2000; Kannan et al., 2000; Koppen et al., 2001).

\section{B. Wise Use of the H4IIE Cell Bioassay}

The H4IIE cell bioassay can be a powerful analytical tool, but like all tools, it must be used for the purposes it is intended and care must be exercised to ensure reliable results. The H4IIE cell bioassay can indicate the presence of AhR ligands, but not all AhR ligands elicit the same toxic responses. Strong relationships between toxicity and EROD induction in H4IIE cells resulting from dioxin, furan and PCB exposure have been demonstrated (see Section ID). Hazard assessments that include the use of the H4IIE cell bioassay for these classes of compounds are therefore justifiable. Insufficient evidence exists that relates toxic responses and H4IIE TCDD-EQs for compounds such as PAHs. For these chemical classes, the H4IIE bioassay should only be used to indicate contaminant exposure. As more data are generated relating toxicity to responses in the H4IIE cell bioassay, the potential for the use of this bioassay as a tool for hazard assessment will continue to grow.

Further experiments are required to determine if TCDD-EQs derived from the H4IIE cell bioassay are the best predictors of toxicity to other species, or if cultured cells should be related to the species being examined (Lipp et al., 1992; Lee et al., 1993; Lorenzen et al., 1997b). For instance, research indicates that the structure-activity relationships for PCBs could be more dependent on the species than is the case for other PHHs (Gooch et al., 1989; Stegeman and Hahn, 1993). However, in nonmammalian species, much less is known about the mechanism by which the AhR controls CYP1A induction (Hahn et al., 1993). The H4IIE cell bioassay currently provides a clear indication of $\mathrm{PHH}$ exposure, and while it does not account for possible differences in the relative toxicity of PHH congeners among species, this exposure estimate can provide a rapid means of ranking environmental samples (e.g., fish or avian tissue samples) according to their TCDD-EQs. As research in the area of taxon-specific differences in PHH structure-activity relationships continues, the role of the H4IIE cell line bioassay in predicting the relative hazard of PHH exposure to different species will become more clear. These challenges considered, the combination of speed, simplicity, and ability to integrate the effects of complex contaminant mixtures makes the H4IIE cell bioassay in its current state a valuable addition to hazard assessment and biomonitoring studies.

\section{ACKNOWLEDGMENTS}

We gratefully acknowledge the financial support of the Biomonitoring of Environmental Status and Trends (BEST) Program and the U.S. Geological Survey. We thank Christine Bunck, Susan 
Finger, and Tim Bartish of the BEST team for providing the opportunity and resources to produce this document. We also thank the following for technical review of the manuscript: Jeremy Buck, U.S. Fish and Wildlife Service; Dr. Michael Denison, University of California-Davis; Dr. Sean Kennedy; Environment Canada; Dr. Mark Melancon, U.S. Geological Survey; and Dr. Dieter Schrenk, University of Kaiserslautern (Germany). We appreciate the advice of Diane Nicks and Sean Birke on several of the technical aspects of the H4IIE cell bioassay. Robin Lipkin provided valuable bibliographic support. This project involves collaboration between CERC and the Cooperative Fish and Wildlife Research Unit at the University of Missouri-Columbia (Charles F. Rabeni, Leader).

\section{REFERENCES}

Aarts, J.M., Denison, M.S., Cox, M.A., Schalk, M.A.C., Garrison, P.M., Tullis, K., De Haan, L.H.J., and Brouwer, A. (1995). Species-specific antagonism of Ah receptor action by $2,2^{\prime}, 5,5^{\prime}$-tetrachloro- and 2,2',3,3',4,4'-hexachlorobiphenyl. Eur. J. Pharmacol. 293:463.

Ankley, G.T., Tillitt, D.E., Giesy, J.P., Jones, P.D., and Verbrugge, D.A. (1991). Bioassay-derived 2,3,7,8-tetrachlorodibenzo- $p$-dioxin equivalents in PCB-containing extracts from the flesh and eggs of Lake Michigan chinook salmon (Oncorhynchus tshawytscha) and possible implications for reproduction. Can. J. Fish. Aquat. Sci. 48: 1685 .

Ankley, G.T., Lodge, K., Call, D.J., Balcer, M.D., Brooke, L.T., Cook, P.M., Kreis, R.G., Jr., Carlson, A.R., Johnson, R.D., Niemi, G.J., Hoke, R.A., West, C.W., Giesy, J.P., Jones, P.D., and Fuying, Z.C. (1992). Integrated assessment of contaminated sediments in the lower Fox River and Green Bay, Wisconsin. Ecotoxicol. Environ. Safety 23:46.

Ankley, G.T., Tillitt, D.E., and Giesy, J.P. (1989). Maternal transfer of bioactive polychlorinated aromatic hydrocarbons in spawning chinook salmon (Oncorhynchus tschawytscha). Mar. Environ. Res. 28:231.

Ankley, G.T., Niemi, G.J., Lodge, K.B., Harris, H.J., Beaver, D.L., Tillitt, D.E., Schwartz, T.R., Giesy, J.P., Jones, P.D., and Hagley, C. (1993). Uptake of planar polychlorinated biphenyls and 2,3,7,8-substituted polychlorinated dibenzofurans and dibenzo- $p$-dioxins by birds nesting in the lower Fox River and Green Bay, Wisconsin, USA. Arch. Environ. Contam. Toxicol. 24:332.
Aulerich, R.J., Ringer, R.K., and Iwamoto, S. (1973). Reproductive failure and mortality in mink fed on Great Lakes fish. J. Reprod. Fertil. Suppl. 19:365.

Aulerich, R.J., Bursian, S.J., Breslin, W.J., Olson, B.A., and Ringer, R.K. (1985). Toxicological manifestations of $2,4,5,2^{\prime}, 4^{\prime}, 5^{\prime}-, \quad 2,3,6,2^{\prime}, 3^{\prime}, 6^{\prime}-$, and $3,4,5,3^{\prime}, 4^{\prime}, 5^{\prime}$-hexachlorobiphenyl and Aroclor 1254 in mink. J. Toxicol. Environ. Health 15:63.

Backlund, M., Weidolf, L., and Ingelman-Sundberg, M. (1999). Structural and mechanistic aspects of transcriptional induction of cytochrome P450 1A1 by benzimidazole derivatives in rat hepatoma H4IIE cells. Eur. J. Biochem. 261:66.

Bandiera, S., Sawyer, T., Romkes, M., Zmudzka, B., Safe, L., Mason, G., Keys, B., and Safe, S. (1984). Polychlorinated dibenzofurans (PCDFs): Effects of structure on binding to the 2,3,7,8-TCDD cytosolic receptor protein, $\mathrm{AHH}$ induction and toxicity. Toxicology 32:131.

Bannister, R., Davis, D., Zacharewski, T., Tizard, I., and Safe, S. (1987). Aroclor 1254 as a 2,3,7,8tetrachlorodibenzo- $p$-dioxin antagonist: Effects on enzyme induction and immunotoxicity. Toxicology 46:29.

Bannister, R., and Safe, S. (1987). Synergistic interactions of 2,3,7,8-TCDD and 2,2',4,4',5,5'hexachlorobiphenyl in C57BL/6J and DBA/2J mice: Role of the Ah receptor. Toxicology 44:159.

Basu, N., Billiard, S., Fragoso, N., Omoike, A., Tabash, S., Brown, S., and Hodson, P. (2001). Ethoxyresorufin- $O$-deethylase induction in trout exposed to mixtures of polycyclic aromatic hydrocarbons. Environ. Toxicol. Chem. 20:1244.

Benedict, W.F., Gielen, J.E., Owens, I.S., Niwa, A., and Nebert, D.W. (1973). Aryl hydrocarbon hydroxylase induction in mammalian liver cell cultureIV. Stimulation of the enzyme activity in established cell lines derived from rat or mouse hepatoma and from normal rat liver. Biochem. Pharmacol. 22:2766.

Bensadoun, A., and Weinstein, D. (1976). Assay of proteins in the presence of interfering materials. Anal. Biochem. 70:241.

Birnbaum, L.S. (1999). TEFs: A practical approach to a real-world problem. Hum. Ecol. Risk Assess. 5:13.

Bols, N.C., Boliska, S.A., Dixon, D.G., Hodson, P.V., and Kaiser, K.L.E. (1985). The use of fish cell cultures as an indication of contaminant toxicity to fish. Aquat. Toxicol. 6:147.

Bols, N.C., Whyte, J.J., Clemons, J.H., Tom, D.J., van den Heuvel, M.R., and Dixon, D.G. (1997). Use of liver cell lines to develop TCDD equivalency factors and 
TCDD equivalent concentrations in environmental samples. In Ecotoxicology: Responses, biomarkers and risk assessment, ed. J.T. Zelikoff, p. 329. Fair Haven, NJ: SOS Publishing.

Borgmann, U., and Whittle, D.M. (1991). Contaminant concentration trends in Lake Ontario lake trout (Salvelinus namaycush): 1977-1988. J. Great Lakes Res. 17:268.

Bradford, M.M. (1976). A rapid and sensitive method for the quantitation of microgram quantities of protein utilizing the principle of protein-dye binding. Anal. Biochem. 72:248.

Bradlaw, J.A., Garthoff, L.H., Hurley, N.E., and Firestone, D. (1980). Comparative induction of aryl hydrocarbon hydroxylase activity in vitro by analogues of dibenzo-p-dioxin. Food. Cosmet. Toxicol. 18:627.

Bradlaw, J.A., and Casterline, J.L., Jr. (1979). Induction of enzyme activity in cell culture: A rapid screen for detection of planar polychlorinated organic compounds. J. Assoc. Off. Anal. Chem. 62:904.

Braune, B.M., and Norstrom, R.J. (1989). Dynamics of organochlorine compounds in herring gulls: III. Tissue distribution and bioaccumulation in Lake Ontario gulls. Environ. Toxicol. Chem. 8:957.

Brunström, B. Ö. (1990). Mono-ortho-chlorinated chlorobiphenyls: Toxicity and induction of 7ethoxyresorufin $O$-deethylase (EROD) activity in chick embryos. Arch. Toxicol. 64:188.

Burke, M.D., and Mayer, R.T. (1974). Ethoxyresorufin: Direct fluorimetric assay of a microsomal $O$ dealkylation which is preferentially inducible by 3methylcholanthrene. Drug. Metab. Dispos. 2:583.

Casterline, J.L., Jr., Bradlaw, J.A., Bartholomew, J.P., and Ku, Y. (1983). Screening of fresh water fish extracts for enzyme-inducing substances by an aryl hydrocarbon hydroxylase induction bioassay technique. J. Assoc. Off. Anal. Chem. 66:1136.

Clemons, J.H., van den Heuvel, M.R., Stegeman, J.J., Dixon, D.G., and Bols, N.C. (1994). Comparison of toxic equivalent factors for selected dioxin and furan congeners derived using fish and mammalian liver cell lines. Can. J. Fish. Aquat. Sci. 51:1577.

Clemons, J.H., Lee, L.E.J., Myers, C.R., Dixon, D.G., and Bols, N.C. (1996). Cytochrome P4501A1 induction by polychlorinated biphenyls (PCBs) in liver cell lines from rat and trout and the derivation of toxic equivalency factors. Can. J. Fish. Aquat. Sci. 53:1177.

Clemons, J.H., Dixon, D.G., and Bols, N.C. (1997). Derivation of 2,3,7,8-TCDD toxic equivalent factors (TEFs) for selected dioxins, furans and PCBs with rainbow trout and rat liver cell lines and the influence of exposure time. Chemosphere 34: 1105.

Clemons, J.H., Myers, C.R., Lee, L.E.J., Dixon, D.G., and Bols, N.C. (1998). Induction of cytochrome P4501A1 by binary mixtures of polychlorinated biphenyls (PCBs) and 2,3,7,8-tetrachlorodibenzo$p$-dioxin (TCDD) in liver cell lines from rat and trout. Aquat. Toxicol. 48:179.

da Costa, E.G., and Curtis, L.R. (1995). Bioaccumulation of dietary $2,2^{\prime}, 4,4^{\prime}, 5,5^{\prime}$-hexachlorobiphenyl and induction of hepatic arylhydrocarbon hydroxylase in rainbow trout (Oncorhynchus mykiss). Environ. Toxicol. Chem. 14:1711.

Delescluse, C., Ledirac, N., de Sousa, G., Pralavorio, M., Lesca, P., and Rahmani, R. (1998). Cytotoxic effects and induction of cytochromes P450 1A1/2 by insecticides, in hepatic or epidermal cells: Binding capability to the Ah receptor. Toxicol. Lett. 9697:33.

Denomme, M.A., Homonko, K., Fujita, T., Sawyer, T., and Safe, S. (1986). Substituted polychlorinated dibenzofuran receptor binding affinities and aryl hydrocarbon hydroxylase induction potencies-A QSAR analysis. Chem. Biol. Interact. 57:175.

Eadon, G., Kaminsky, L., Silkworth, J., Aldous, K., Hilker, D., O’Keefe, P., Smith, R., Gierthy, J., Hawley, J., Kim, N., and DeCaprio, A. (1986). Calculation of 2,3,7,8-TCDD equivalent concentrations of complex environmental contaminant mixtures. Environ. Health. Perspect. 22:517.

Enan, E., and Matsumura, F. (1995). Evidence for a second pathway in the action mechanism of 2,3,7,8-tetrachlorodibenzo- $p$-dioxin (TCDD): Significance of Ah-receptor mediated activation of protein kinase under cell-free conditions. Biochem. Pharmacol. 49:249.

Fragoso, N.M., Hodson, P.V., Kozin, I.S., Brown, R.S., and Parrott, J.L. (1999). Kinetics of mixed munction oxygenase inducion and retene excretion in retene-exposed rainbow trout (Oncorhynchus mykiss). Environ. Toxicol. Chem. 18:2268.

Finney, D.J. (1964). Probit analysis. Cambridge: Cambridge University Press.

Fisher, S.W. (1995). Mechanisms of bioaccumulation in aquatic systems. Rev. Environ. Contam. Toxicol. 142:87.

Fitzsimons, J.D. (1995). A critical review of the effects of contaminants on early life stage (ELS) mortality of lake trout in the Great Lakes. J. Great Lakes Res. 21(suppl. 1): 267.

Fox, G.A., Kennedy, S.W., Norstrom, R.J., and Wigfield, D.C. (1998). Porphyria in herring gulls a 
biochemical response to chemical contamination of Great Lakes USA-Canada food chains. Environ. Toxicol. Chem. 7:831.

Fox, G.A. (1991). Practical causal inference for ecoepidemiologists. J. Toxicol. Environ. Health 33:359.

Franzén, B., Haaparanta, T., Gustafsson, J., and Toftgard, R. (1988). TCDD receptor ligands present in extracts of urban air particulate matter induce aryl hydrocarbon hydroxylase activity and cytochrome P-450 gene expression in rat hepatoma cells. Carcinogenesis 9:111.

Freshney, R.I. (1992). Animal cell culture. New York: Oxford University Press.

Gale, R.W., Long, E.R., Schwartz, T.R., and Tillitt, D.E. (2000). Planar halogenated hydrocarbons and polycyclic aromatic hydrocarbons in estuarine sediments using ethoxyresorufin- $O$-deethylase induction of H4IIE cells. Environ. Toxicol. Chem. 19:1348.

Gardinali, P., Willett, K., Sericano, J., Safe, S., and Wade, T. (1995). Chemical analysis and in vitro EROD activities in extracts from the American oyster. Abstract Book of the Society of Environmental Toxicology and Chemistry's Second SETAC World Congress (16th Annual Meeting); Global Environmental Protection: Science, Politics, and Common Sense, Vancouver, British Columbia.

Giesy, J.P., Bowerman, W.W., Mora, M.A., Verbrugge, D.A., Othoudt, R.A., Newsted, J.L., Summer, C.L., Aulerich, R.J., Bursian, S.J., Ludwig, J.P., Dawson, G.A., Kubiak, T.J., Best, D.A., and Tillitt, D.E. (1995). Contaminants in fishes from Great Lakes-influenced sections and above dams of three Michigan rivers: III. Implications for health of bald eagles. Arch. Environ. Contam. Toxicol. 29: 309.

Giesy, J.P., Jude, D.J., Tillitt, D.E., Gale, R.W., Meadows, J.C., Zajicek, J.L., Peterman, P.H., Verbrugge, D.A., Sanderson, J.T., Schwartz, T.R., and Tuchman, M.L. (1997). Polychlorinated dibenzop-dioxins, dibenzofurans, biphenyls and 2,3,7,8tetrachlorodibenzo- $p$-dioxin equivalents in fishes from Saginaw Bay, Michigan. Environ. Toxicol. Chem. 16:713.

Goks $\varnothing y r$, A., and Förlin, L. (1992). The cytochrome P-450 system in fish, aquatic toxicology and environmental monitoring. Aquat. Toxicol. 22:287.

Gooch, J.W., Elskus, A.A., Kloepper-Sams, P.J., Hahn, M.E., and Stegeman, J.J. (1989). Effects of ortho- and non-ortho-substituted polychlorinated biphenyl congeners on the hepatic monooxygenase system in scup (Stenotomus chrysops). Toxicol. App. Pharmacol. 98:422.
Grimwood, M.J., and Dobbs, T.J. (1995). A review of the aquatic ecotoxicology of polychlorinated dibenzop-dioxins and dibenzofurans. Environ. Toxicol. Water Qual. 10:57.

Guengerich, F.P., and Liebler, D.C. (1985). Enzymatic activation of chemicals to toxic metabolites. Crit. Rev. Toxicol. 14:259.

Hahn, M.E. (1998). The aryl hydrocarbon receptor: A comparative perspective. Comp. Biochem. Physiol. C Pharmacol. Toxicol. Endocrinol. 121:23.

Hahn, M.E. (2002). Biomarkers and bioassays for detecting dioxin-like compounds in the marine environment. Sci. Total. Environ. 289:49.

Hahn, M.E., and Chandran, K. (1996). Uroporphyrin accumulation associated with cytochrome P4501A induction in fish hepatoma cells exposed to aryl hydrocarbon receptor agonists, including 2,3,7,8tetrachlorodibenzo- $p$-dioxin and planar chlorobiphenyls. Arch. Biochem. Biophys. 329:163.

Hahn, M.E., Woodin, B.R., Stegeman, J.J., and Tillitt, D.E. (1998). Aryl hydrocarbon receptor function in early vertebrates: Inducibility of cytochrome P450 1A in agnathan and elasmobranch fish. Comp. Biochem. Physiol. C. 120:67.

Hahn, M.E., Lamb, T.M., Schultz, M.E., Smolowitz, R.M., and Stegeman, J.J. (1993). Cytochrome P4501A induction and inhibition by $3,3^{\prime}, 4,4^{\prime}-$ tetrachlorobiphenyl in an Ah receptor-containing fish hepatoma cell line (PLHC-1). Aquat. Toxicol. 26:185.

Hahn, M.E., Woodward, B.L., Stegeman, J.J., and Kennedy, S.W. (1996). Rapid assessment of induced cytochrome P4501A protein and catalytic activity in fish hepatoma cells grown in multiwell plates: Response to TCDD, TCDF, and two planar PCBs. Environ. Toxicol. Chem. 15:582.

Hale, R.C., and Greaves, J. (1992). Methods for the analysis of persistent chlorinated hydrocarbons in tissues. J. Chromatogr. 580:257.

Hamers, T., van Schaardenburg, M.D., Felzel, E.C., Murk, A.J., and Koeman, J.H. (2000). The application of reporter gene assays for the determination of the toxic potency of diffuse air pollution. Sci. Total Environ. 262:159.

Hammond, A.H., and Fry, J.R. (1992). Effect of serumfree medium on cytochrome P450-dependent metabolisim and toxicity in rat cultured hepatocytes. Biochem. Pharmacol. 44:1461.

Hammond, D.K., and Strobel, H.W. (1992). Ethoxyresorufin $O$-deethylase activity in intact human cells. Toxicol. In Vitro 6:41. 
Hanberg, A., Wærn, F., Asplund, L., Haglund, E., and Safe, S. (1990). Swedish dioxin survey: Determination of 2,3,7,8-TCDD toxic equivalent factors for some polychlorinated biphenyls and naphthalenes using biological tests. Chemosphere 20:1161.

Hanberg, A., Ståhlberg, M., Georgellis, A., de Wit, C., and Ahlborg, U.G. (1991). Swedish dioxin survey: Evaluation of the H-4-II E bioassay for screening environmental samples for dioxin-like enzyme induction. Pharmacol. Toxicol. 69:442.

Harris, M., Zacharewski, T., Astroff, B., and Safe, S. (1989). Partial antagonism of 2,3,7,8tetrachlorodibenzo- $p$-dioxin-mediated induction of aryl hydrocarbon hydroxylase by 6-methyl1,3,8-trichlorodibenzofuran: Mechanistic studies. Mol. Pharmacol. 35:729.

Heaton, S.N., Bursian, S.J., Giesy, J.P., Tillitt, D.E., Render, J.A., Jones, P.D., Verbrugge, D.A., Kubiak, T.J., and Aulerich, R.J. (1995). Dietary exposure of mink to carp from Saginaw Bay, Michigan: 2. Hematology and liver pathology. Arch. Environ. Contam. Toxicol. 29:411.

Hellou, J., Warren, W.G., and Payne, J.F. (1993). Organochlorines including polychlorinated biphenyls in muscle, liver, and ovaries of cod. Gadus morhua. Arch. Environ. Contam. Toxicol. 25:497.

Henningsen, G., Roy, R., Bradbury, S., Henry, T., and Hoff, D. (1998). Dioxin analyses for ecological risk assessment: Scientific approach and practical considerations. Abstract Book of the Society of Environmental Toxicology and Chemistry's 19th Annual Meeting, Charlotte, NC.

Hestermann, E.V., Stegeman, J.J., and Hahn, M.E. (2000). Serum alters the uptake and relative potencies of halogenated aromatic hydrocarbons in cell culture bioassays. Toxicol. Sci. 53:316.

Hewitt, L.M., Carey, J.H., Munkittrick, K.R., Parrott, J.L., Solomon, K.R., and Servos, M.R. (1998). Identification of chloro-nitro-trifluoromethyl-substituted dibenzo- $p$-dioxins in lampricide formulations of 3-trifluoromethyl-4-nitrophenol: Assessment to induce mixed function oxidase activity. Environ. Toxicol. Chem. 17:941.

Hightower, L.E., and Renfro, J.L. (1988). Recent applications of fish cell culture to biomedical research. J. Exp. Zool. 248:290.

Hilscherova, K., Dusek, L., Kannan, K., Giesy, J.P., and Holoubek, I. (2000). Evaluation of cytotoxicity, dioxin-like activity and estrogenicity of complex environmental mixtures. Cent. Eur. J. Public Health 8:28.

Hoffer, A., Chang, C.Y., and Puga, A. (1996). Dioxin induces transcription of fos and jun genes by $\mathrm{Ah}$ receptor-dependent and -independent pathways. Toxicol. App. Pharmacol. 141:238.

Hoffman, D.J., Rattner, B.A., Sileo, L., Docherty, D., and Kubiak, T.J. (1987). Embryotoxicity, teratagenicity, and aryl hydrocarbon hydroxylase activity in Forster's terns on Green Bay, Lake Michigan. Environ. Res. 42:176.

Hoke, R.A., Jones, P.D., Maccubbin, A.E., Zabik, M.J., and Giesy, J.P. (1994). Use of in vitro microbial assays of sediment extracts to detect and quantify contaminants with similar modes of action. Chemosphere 28:169.

Honeycutt, M.E., Jarvis, A.S., and McFarland, V.A. (1996). Cytotoxicity and mutagenicity of 2,4,6trinitrotoluene and its metabolites. Ecotoxicol. Environ. Safety 35:282.

Hoogenboom, R., and Hamers, A. (1995). Effects of oxfendazole on the Ah receptor-mediated induction of ethoxyresorufin $O$-deethylase and luciferase activity by 2,3,7,8-tetrachlorodibenzop-dioxin in Hepta-1c1c7 and H4IIE cell-lines. Organohalogen Compdounds 25:53.

Huckins, J.N., Petty, J.D., Lebo, J.A., Orazio, C.E., Prest, H.F., Tillitt, D.E., Ellis, G.S., Johnson, B.T., and Manuweera, G.K. (1996). Semipermeable membrane devices (SPMDs) for the concentration and assessment of bioavailable organic contaminants in aquatic environments. In Techniques in aquatic toxicology, ed. G. Ostrander, p. 625. Boca Raton, FL: Lewis.

Huestis, S.Y., Servos, M.R., Whittle, D.M., van den Heuvel, M., and Dixon, D.G. (1997). Evaluation of temporal and age-related trends of chemically and biologically generated 2,3,7,8-tetrachlorodibenzo$p$-dioxin equivalents in Lake Ontario lake trout, 1977 to 1993. Environ. Toxicol. Chem. 16:154.

Huestis, S.Y., Servos, M.R., Sergeant, D.B., Leggett, M., and Dixon, D.G. (1995). Methods for determination of organochlorine pesticides, polychlorinated biphenyl congeners and chlorinated dibenzo- $p$ dioxins and furans in fish. Can. Tech. Rep. Fish. Aquat. Sci. 2044:1.

Hutzinger, O., Safe, S., and Zitko, V. (1974). Preparation, gas chromatographic behavior, and spectroscopic properties of hydroxylated chlorobiphenyls. J. Assoc. Off. Anal. Chem. 57:1061.

Hyenstrand, P., Metcalf, J.S., Beattie, K.A., and Codd, G.A. (2001). Losses of the cyanobacterial toxin microcystin-LR from aqueous solution by adsorption during laboratory manipulations. Toxicon 39:589.

Jones, P.D., Ankley, G.T., Best, D.A., Crawford, R., DeGalan, N., Giesy, J.P., Kubiak, T.J., Ludwig, 
J.P., Newsted, J.L., Tillitt, D.E., and Verbrugge, D.A. (1993a). Biomagnification of bioassay derived 2,3,7,8-tetrachlorodibenzo- $p$-dioxin equivalents. Chemosphere 26:1203.

Jones, P.D., Giesy, J.P., Newsted, J.L., Verbrugge, D.A., Beaver, D.L., Ankley, G.T., Tillitt, D.E., Lodge, K.B., and Niemi, G.J. (1993b). 2,3,7,8tetrachlorodibenzo- $p$-dioxin equivalents in tissues of birds at Green Bay, Wisconsin, USA. Arch. Environ. Contam. Toxicol. 24:345.

Jones, P.D., Giesy, J.P., Newsted, J.L., Verbrugge, D.A., Ludwig, J.P., Ludwig, M.E., Auman, H.J., Crawford, R., Tillitt, D.E., Kubiak, T.J., and Best, D.A. (1994). Accumulation of 2,3,7,8tetrachlorodibenzo- $p$-dioxin equivalents by double-crested cormorant (Phalacrocorax auritus, Pelicaniformes) chicks in the North American Great Lakes. Ecotoxicol. Environ. Safety 27:192.

Jones, P.D., Kannan, K., Newsted, J.L., Tillitt, D.E., Williams, L.L., and Giesy, J.P. (2001). Accumulation of 2,3,7,8-tetrachlorodibenzo- $p$-dioxin by rainbow trout (Onchorhynchus mykiss) at environmentally relevant dietary concentrations. Environ. Toxicol. Chem. 20:344.

Jung, D.K.J., Klaus, T., and Fent, K. (2001). Cytochrome P450 induction by nitrated polycyclic aromatic hydrocarbons, azaarenes, and binary mixtures in fish hepatoma cell line PLHC-1. Environ. Toxicol. Chem. 20:149.

Kafafi, S.A., Afeefy, H.Y., Said, H.K., and Kafafi, A.G. (1993). Relationship between aryl hydrocarbon receptor binding, induction of aryl hydrocarbon hydroxylase and 7-ethoxyresorufin $O$-deethylase enzymes, and toxic activities of aromatic xenobiotics in animals. A new model. Chem. Res. Toxicol. 6:328.

Kannan, K., Yamashita, N., Villeneuve, D.L., Hashimoto, S., Miyazaki, A., and Giesy, J.P. (2000). Vertical profile of dioxin-like and estrogenic potencies in a sediment core from Tokyo Bay, Japan. Cent. Eur. J. Public Health 8:32.

Keith, R.F., Crummett, W., Deegan, J., Libby, R.A., Taylor, J.K., and Wentler, G. (1983). Principles of environmental analysis. Anal. Chem. 55:2210.

Kennedy, S.W., and Jones, S.P. (1994). Simultaneous measurement of cytochrome P4501A catalytic activity and total protein concentration with a fluorescence plate reader. Anal. Biochem. 222:217.

Kennedy, S.W., Jones, S.P., and Bastien, L.J. (1995). Efficient analysis of cytochrome P4501A catalytic activity, porphyrins, and total proteins in chicken embryo hepatocyte cultures with a fluorescence plate reader. Anal. Biochem. 226:362.
Kennedy, S.W., Lorenzen, A., James, C.A., and Collins, B.T. (1993). Ethoxyresorufin- $O$-deethylase and porphyrin analysis in chicken embryo hepatocyte cultures with a fluorescence multiwell plate reader. Anal. Biochem. 211:102.

Kennedy, S.W., Lorenzen, A., and Norstrom, R.J. (1996). Chicken embryo hepatocyte bioassay for measuring cytochrome P4501A-based 2,3,7,8tetrachlorodibenzo- $p$-dioxin equivalent concentrations in environmental samples. Environ. Sci. Technol., 30:706.

Kennicutt, M.C., McDonald, S.J., Sericano, J.L., Boothe, P., Oliver, J., Safe, S., Presley, B.J., Liu, H., Wolfe, D., Wade, T.L., Crockett, A., and Bockus, D. (1995). Human contamination of the marine environment: Arthur Harbor and McMurdo Sound, Antarctica. Environ. Sci. Technol. 29:1279.

Kerr, D.R., and Meador, J.P. (1996). Modeling dose response using generalized linear models. Environ. Toxicol. Chem. 15:395.

Keys, B., Piskorska-Pliszczynska, J., and Safe, S. (1986). Polychlorinated dibenzofurans as 2,3,7,8-TCDD antagonists: In vitro inhibition of monooxygenase enzyme induction. Toxicol. Lett. 31:151.

Khim, J.S., Villeneuve, D.L., Kannan, K., Hu, W.Y., Giesy, J.P., Kang, S.G., Song, K.J., and Koh, C.H. (2000). Instrumental and bioanalytical measures of persistent organochlorines in blue mussel (Mytilus edulis) from Korean coastal waters. Arch. Environ. Contam. Toxicol. 38:360.

Klotz, A.V., Stegeman, J.J., and Walsh, C. (1984). An alternative 7-ethoxyresorufin- $O$-deethylase activity assay: A continuous visible spectrophotometric method for measurement of cytochrome $\mathrm{P}$ 450 monooxygenase activity. Anal. Biochem. 140: 138.

Koistinen, J., Koivusaari, J., Nuuja, I., Vuorinen, P.J., Paasivirta, J., and Giesy, J.P. (1997). 2,3,7,8Tetrachlorodibenzo- $p$-dioxin equivalents in extracts of Baltic white-tailed sea eagles. Environ. Toxicol. Chem. 16:1533.

Koppen, G., Covaci, A., Van Cleuvenbergen, R., Schepens, P., Winneke, G., Nelen, V., and Schoeters, G. (2001). Comparison of CALUXTEQ values with PCB and PCDD/F measurements in human serum of the Flanders Environmental and Health Study (FLEHS). Toxicol. Lett. 123:59.

Kubiak, T.J., Harris, H.J., Smith, L.M., Schwartz, T.R., Stalling, D.L., Trick, J.A., Sileo, L., Docherty, D.E., and Erdman, T.C. (1989). Microcontaminants and reproductive impairment of the Forster's tern on Green Bay, Lake Michigan-1983. Arch. Environ. Contam. Toxicol. 18:706. 
Kucharczyk, N. (1993). Estimation of the lower limit of quantitation, a method detection performance parameter for biomedical assays, from calibration curves. J. Chromatogr. 612:71.

Lebo, J.A., Gale, R.W., Petty, J.D., Tillitt, D.E., Huckins, J.N., Meadows, J.C., Orazio, C.E., Echols, K.R., Schroeder, D.J., and Inmon, L.E. (1995). Use of the semipermeable membrane device as an in situ sampler of waterborne bioavailable PCDD and PCDF residues at sub-parts-per-quadrillion concentrations. Environ. Sci. Technol. 29:2886.

Lee, L.E.J., Clemons, J.H., Bechtel, D.G., Caldwell, S.J., Han, K., Pasitschniak-Arts, M., Mosser, D.D., and Bols, N.C. (1993). Development and characterization of a rainbow trout liver cell line expressing cytochrome P450-dependent monooxygenase activity. Cell Biol. Toxicol. 9:279.

Lindsay, C.K., Burke, M.D., Weaver, R.J., Melvin, W.T., and Hawksworth, G.M. (1990). Isoenzymespecific induction of cytochromes P-450 in rat hepatocytes cultured in the presence of dimethylsulphoxide. Biochem. Soc. Trans. 18:1212.

Lipp, H.P., Schrenk, D., Wiesmuller, T., Hagenmaier, H., and Bock, K.W. (1992). Assessment of biological activities of mixtures of polychlorinated dibenzo$p$-dioxins (PCDDs) and their constituents in human HepG2 cells. Arch. Toxicol. 66:220.

Liu, H., Santostefano, M., Lu, Y., and Safe, S. (1993). A new class of inducers and inhibitors of CYP1A1-dependent responses: 6-Substituted3,4-benzocoumarins. Organohalogen Compounds 13:249.

Lorenzen, A., and Kennedy, S.W. (1993). A fluorescencebased protein assay for use with a microplate reader. Anal. Biochem. 214:346.

Lorenzen, A., Kennedy, S.W., Bastien, L.J., and Hahn, M.E. (1997a). Halogenated aromatic hydrocarbonmediated porphyrin accumulation and induction of cytochrome P4501A in chicken embryo hepatocytes. Biochem. Pharmacol. 53:373.

Lorenzen, A., Shutt, J.L., and Kennedy, S.W. (1997b). Sensitivity of common tern (Sterna hirundo) embryo hepatocyte cultures to CYP1A induction and porphyrin accumulation by halogenated aromatic hydrocarbons and common tern egg extracts. Arch. Environ. Contam. Toxicol. 32:126.

Lowry, O.H., Rosebrough, N.J., Farr, A.L., and Randall, R.J. (1951). Protein measurement with the Folin phenol reagent. J. Biol. Chem. 193:265.

Lubet, R.A., Nims, R.W., Mayer, R.T., Cameron, J.W., and Schechtman, L.M. (1985). Measurement of cytochrome P-450 dependent dealkylation of alkoxyphenoxazones in hepatic S9s and hepatocyte homogenates: Effects of dicumarol. Mutat. Res. 142:127.

Ludwig, J.P., Kurita-Matsuba, H., Auman, H.J., Ludwig, M.E., Summer, C.L., Giesy, J.P., Tillitt, D.E., and Jones, P.D. (1996). Deformities, PCBs, and TCDD-equivalents in double-crested cormorants (Phalacrocorax auritus) and Caspian terns (Hydroprogne caspia) of the upper Great Lakes 19861991: Testing a cause-effect hypothesis. J. Great Lakes Res. 22:172.

Ludwig, J.P., Auman, H.J., Weseloh, D.V., Fox, G.A., Giesy, J.P., and Ludwig, M.E. (1995). Evaluation of the effects of toxic chemicals in Great Lakes cormorants: Has causality been established? Colonial Waterbirds 18:60.

Mason, G., Farrell, K., Keys, B., Piskorska-Pliszczynska, J., Safe, L., and Safe, S. (1986). Polychlorinated dibenzo-p-dioxins: Quantitative in vitro and vivo structure-activity relationships. Toxicology 41:21.

McDonald, G., Fitzsimons, J.D., and Honeyfield, D.C. (1998). Early life stage mortality syndrome in fishes of the Great Lakes and Baltic Sea. American Fisheries Society, Bethesda, MD, USA.

McDonald, S.J., Kennicutt, M.C., Liu, H., and Safe, S.H. (1995). Assessing aromatic hydrocarbon exposure in Antarctic fish captured near Palmer and McMurdo Stations, Antarctica. Arch. Environ. Contam. Toxicol. 29:232.

McDonald, S.J., Kennicutt, M.C., II., Sericano, J., Wade, T.L., Liu, H., and Safe, S.H. (1994). Correlation between bioassay-derived P4501A1 induction activity and chemical analysis of clam (Laternula elliptica) extracts from McMurdo Sound, Antarctica. Chemosphere 28:2237.

McFarland, M., England, S., and Hamilton, M.C. (1995). Assessment of the integrity of chemicals in environmental samples over an extended period of time. Environment Canada-Fraser River Action Plan: DOE FRAP 1996-27. Vancouver, BC, Canada.

Meadows, J., Tillitt, D., Huckins, J., and Schroeder, D. (1993). Large-scale dialysis of sample lipids using a semipermeable membrane device. Chemosphere 26:1993.

Menzel-Soglowek, S., Geisslinger, G., Mollenhauer, J., and Brune, K. (1992). Metabolic chiral inversion of 2-arylpropionates in rat H4IIE and human Hep G2 hepatoma cells. Relationship to in vivo metabolism. Biochem. Pharmacol. 43:1487.

Metcalfe, C.D., and Haffner, G.D. (1995). The ecotoxicology of coplanar polychlorinated biphenyls. Environ. Rev. 3:171. 
Muir, D.C.G., Marshall, W.K., and Webster, G.R.B. (1985). Bioconcentration of PCDDs by fish: Effects of molecular structure and water chemistry. Chemosphere 14:829.

Murk, A.J., Legler, J., Denison, M.S., Giesy, J.P., Van de Guchte, C., and Brouwer, A. (1996). Chemicalactivated luciferase gene expression (CALUX): A novel in vitro bioassay for Ah receptor active compounds in sediments and pore water. Fundam. Appl. Toxicol. 33:149.

Nagy, S.R., Sanborn, J.R., Hammock, B.D., and Denison, M.S. (2002a). Development of a green fluorescent protein-based cell bioassay for the rapid and inexpensive detection and characterization of Ah receptor agonists. Toxicol. Sci. 65:200.

Nagy, S.R., Liu, G., Lam, K.S., and Denison, M.S. (2002b). Identification of novel Ah receptor agonists using a high-throughput green fluorescent protein-based recombinant cell bioassay. Biochemistry. 41:861.

Nebert, D.W., and Gelboin, H.V. (1968a). Substrateinducible microsomal aryl hydroxylase in mammalian cell culture. I. Cellular responses during enzyme induction. J. Biol. Chem. 243:6242.

Nebert, D.W., and Gelboin, H.V. (1968b). Substrateinducible microsomal aryl hydroxylase in mammalian cell culture. II. Cellular responses during enzyme induction. J. Biol. Chem. 243:6250.

Nebert, D.W., Puga, A., and Vasiliou, V. (1993). Role of the Ah receptor and the dioxin-inducible $[A h]$ gene battery in toxicity, cancer, and signal transduction. Ann. NY Acad. Sci. 685:624.

Nebert, D.W., Roe, A.L., Dieter, M.Z., Solis, W.A., Yang, Y., and Dalton, T.P. (2000). Role of the aromatic hydrocarbon receptor and $[\mathrm{Ah}]$ gene battery in the oxidative stress response, cell cycle control, and apoptosis. Biochem. Pharmacol. 59:65.

Niwa, A., Kumaki, K., and Nebert, D.W. (1975). Induction of aryl hydrocarbon hydroxlylase activity in various cell cultures by 2,3,7,8-tetrachlorodibenzo- $p$ dioxin. Mol. Pharmacol. 11:399.

Nosek, J.A., Sullivan, J.R., Craven, S.R., GendronFitzpatrick, A., and Peterson, R.E. (1993). Embryotoxicity of 2,3,7,8-tetrachlorodibenzo- $p$-dioxin in the ring-necked pheasant. Environ. Toxicol. Chem. 12:1215.

Oikari, A., Fragoso, N., Leppanen, H., Chan, T., and Hodson, P.V. (2002). Bioavailability to juvenile rainbow trout (Oncorynchus mykiss) of retene and other mixed-function oxygenase-active compounds from sediments. Environ. Toxicol. Chem. 21:121.
Okey, A.B., Riddick, D.S., and Harper, P.A. (1994). The Ah receptor: Mediator of the toxicity of 2,3,7,8tetrachlorodibenzo- $p$-dioxin (TCDD) and related compounds. Toxicol. Lett. 70:1.

Oris, J.T., and Bailer, A.J. (1997). Equivalence of concentration-response relationships in aquatic toxicity studies: Testing and implications for potency estimation. Environ. Toxicol. Chem. 16:2204.

Paasivirta, J., Vuorinen, P.J., Vuorinen, M., Koistinen, J., Rantio, T., Hyotylainen, T., and Welling, L. (1995). TCDD-toxicity and M74 syndrome of Baltic salmon. Organohalogen Compounds 25:355.

Päivi, K., Erkki, M., and Sirpa, K. (1992). Induction of aryl hydrocarbon hydroxylase AHH by two previously uncharacterized pentachlorinated biphenyls in a mouse and a rat hepatoma cell line. Chemosphere 24:201.

Palace, V.P., Baron, C.L., and Klaverkamp, J.F. (1998). An assessment of Ah-inducible phase I and phase II enzymatic activities and oxidative stress indices in adult lake trout (Salvelinus namaycush) from Lake Ontario and Lake Superior. Aquat. Toxicol. 42:149.

Parrott, J.L., van den Heuvel, M.R., Hewitt, L.M., Baker, M.A., and Munkittrick, K.R. (2000). Isolation of MFO inducers from tissues of white suckers caged in bleached kraft mill effluent. Chemosphere 41:1083.

Parrott, J.L., and Tillitt, D.E. (1997). The use of semipermeable membrane devices (SPMDs) to concentrate inducers of hepatic mixed function oxygenase (MFO). In Ecotoxicology: Responses, biomarkers, and risk assessment, ed. J.T. Zelikoff, p. 185. Fair Haven, NJ: SOS Publishing.

Peters, J.M., Narotsky, M.G., Elizondo, G., FernandezSalguero, P.M., Gonzalez, F.J., and Abbott, B.D. (1999). Amelioration of TCDD-induced teratogenesis in aryl hydrocarbon receptor (AhR)-null mice. Toxicol. Sci. 47:86.

Peterson, R.E., Theobald, H.M., and Kimmel, G.L. (1993). Developmental and reproductive toxicity of dioxins and related compounds: Crossspecies comparisons. Crit. Rev. Toxicol. 23: 283.

Pitot, H.C., Peraino, C., Morse, P.A., Jr., and Potter, V.R. (1964). Hepatomas in tissue culture compared with adapting liver in vivo. Natl. Cancer Inst. Monogr. 13:229.

Pohl, R.J., and Fouts, J.R. (1980). A rapid method for assaying the metabolism of 7-ethoxyresorufin by microsomal subcellular fractions. Anal. Biochem. 107:150. 
Poland, A., and Bradfield, C. (1992). A brief review of the Ah locus. Tohoku J. Exp. Med. 168:83.

Poland, A., and Glover, E. (1973). Chlorinated dibenzop-dioxins: Potent inducers of delta-aminolevulinic acid synthetase and aryl hydrocarbon hydroxylase. II. A study of the structure-activity relationship. Mol. Pharmacol. 9:736.

Poland, A., Glover, E., and Kende, A.S. (1976). Stereospecific, high affinity binding of 2,3,7,8tetrachlorodibenzo- $p$-dioxin by hepatic cytosol: Evidence that the binding species is receptor for induction of aryl hydrocarbon hydroxylase. J. Biol. Chem. 251:4936.

Poland, A., Greenlee, W.F., and Kende, A.S. (1972). Studies on the mechanism of action of the chlorinated dibenzo- $p$-dioxins and related compounds. Ann. NY Acad. Sci. 320:214.

Powell, D.C., Aulerich, R.J., Meadows, J.C., Tillitt, D.E., Stromborg, K.L., Kubiak, T.J., Giesy, J.P., and Bursian, S.J. (1997). Organochlorine contaminants in double-crested cormorants from green bay, Wisconsin: II. Effects of an extract derived from cormorant eggs on the chicken embryo. Arch. Environ. Contam. Toxicol. 32:316.

Putzrath, R.M. (1995). Reassessment of TEFs: A mathematical approach. Organohalogen Compounds 25:111.

Rappe, C., Andersson, R., Bergqvist, P.A., Brohede, C., Hansson, M., Kjeller, L.O., Lindström, G., Marklund, S., and Nygren, M. (1987). Overview on environmental fate of chlorinated dioxins and dibenzofurans. Sources, levels and isomeric pattern in various matrixes. Chemosphere 16:1603.

Rattner, B.A., Melancon, M.J., Custer, T.W., and Hothem, R.L. (1996). Cytochrome P450 and contaminant concentrations in nestling black-crowned nightherons and their interrelation with sibling embryos. Environ. Toxicol. Chem. 15:715.

Rattner, B.A., Hatfield, J.S., Melancon, M.J., Custer, T.W., and Tillitt, D.E. (1994). Relation among cytochrome P450, Ah-active PCB congeners and dioxin equivalents in pipping black-crowned nightheron embryos. Environ. Toxicol. Chem. 13:1805.

Rees, K.R. (1980). Cells in culture in toxicity testing: A review. J. Royal Soc. Med. 73:261.

Reuber, M.D. (1961). A transplantable bile-secreting hepatocellular carcinoma in the rat. J. Natl. Cancer Inst. 26:791.

Ribick, M.A., Smith, L.M., Dubay, G.R., and Stalling, D.L. (1981). Aquatic Toxicology and Hazard Assessment. Proceedings of the Fourth Annual Conference on Aquatic Toxicology. ASTM Special
Technical Publication 737. Philadelphia: American Society for Testing and Materials.

Richter, C.A., Tieber, V.L., Denison, M.S., and Giesy, J.P. (1997). An in vitro rainbow trout cell bioassay for aryl hydrocarbon receptor-mediated toxins. Environ. Toxicol. Chem. 16:543.

Roberts, M.A., and Durst, R.A. (1995). Investigation of liposome-based immunomigration sensors for the detection of polychlorinated biphenyls. Anal. Chem. 67:482.

Ronis, M.J.J., and Walker, C.H. (1985). Species variations in the metabolism of liposoluble organochlorine compounds by hepatic microsomal monooxygenase: Comparative kinetics in four vertebrate species. Comp. Biochem. Physiol. 82C:445.

Safe, S. (1987). Determination of 2,3,7,8-TCDD toxic equivalent factors (TEFs): Support for the use of the in vitro $\mathrm{AHH}$ induction assay. Chemosphere 16:791.

Safe, S. (1990). Polychlorinated biphenyls (PCBs), dibenzo- $p$-dioxins (PCDDs), dibenzofurans (PCDFs), and related compounds: Environmental and mechanistic considerations which support the development of toxic equivalency factors (TEFs). Crit. Rev. Toxicol. 21:51.

Safe, S.H. (1994). Polychlorinated biphenyls (PCBs): Environmental impact, biochemical and toxic responses, and implications for risk assessment polychlorinated biphenyls (PCBs): Environmental impact, biochemical and toxic responses, and implications for risk assessment. Crit. Rev. Toxicol. 24:87.

Safe, S.H. (1999). Development and application of TEF's. Hum. Ecol. Risk Assess. 5:9.

Safe, S., Mason, G., Keys, B., Farrell, K., Zmudzka, B., Sawyer, T., Piskorska-Pliszczynska, J., Safe, L., Romkes, M., and Bandiera, S. (1986). Polychlorinated dibenzo- $p$-dioxins and dibenzofurans: Correlation between in vitro and in vivo structure-activity relationships (SARs). Chemosphere 15: 1725 .

Safe, S., Mason, G., Farrell, K., Keys, B., PiskorskaPliszczynska, J., Madge, J.A., and Chittim, B. (1987). Validation of in vitro bioassays for 2,3,7,8TCDD equivalents. Chemosphere 16:1723.

Safe, S., Mason, G., Sawyer, T., Zacharewski, T., Harris, M., Yao, C., Keys, B., Farrell, K., Holcomb, M., Davis, D., Safe, L., Piskorska-Pliszczynska, J., Leece, B., Denomme, M.A., Hutzinger, O., Thoma, H., Chittim, B., and Madge, J. (1989). Development and validation of in vitro induction assays for toxic halogenated aromatic mixtures: A review. Toxicol. Ind. Health 5:757. 
Sanderson, J.T., Aarts, J.M., Brouwer, A., Froese, K.L., Denison, M.S., and Giesy, J.P. (1996). Comparison of Ah receptor-mediated luciferase and ethoxyresorufin- $O$-deethylase induction in H4IIE cells: Implications for their use as bioanalytical tools for the detection of polyhalogenated aromatic hydrocarbons. Toxicol. App. Pharmacol. 137: 316.

Sanderson, J.T., Kennedy, S.W., and Giesy, J.P. (1998). In vitro induction of ethoxyresorufin- $O$-deethylase and porphyrins by halogenated aromatic hydrocarbons in avian primary hepatocytes. Environ. Toxicol. Chem. 17:2006.

Sanderson, J.T., and van den Berg, M. (1999). Toxic equivalency factors (TEFs) and their use in ecological risk assessment: A successful method when used appropriately. Hum. Ecol. Risk Assess. 5:43.

Sawyer, T., Bandiera, S., Safe, S., Hutzinger, O., and Olie, K. (1983). Bioanalysis of polychlorinated dibenzofuran and dibenzo- $p$-dioxin mixtures in fly ash. Chemosphere 12:529.

Sawyer, T., and Safe, S. (1982). PCB isomers and congeners: Induction of aryl hydrocarbon hydroxylase and ethoxyresorufin $O$-deethylase enzyme activities in rat hepatoma cells. Toxicol. Lett. 13:87.

Sawyer, T.W., and Safe, S. (1985). In vitro AHH induction by polychlorinated biphenyl and dibenzofuran mixtures: Additive effects. Chemosphere 14:79.

Sawyer, T.W., Vatcher, A.D., and Safe, S. (1984). Comparative aryl hydrocarbon hydroxylase induction activities of commercial PCBs in Wistar rats and rat hepatoma H-4-II E cells in culture. Chemosphere 13:695.

Scharenberg, W. (1991). Prefledgling terns (Sterna paradisaea, Sterna hirundo) as bioindicators for organochlorine residues in the German Wadden Sea. Arch. Environ. Contam. Toxicol. 21:102.

Schmitt, C.J., Zajicek, J.L., May, T.W., and Cowman, D.F. (1999). Organochlorine residues and elemental contaminants in U.S. freshwater fish, 19761986: National Contaminant Biomonitoring Program. Rev. Environ. Contam. Toxicol. 162:43.

Schmitz, H.J., Behnisch, P., Hagenmaier, A., Hagenmaier, H., Bock, K.W., and Schrenk, D. (1996). CYP1A1inducing potency in H4IIE cells and chemical composition of technical mixtures of polychlorinated biphenyls. Environ. Toxicol. Pharmacol. 1:73.

Schmitz, H.J., Hagenmaier, A., Hagenmaier, H.P., Bock, K.W., and Schrenk, D. (1995). Potency of mixtures of polychlorinated biphenyls as inducers of dioxin receptor-regulated CYP1A activity in rat hepatocytes and H4IIE cells. Toxicology 99:47.
Schnitz, A.R., and O'Connor, J.M. (1992). In vivo DNA/RNA adduction of 7,12dimethylbenz(a)anthracene (DMBA) and benzo(a)pyrene $(\mathrm{BaP})$ in the liver of rainbow trout (Oncorhynchus mykiss). J. Environ. Pathol. Toxicol. Oncol. 11:229.

Schrenk, D., Lipp, H.P., Wiesmüller, T., Hagenmaier, H., and Bock, K.W. (1991). Assessment of biological activities of mixtures of polychlorinated dibenzo$p$-dioxins: Comparison between defined mixtures and their constituents. Arch. Toxicol. 65:114.

Schwartz, T.R., and Lehmann, R.G. (1982). Determination of polychlorinated biphenyls in plant tissue. Bull. Environ. Contam. Toxicol. 28:723.

Smith, I.R., Marchant, B., van den Heuvel, M.R., Clemons, J.H., and Frimeth, J. (1994). Embryonic mortality, bioassay derived 2,3,7,8tetrachlorodibenzo- $p$-dioxin equivalents, and organochlorine contaminants in Pacific salmon from Lake Ontario. J. Great Lakes Res. 20:497.

Spear, P.A., Bourbonnais, D.H., Norstrom, R.J., and Moon, T.W. (1990). Yolk retinoids vitamin a in eggs of the herring gull and correlations with polychlorinated dibenzo- $p$-dioxins and dibenzofurans. Environ. Toxicol. Chem. 9:1053.

Sperelakis, N. (2001). Cell physiology sourcebook: A molecular approach, 3rd ed. San Diego: Academic Press.

Stegeman, J.J., and Hahn, M.E. (1993). Biochemistry and molecular biology of monooxygenases: Current perspectives on forms, functions, and regulation of cytochrome $\mathrm{P} 450$ in aquatic species. In Aquatic toxicology: Molecular, biochemical and cellular perspectives, eds. D.C. Malins and G.K. Ostrander, p. 87. Boca Raton, FL: Lewis.

Takahashi, T., and Hori, S.H. (1998). Intramembraneous localization of rat liver microsomal hexose-6phosphate dehydrogenase and membrane permeability to its substrates. Biochim. Biophys. Acta 524:262.

Taylor, J.K. (1981). Quality assurance of chemical measurements. Anal. Chem. 53:1588A.

Thomas, C.M., and Anthony, R.G. (1999). Environmental contaminants in great blue herons (Ardea herodias) from the lower Columbia and Willamette Rivers, Oregon and Washington, USA. Environ. Toxicol. Chem. 18:2804.

Till, M., Behnisch, P., Hagenmaier, H., Bock, K.W.W., and Schrenk, D. (1997). Dioxin-like components in incinerator fly ash: A comparison between chemical analysis data and results from a cell culture bioassay. Environ. Health. Perspect. 105:1326. 
Till, M., Riebniger, D., Schmitz, H. J., and Schrenk, D. (1999). Potency of various polycyclic aromatic hydrocarbons as inducers of CYP1A1 in rat hepatocyte cultures. Chem. Biol. Interact. 117:135.

Tillitt, D.E. (1989). Characterization studies of the H4IIE bioassay for assessment of planar halogenated hydrocarbons in fish and wildlife. $\mathrm{PhD}$ Thesis, Michigan State University, Lansing.

Tillitt, D.E. (1999). The toxic equivalents approach for fish and wildlife. Hum. Ecol. Risk Assess. 5:25.

Tillitt, D.E., Ankley, G.T., and Giesy, J.P. (1989). Planar chlorinated hydrocarbons (PCHs) in colonial fisheating waterbird eggs from the Great Lakes. Mar. Environ. Res. 28:505.

Tillitt, D.E., Giesy J.P., and Ankley, G.T. (1991a). Characterization of the H4IIE rat hepatoma cell bioassay as a tool for assessing toxic potency of planar halogenated hydrocarbons in environmental samples. Environ.Sci. Technol. 25:87.

Tillitt, D.E., Ankley, G.T., Verbrugge, D.A., Giesy, J.P., Ludwig, J.P., and Kubiak, T.J. (1991b). H4IIE rat hepatoma cell bioassay-derived 2,3,7,8tetrachlorodibenzo- $p$-dioxin equivalents in colonial fish-eating waterbird eggs from the Great Lakes. Arch. Environ. Contam. Toxicol. 21:91.

Tillitt, D.E., Ankley, G.T., Giesy, J.P., Ludwig, J.P., Kurita-Matsuba, H., Weseloh, D.V., Ross, P.S., Bishop, C.A., Sileo, L., Stromborg, K.L., Larson, J., and Kubiak, T.J. (1992). Polychlorinated biphenyl residues and egg mortality in doublecrested cormorants from the Great Lakes. Environ. Toxicol. Chem. 11:1281.

Tillitt, D.E., Kubiak, T.J., Ankley, G.T., and Giesy, J.P. (1993). Dioxin-like toxic potency in Forster's tern eggs from Green Bay, Lake Michigan, North America. Chemosphere 26:2079.

Tillitt, D.E., Gale, R.W., Meadows, J.C., Zajicek, J.L., Peterman, P.H., Heaton, S.N., Jones, P.D., Bursian, S.J., Kubiak, T.J., Giesy, J.P., and Aulerich, R.J. (1996). Dietary exposure of mink to carp from Saginaw Bay 3. Characterization of dietary exposure to planar halogenated hydrocarbons, dioxin equivalents, and biomagnification. Environ.Sci. Technol. 30:283.

Trivedi, A.B., Kitabatake, N., and Doi, E. (1990). Toxicity of dimethyl sulfoxide as a solvent in bioassay system with HeLa cells evaluated colorimetrically with 3-(4,5-dimethyl thiazol-2-yl)-2,5-diphenyltetrazolium bromide. Agric. Biol. Chem. 54: 2961.

Tysklind, M., Tillitt, D., Eriksson, L., Lundgren, K., and Rappe, C. (1994). A toxic equivalency factor scale for polychlorinated dibenzofurans. Fundam. Appl. Toxicol. 22:277.

Udenfriend, S., Stein, S., Böhlen, P., Dairman, W., Leimgruber, W., and Weigele, M. (1972). Fluorescamine: A reagent for assay of amino acids, peptides, proteins, and primary amines in the picomole range. Science 178:871.

Upton, R.N., Mather, L.E., and Runciman, W.B. (1987). The influence of drug sorption on pharmacokinetic studies of chlormethiazole and lignocaine. J. Pharm. Pharmacol. 39:485.

Vamvakas, A., Keller, J., and Dufresne, M. (1996). In vitro induction of CYP1A1-associated activities in human and rodent cell lines by commercial and tissueextracted halogenated aromatic hydrocarbons. Environ. Toxicol. Chem. 15:814.

van den Berg, M., Birnbaum, L., Bosveld, B.T.C., Brunström, B., Cook, B., Feeley, M., Giesy, J. P., Hanberg, A., Hasegawa, R., Kennedy, S.W., Kubiak, T., Larsen, J.C., Rolaf van Leeuwen, F.S., Dijien Liem, A. K., Nolt, C., Peterson, R.E., Poellinger, L., Safe, S., Schrenk D., Tillitt, D., Tysklind, M., Younes, M., Waern, F., and Zacherewski, T. (1998). Toxic equivalency factors (TEFs) for PCBs, PCDDs, PCDFs for humans and wildlife. Environ. Health Perspect 106: 775.

van den Heuvel, J. P., and Lucier, G. (1993). Environmental toxicology of polychlorinated dibenzo- $p$ dioxins and polychlorinated dibenzofurans. Environ. Health Perspect 100:189.

van den Heuvel, M.R., Munkittrick, K.R., van der Kraak, G.J., McMaster, M.E., Portt, C.B., Servos, M.R., and Dixon, D.G. (1994). Survey of receiving-water environmental impacts associated with discharges from pulp mills 4 . Bioassayderived 2,3,7,8-tetrachlorodibenzo- $p$-dioxin toxic equivalent concentration in white sucker (Catostomus commersoni) in relation to biochemical indicators of impact. Environ. Toxicol. Chem. 13:1117.

van den Heuvel, M.R., Munkittrick, K.R., van der Kraak, G.J., Servos, M.R., and Dixon, D.G. (1995a). Hepatic 7-ethoxyresorufin- $O$-deethylase activity, plasma steroid hormone concentrations, and liver bioassay-derived 2,3,7,8-TCDD toxic equivalent concentrations in wild white sucker (Catostomus commersoni) caged in bleached kraft pulp mill effluent. Can. J. Fish. Aquat. Sci. 52:1339.

van den Heuvel, M.R., Munkittrick, K.R., Stegeman, J.J., and Dixon, D.G. (1995b). Second-round interlaboratory comparison of hepatic ethoxyresorufin- $O$ deethylase activity in white sucker (Catostomus commersoni) exposed to bleached-kraft pulp mill effluent. Environ. Toxicol. Chem. 14:1513. 
van den Heuvel, M.R., Servos, M.R., Munkittrick, K.R., Bols, N.C., and Dixon, D.G. (1996). Evidence for a reduction of 2,3,7,8-TCDD toxic equivalent concentrations in white sucker (Catostomus commersoni) exposed to bleached kraft pulp mill effluent, following process and treatment improvements. J. Great Lakes Res. 22:264.

Villeneuve, D.L., Blankenship, A.L., and Giesy, J.P. (2000a). Derivation and application of relative potency estimates based on in vitro bioassay results. Environ. Toxicol. Chem. 19:2835.

Villeneuve, D.L., Kannan, K., Khim, J.S., Falanysz, J., Nikiforov, V.A., Blankenship, A.L., and Giesy, J.P. (200b). Relative potencies of individual polychlorinated napthalenese to induce dioxin-like responses in fish and mammalian in vitro bioassays. Arch. Environ. Contam. Toxicol. 39:273.

Vodicnik, M.J., Elcombe, C.R., and Lech, J.J. (1981). The effect of various types of inducing agents on hepatic microsomal monooxygenase activity in rainbow trout. Toxicol. Appl. Pharmacol. 59:364.

Walker, M.K., Cook, P.M., Butterworth, B.C., Zabel, E.W., and Peterson, R.E. (1996). Potency of a complex mixture of polychlorinated dibenzo- $p$-dioxin, dibenzofuran, and biphenyl congeners compared to 2,3,7,8-tetrachlorodibenzo- $p$-dioxin in causing fish early life stage mortality. Fundam. Appl. Toxicol. 30:178.

Walker, M.K., Cook, P.M., Batterman, A.R., Butterworth, B.C., Berini, C., Libal, J.J., Hufnagle, L.C., and Peterson, R.E. (1994). Translocation of 2,3,7,8-tetrachlorodibenzo- $p$-dioxin from adult female lake trout (Salvelinus namaycush) to oocytes: Effects on early life stage development and sac fry survival. Can. J. Fish. Aquat. Sci. 51:1410.

Whitlock, J.P., Jr. (1999). Induction of cytochrome P4501A1. Annu. Rev. Pharmacol. Toxicol. 39:103.

Whyte, J.J., Jung, R.E., Schmitt, C.J., and Tillitt, D.E. (2000a). Ethoxyresorufin $O$-deethylase (EROD) activity in fish as a biomarker of chemical exposure. Crit. Rev. Toxicol. 30:347.

Whyte, J.J., Karrow, N.A., Boermans, H.J., Dixon, D.G., and Bols, N.C. (2000b). Combined methodologies for measuring exposure of rainbow trout $(\mathrm{On}$ corhynchus mykiss) to polycyclic aromatic hydrocarbons (PAHs) in creosote contaminated microcosms. Polycyclic Aromatic Compounds 18:71.

Whyte, J.J., and Tillitt, D.E. (2000). Biomonitoring of Environmental Status and Trends (BEST) Program: Selected methods for monitoring chemical contaminants in aquatic ecosystems, U.S. Geological Survey, Biological Resources Division. Columbia
Environmental Research Center, Columbia, MO, USA.

Whyte, J.J., van den Heuvel, M.R., Clemons, J.H., Huestis, S.Y., Servos, M.R., Dixon, D.G., and Bols, N.C. (1998). Mammalian and teleost cell line bioassay and chemically derived 2,3,7,8tetrachlorodibenzo- $p$-dioxin equivalent concentrations in lake trout (Salvelinus namaycush) from Lake Superior and Lake Ontario, North America. Environ. Toxicol. Chem. 17:2214.

Willett, K.L., Gardinali, P.R., Sericano, J.L., Wade, T.L., and Safe, S.H. (1997). Characterization of the H4IIE rat hepatoma cell bioassay for evaluation of environmental samples containing polynuclear aromatic hydrocarbons (PAHs). Arch. Environ. Contam. Toxicol. 32:442.

Williams, L.L., Giesy, J.P., Verbrugge, D.A., Jurzysta, S., and Stromborg, K. (1995). Polychlorinated biphenyls and 2,3,7,8-tetrachlorodibenzo- $p$ dioxin equivalents in eggs of double-crested cormorants from a colony near Green Bay, Wisconsin, USA. Arch. Environ. Contam. Toxicol. 29:327.

Williams, T.G., Lockhart, W.L., Metner, D.A., and Harbicht, S. (1997). Baseline studies in the Slave River, NWT, 1990-1994 Part III. MFO enzyme activity in fish. Sci. Total Environ. 197:87.

Winefordner, J.D., and Long, G.L. (1983). Limit of detection: A closer look at the IUPAC definition. Anal. Chem. 55:712A.

Xu, L.C., Sinclair, P.R., and Bresnick, E. (1993). Induction of cytochrome P450IA1 and its recombinant construct in H4IIE rat hepatoma cells. Int. J. Biochem. 25: 13 .

Yu, K.O., Tillitt, D.E., Byczkowski, J.Z., Burton, G.A., Jr., Channel, S.R., Drerup, J.M., Flemming, C.D., and Fisher, J.W. (1996). In vivo/in vitro comparison of the pharmacokinetics and pharmacodynamics of 3,3',4,4'-tetrachlorobiphenyl (PCB77). Toxicol. Appl. Pharmacol. 141:434.

Yu, K.O., Fisher, J.W., Burton, G.A., Jr., and Tillitt, D.E. (1997). Carrier effects of dosing the H4IIE cells with 3,3',4,4'-tetrachlorobiphenyl (PCB 77) in dimethyl sulfoxide or isooctane. Chemosphere 35:895.

Zacharewski, T., Harris, M., Safe, S., Thoma, H., and Hutzinger, O. (1988). Applications of the in vitro aryl hydrocarbon hydroxylase induction assay for determining " $2,3,4,8$-tetrachlorodibenzo- $p$-dioxin equivalents": Pyrolyzed brominated flame retardants. Toxicology 51:177.

Zacharewski, T., Safe, L., Safe, S., Chittim, B., DeVault, D., Wiberg, K., Bergqvist, P.A., and Rappe, C. 
(1989). Comparative analysis of polychlorinated dibenzo- $p$-dioxin and dibenzofuran congeners in Great Lakes fish extracts by gas chromatographymass spectrometry and in vitro enzyme induction activities. Environ.Sci. Technol. 23: 730 .
Zajicek, J.L., Tillitt, D.E., Schwartz, T.R., Schmitt, C.J., and Harrison, R.O. (2000). Comparison of an enzyme-linked immunosorbent assay (ELISA) to gas chromatography (GC)-Measurement of polychlorinated biphenyls (PCBs) in selected United States fish extracts. Chemosphere 40:539. 